\title{
Estudo de Modelos Matemáticos \\ Determinísticos em Interação Populacional
}

\author{
Elvia Eleonora Sauceda Rodríguez \\ Orientador: José Alberto Cuminato
}

Dissertação apresentada ao Instituto de Ciências Matemáticas de São Carlos - USP, como parte dos requisitos para a obtenção do título de mestre em "Ciências de Computação e Matemática Computacional".

São Carlos

1992 
Agradeço:

A Deus, por tudo.

Ao Prof. Dr. José Alberto Cuminato, por ter aceito e conduzido de forma segura e objetiva, a orientação deste trabalho.

Ao Prof. Dr. José Gaspar Ruas Filho (ICMSC-USP) e Prof. Dr. Rodney Carlos Bassanezi (IMECC-UNICAMP), pelos comentários e sugestões para a versão final desta dissertação.

Ao MRE/ICMSC-USP/CAPES/CNPq, pela oportunidade de dar continuidade à minha formação acadêmica e, pelo apoio financeiro, através do Programa de Estudante-Convênio PósGraduação (PEC-PG), Convênio Cultural Brasil-Honduras.

A todas as pessoas que, direta ou indiretamente, colaboraram na realização deste trabalho. 


\begin{abstract}
In this dissertation deterministic population interaction models are analysed. Mathematical models for ecosystem species interacting and the spread of infectious disease through a community are considered. These models are analysed in the light of Qualitative theory for Ordinary Differential Equations. Conditions are discussed under which ecological communities can lose their permanence or an epidemy occur.

The knowledge of the population dynamics allows for practical applications such as: The control of pest in agriculture or the control of infectious diseases. An example is shown which illustrats the use of epidemics models for planing control of diseases: The Vacination policy is analysed for a heterogeneous population model.
\end{abstract}




\section{Resumo}

Nesta dissertação são apresentados modelos determinísticos em interação populacional. Tais interações foram estudadas abordando-se dois aspectos: $\mathrm{O}$ ecológico, que trata da relação entre as diferentes espécies de um ecossistema, e o epidemiológico, que trata da propagação de doenças infecciosas em uma comunidade. Os modelos são analisados usando a Teoria Qualitativa das Equações Diferenciais. São discutidas as condições sob as quais uma doença infecciosa pode tornar-se epidêmica, e as condições para que o equilíbrio de um ecossistema seja mantido ou não, o que pode se dar por exemplo, pela remoção de uma das espécies presentes.

0 conhecimento da dinâmica populacional permite aplicações práticas, tais como o controle biológico de pragas na agricultura, o controle da propagação de doenças infecciosas, entre outras. Como exemplo, apresenta-se a aplicação da teoria na Vacinação, usando-se para isto um modelo epidêmico com subpopulações. 


\section{Introdução}

Embora o estudo das Interações Populacionais possa ser extendido à diferentes áreas do conhecimento como Física, Química, Economia, entre outras, optou-se por abordar o tema na área da Biologia. Existe na literatura consultada nesta área uma acentuada tendência a estudar em separado modelos de interação populacional em Ecologia e Epidemiologia. No entanto, o tratamento matemático é similar e assim sendo, nada impede sua abordagem de forma conjunta e, em nossa opinião, isto o torna interessante, uma vez que, possibilita aos pesquisadores interessados na área, o acesso à informação de forma generalizada de modelos já existentes.

Os primeiros trabalhos na área [29], foram as pesquisas do matemático italiano V. Volterra sobre as flutuações (nos anos 1910-1923) nas populações de peixes no mar Adriático, que propôs um modelo matemático para descrever este fenômeno e na mesma época (em torno de 1925), A.J. Lotka em pesquisa independente apresentou o mesmo modelo no seu trabalho Elements of Physical Biology. Outras contribuições notáveis foram os trabalhos de Kermack e McKendrick (1927), direcionados ao estudo da propagação de doenças infecciosas numa população.

Os modelos matemáticos descritos por equações de Lotka-Volterra permanecem como a ferramenta principal no estudo dos fenômenos relacionados com o comportamento de populações que se interagem. Quando várias populações se interagem, a dinâmica populacional de cada uma delas é afetada, o resultado de tal interaçã́o pode ser benéfico em alguns casos e catastrófico em outros.

Estudaremos neste trabalho modelos matemáticos deterministicos que descrevem os seguintes tipos de interação:

1. Interações entre espécies:

Predação: Uma espécie (predadora) tem um efeito inibidor sobre o crescimento da outra (presa) que tem um efeito de aceleração sobre o crescimento da primeira. 
Competição: Cada espécie tem um efeito inibidor sobre o crescimento da outra.

Mutualismo: Cada espécie tem um efeito de aceleração sobre o crescimento da outra.

2. Interação entre elementos de uma espécie:

Propagação de doenças trasmissíveis: Embora a doença seja causada pelos agentes patogênicos (vírus, bactérias, etc.) ela é distribuída na população por interações entre seus membros.

Apresentaremos os modelos gerais representativos de cada tipo de interação. O conhecimento da dinâmica populacional permite o controle e manipulação dos parâmetros que a regem, podendo-se assim, utilizar os modelos para avaliar as conseqüências de manipulações externas sobre os sistemas reais. Neste aspecto, discutiremos o uso de modelos epidêmicos para estudar o efeito de programas de vacinação sobre o controle ou erradicação de doenças infecciosas.

A dinâmica populacional é descrita por um sistema de equações diferenciais ordinárias autônomas, em geral, não lineares. Soluções analíticas de tais sistemas geralmente são difíceis de serem obtidas, porém, dado que não se faz necessária a quantificação dos resultados, analisaremos estes sistemas sob o enfoque qualitativo baseado na teoria de H. Poincaré (1881), A.M. Lyapunov (1892) e G.D. Birkhoff, que se baseia na determinação das propriedades da solução pela análise das suas trajetórias no espaço de fase.

Para auxiliar-nos nesta análise utilizaremos os programas de computador Phaser e o Programa Traçador de diagramas de fase [19,25], simuladores gráficos, que possibilitam o estudo qualitativo de equações diferenciais e equações a diferenças.

No primeiro capítulo é apresentada a teoria matemática necessária para os capitulos posteriores, no segundo capítulo são apresentados os modelos clássicos de interações entre espécies, no terceiro capítulo são apresentados alguns modelos gerais em dinâmica populacional das doenças transmissíveis e, no quarto capítulo é apresentada uma aplicação de modelos epidêmicos na vacinação. 


\section{Conteúdo}

1 Resultados Básicos 1

1.1 Equações Diferenciais Ordinárias (EDO) $\ldots \ldots \ldots \ldots \ldots$

1.20 Método do Plano de Fase $\ldots \ldots \ldots \ldots \ldots \ldots$

1.2 .10 Plano de Fase Geral . . . . . . . . . . . 2

1.2 .2 Sistemas Lineares . . . . . . . . . . . . 9

1.2.3 Sistemas Aproximadamente Lineares . . . . . . . . 16

1.3 O Método Direto de Lyapunov . . . . . . . . . . . . . . 18

1.4 Existência de Soluções Periódicas e Cịclos-Limites . . . . . . . 18

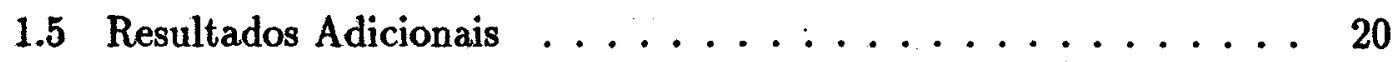

1.5.1 Propriedades de Matrizes . . . . . . . . . . . 20

1.5.2 Um Teorema de Ponto Fixo . . . . . . . . . . . 22

2 Interações entre Espécies 23

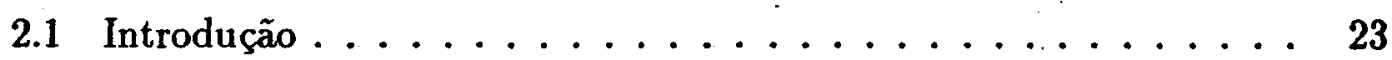

2.2 Modelos de Crescimento Populacional . . . . . . . . . . 24

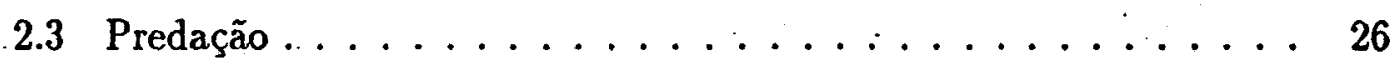

2.3.1 Modelo Clássico de Lotka-Volterra . . . . . . . . . 26

2.3.2 Modelos Presa-Predador Realísticos . . . . . . . . . 30

2.3.3 Modelo Presa-Predador com Solução Periódica de CicloLimite: Modelo de Murray . . . . . . . . . . . . . . 32

2.3.4 Complexidade e Estabilidade de Sistemas Presa-Predador , 39

2.4 Competição . . . . . . . . . . . . . . . . 41

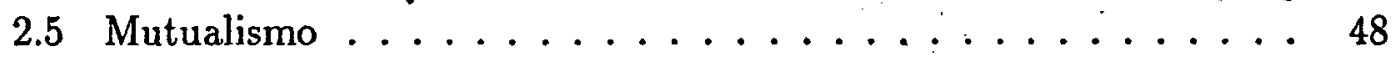


2.6 Modelos para $n$ Espécies $\ldots \ldots \ldots \ldots \ldots \ldots \ldots$

2.7 Comentários . . . . . . . . . . . . . . . 54

3 Dinâmica Populacional das Doenças Transmissíveis 56

3.1 Introdução . . . . . . . . . . . . . 56

3.2 Terminologia $\ldots \ldots \ldots \ldots \ldots \ldots \ldots \ldots \ldots$

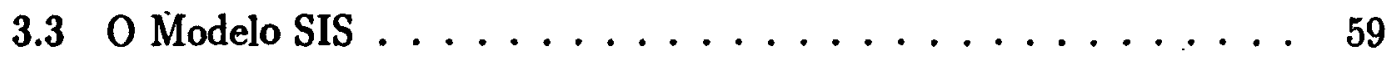

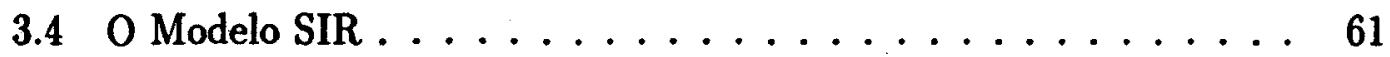

3.4.1 Modelo SIR sem Dinâmica Vital . . . . . . . . . . . 62

3.4.2 Modelo SIR com Dinâmica Vital . . . . . . . . 67

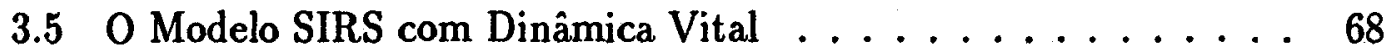

3.6 Um Modelo para Populações Heterogêneas . . . . . . . . . 73

3.6.1 O Modelo SIR com $n$ Grupos . . . . . . . . . . . 73

3.6.2 Análise do Modelo . . . . . . . . . . . 75

4 Aplicação: Controle de Doenças por Vacinação 83

4.1 Introdução . . . . . . . . . . . . . . . 83

4.20 modelo para um grupo $(n=1) \ldots \ldots \ldots \ldots \ldots$

4.30 modelo para $n>1$ grupos . . . . . . . . . . . 85

4.4 Aspectos de Políticas de Vacinação . . . . . . . . . 86

4.4.1 Formulação do Problema . . . . . . . . . . . 87

4.4.2 A Política de Vacinação Ótima para o Modelo SIR com n Grupos .................... 89

4.4.3 Resultados Gerais para $n$ Grupos . . . . . . . . . 92

4.5 Comentários . . . . . . . . . . . . . . . 93

$\begin{array}{ll}\text { Conclusão } & 95\end{array}$

$\begin{array}{ll}\text { Bibliografia } & 96\end{array}$ 


\section{Capítulo 1}

\section{Resultados Básicos}

Neste capítulo apresentamos os principais resultados indispensáveis ao desenvolvimento deste trabalho $[3,4,5,8,14,16,17,28]$.

\subsection{Equações Diferenciais Ordinárias (EDO)}

Consideramos sistemas de equações da forma

$$
\frac{d \mathbf{x}}{d t}=f(t, \mathbf{x})
$$

onde $\mathrm{x}$ é um elemento de $\mathcal{R}^{n}$ e $f$ é uma função vetorial definida numa região $\mathcal{G}$ do espaço $\mathcal{R}^{n+1}$.

Resolver o sistema (1.1) corresponde à determinação de uma função vetorial $\mathbf{x}=\mathbf{x}(t)$, definida num intervalo $I$, tal que:

1. $d \mathrm{x} / d t$ exista para todo $t$ em $I$.

2. $O$ ponto $(t, \mathrm{x}(t))$ está contido em $\mathcal{G}$ para todo $t$ em $I$.

3. $d \mathrm{x} / d t=f(t, \mathrm{x}(t))$ para todo $t \mathrm{em} I$.

Qualquer função que satisfaça estas propriedades é uma solução do sistema (1.1).

Resolver o problema de valor inicial (PVI), isto é, o sistema (1.1) com as condicõos iniciais $\mathbf{x}\left(t_{0}\right)=\mathbf{x}_{0}$, onde o ponto $\left(t_{0}, \mathbf{x}_{0}\right)$ está contido em $\mathcal{G}$, significa encontrar uma solução $\mathbf{x}=\mathbf{x}(t)$ de (1.1) satisfazendo $\mathbf{x}\left(t_{0}\right)=\mathbf{x}_{0}$. Assumimos 
que a função $f$ é suficientemente bem comportada para garantir a existência e unicidade da solução do PVI.

Quando a função $f(t, \mathbf{x})$ não depende explicitamente de $t$, o sistema (1.1). é dito autônomo, e pode ser escrito na forma

$$
\frac{d x}{d t}=f(x)
$$

\section{Espaço de Fase}

Devemos distinguir claramente os seguintes espaços:

1. O espaço de definição da variável independente $t$, a reta real $\mathcal{R}$.

2. 0 espaço $\mathcal{R}^{n}$, que contém a solução $x(t)$.

3. O espaço $\mathcal{R} \times \mathcal{R}^{n}$ cujos pontos são os pares $(t, \mathbf{x})$.

Qualquer solução de (1.1) determina no espaço $\mathcal{R} \times \mathcal{R}^{n}$ uma curva chamada curva integral. Quando se cumpre o teorema de existência e unicidade da solução do PVI, por cada ponto deste espaço passa uma única curva integral, esta curva pode ser interpretada como um ponto em movimento no espaço $\mathcal{R}^{n}$. A curva geométrica descrita por $\mathrm{x}=\mathbf{x}(t)$ é chamada trajetória, ela é a projeção sobre o espaço $\mathcal{R}^{n}$ da curva integral no espaço $\mathcal{R} \times \mathcal{R}^{n}$. O espaço $\mathcal{R}^{n}$ é chamado Espaço de Fase e as trajetórias Órbitas ou Trajetórias de Fase.

\subsection{O Método do Plano de Fase}

\subsubsection{O Plano de Fase Geral}

Consideremos o sistema autônomo de primeira ordem

$$
\frac{d x}{d t}=f(x, y), \quad \frac{d y}{d t}=g(x, y)
$$

Uma solução de (1.3) é um par de funçôes $x(t)$ e $y(t)$ cujo gráfico é uma curva $(t, x(t), y(t))$ no espaço tridimensional $(t, x, y)$. Dado que o sistema é autônomo 
a solução pode ser representada no plano- $x y$ (o plano de fase). Quando $t$ varia na reta, $(x(t), y(t))$ descreve uma curva no plano- $x y$ (a trajetória de fase). Desta forma o comportamento do sistema pode ser descrito pelo movimento de um ponto ao longo desta curva.

Pelo teorema de existência e unicidade da solução do PVI, através de cada ponto do espaço $(t, x, y)$ passa uma única curva integral de (1.3), isto é, as curvas integrais em $(t, x, y)$ não podem cruzar-se. Como o sistema é autônomo isto também vale para as trajetórias de fase, isto é, através de cada ponto no plano de fase passa uma única trajetória, ou seja, todas as curvas integrais com o mesmo valor inicial $\left(x_{0}, y_{0}\right)$, porém, com $t_{0}$ distinto, são representados no plano de fase por uma única trajetória.

O conjunto de todas as trajetórias representando as soluções de (1.3) no plano de fase, é o Diagrama ou Retrato de Fase. Ele descreve a evolução dos estados do sistema a partir de pontos iniciais arbitrários.

Como, em geral, nem sempre é possível resolver explicitamente o sistema (1.3), nem sempre poderemos determinar diretamente as trajetórias. Porém, em geral, é possivel obter todas as trajetórias das soluções de (1.3) sem ter que resolvê-lo. A fundamentação teórica é a seguinte:

\section{Equação das trajetórias de fase}

Sejam as funções $x=x(t)$ e $y=y(t)$ uma solução de (1.3). Se $\frac{d x}{d t} \neq 0$ em $t=t^{*}$, então podemos tirar o valor de $t=t(x)$ numa vizinhança do ponto $x^{*}=x\left(t^{*}\right)$ e, desta forma, para $t$ próximo de $t^{*}$, a trajetória da solução $x=x(t)$, $y=y(t)$ é a curva $y=y(t(x))$. Como

$$
\frac{d y}{d x}=\frac{d y}{d t} \frac{d t}{d x}=\frac{d y / d t}{d x / d t}=\frac{g(x, y)}{f(x, y)},
$$

as trajetórias das soluções de (1.3) são as curvas-soluções da equação

$$
\frac{d y}{d x}=\frac{g(x, y)}{f(x, y)}
$$

A solução desta equação, é uma família de curvas integrais tais que a inclinação da tangente em cada ponto é determinada pela equação (1.3), esta tangente coincide com a tangente à trajetória da solução de (1.3) que passa por este ponto.

Existem dois tipos de pontos importantes no plano de fase:

1. Os pontos onde $\frac{g(x, y)}{f(x, y)}$ apresenta singularidades: 
(a) Os pontos onde $f(x, y)=0$. Se $f(x, y)=0$, então $\frac{d x}{d t}=0$ e $x$ permanece invariante com o tempo, isto significa que a tangente nestes pontos da trajetória é paralela ao eixo $y$ uma vez que a primeira componente é nula.

(b) Os pontos onde $g(x, y)=0$. Se $g(x, y)=0$, então $\frac{d y}{d t}=0$ e $y$ permanece invariante com o tempo, isto significa que a tangente nestes pontos da trajetória é paralela ao eixo $x$ uma vez que a segunda componente é nula.

2. Os pontos onde se têm simultaneamente $f(x, y)=0$ e $g(x, y)=0$ :

Nestes pontos a tangente à trajetória é indeterminada, neles o sistema permanece invariante com o tempo, uma vez que $\frac{d x}{d t}=0 \mathrm{e} \frac{d y}{d t}=0$. Estes pontos são chamados pontos de equilibrio e são as soluções constantes de (1.3). Os pontos de equilíbrio são classificados de acordo com o comportamento das trajetórias nas vizinhanças do ponto. (isto será feito quando estudarmos os sistemas lineares).

Uma curva integral de (1.4) pode consistir de uma ou várias trajetórias de fase de (1.3). Uma curva integral consiste de uma única trajetória se $\frac{d y}{d t} \mathrm{e} \frac{d x}{d t}$ não se anulam simultânemente sobre ela. As trajetórias são:

1. Os pontos de equilíbrio de (1.3) (trajetórias degeneradas).

2. As curvas integrais de (1.4) que não contêm pontos de equilíbrio de (1.3).

3. Os arcos de curvas integrais de (1.4) comprendidos entre dois pontos de equilíbrio ou entre um ponto de equilíbrio e o infinito.

\section{Campo de direções}

A cada ponto $(x, y)$ no plano de fase é associado um segmento de reta orientado de $(x, y)$ a $(x, y)+(f(x, y), g(x, y))$, a curva solução de (1.3) que passa através de $(x, y)$ tem estes vetores como suas tangentes. $O$ conjunto de todos os segmentos é chamado campo vetorial gerado pelo sistema (1.3).

Se a equação (1.4) é integrável podemos obter a equação das trajetórias diretamente, caso contrário, é possivel traçar as trajetórias no plano de fase com ajuda do campo de direções.

Para mostrar como construir o diagrama de fase, vamos dar um exemplo. 


\section{Construção do diagrama de fase para o modelo clássico presa-predador de Lotka-Volterra}

0 modelo é descrito pelo sistema de equações diferenciais [26]:

$$
\begin{aligned}
& \frac{d N}{d t}=a N-b N P \\
& \frac{d P}{d t}=-d P+c N P
\end{aligned}
$$

onde $N(t)$ e $P(t)$ são as populações das presas e dos predadores no tempo $t$, respectivamente. Sendo $a>0$ a taxa de crescimento das presas, $d>0$ a taxa de mortalidade dos predadores, $b>0$ é o coeficiente de decrescimento das presas como efeito da predação e $c>0$ é o coeficiente de crescimento dos predadores como efeito da predação. A descrição em detalhes deste modelo será feita no capítulo 2.

Para investigar o comportamento das populações, estudaremos as trajetórias da solução de (1.5) no plano de fase. Dado que estamos trabalhando com densidades populacionais a análise é restrita ao quadrante positivo do plano $N P$.

Para determinar os pontos onde $\frac{d P}{d N}$ apresenta singularidades, resolvemos as equaçóes $\frac{d N}{d t}=0 \mathrm{e} \frac{d P}{d t}=0$.

Para $a N-b N P=0$ obtemos as retas $N=0$ e $P=\frac{a}{b}$. Sobre estas retas o valor de $N$ permanece invariante com o tempo, e a tangente em cada ponto é paralela ao eixo $P$. Estas retas são representadas no plano de fase.

Para $-d P+c N P=0$ obtemos as retas $P=0$ e $N=\frac{d}{c}$. Sobre estas retas o valor de $P$ permanece invariante com o tempo, e a tangente em cada ponto é paralela ao eixo $N$. Estas retas são representadas ño plano de fase.

Para determinar os pontos de equilíbrio (soluções constantes) de (1.5) resolvemos o sistema

$$
\begin{array}{r}
a N-b N P=0 \\
-d P+c N P=0
\end{array}
$$

Resolvendo (1.6) obtemos os pontos $(0,0)$ e $\left(\frac{d}{c}, \frac{a}{b}\right)$, estes pontos são representados no plano de fase.

No plano de fase podemos traçar as trajetórias das soluções de (1.5) como um ponto deslocando-se em função do tempo $t$ tomado como parâmetro. A análise de crescimento da curva no plano de fase depende dos sinais de $\frac{d N}{d t}$ e 
$\frac{d P}{d t}$. A direção com respeito a cada coordenada é dada por:

$$
\begin{aligned}
& \rightarrow \quad \text { se } \cdot \frac{d N}{d t}>0 \quad \text { e } \leftarrow \text { se } \frac{d N}{d t}<0 \\
& \uparrow \text { se } \frac{d P}{d t}>0 \text { e } \quad \downarrow \text { se } \frac{d P}{d t}<0
\end{aligned}
$$

Neste exemplo a equação das trajetórias pode ser determinada explicitamente, uma vez que a equação

$$
\frac{d P}{d N}=\frac{(-d+c N) P}{(a-b P) N}
$$

é separável e pode ser integrada exatamente, obtendo-se a família de soluções

$$
(d \ln N-c N)+(a \ln P-b P)=C,(\text { constante) }
$$

As soluções da equação (1.8) representam curvas fechadas em volta de $\left(\frac{d}{c}, \frac{a}{b}\right),\left[14\right.$, pag 262]. A constante $C$ é determinada pelas condiçóes iniciais $N_{0}$ e $P_{0}$ para cada trajetória. $O$ diagrama de fase é mostrado na seguinte figura:

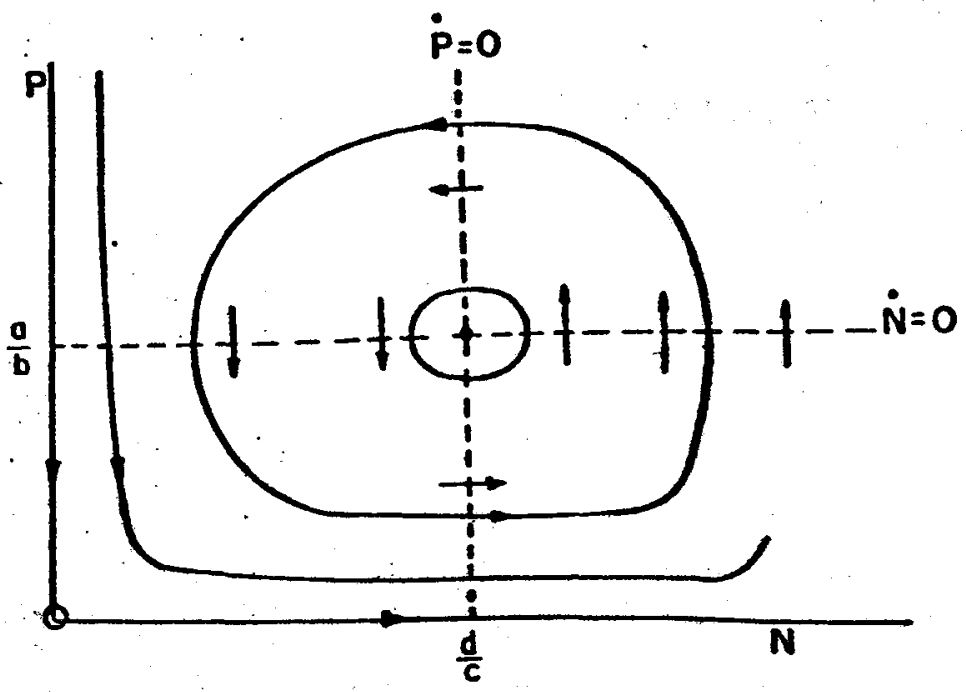

Figura 1.1: Trajetórias de fase para o sistema (1.5), problema Presa-Predador. (reproduzida.de [7])

Do diagrama de fase podemos concluir: 
1. Se o ponto inicial for $(0,0)$ temos $\frac{d N}{d t}=0, \frac{d P}{d t}=0$ e portanto não existe populąção em qualquer instante.

2. Se a população dos predadores é zero $(P=0)$ a população das presas cresce sem limite $(N \rightarrow \infty)$.

3. Se a população das presas é zero $(N=0)$ a população dos predadores tende a extinção $(P \rightarrow 0)$.

4. Com um nível baixo de predadores, o número de presas aumenta $\left(\frac{d N}{d t}>0\right.$, quando $\left.P<\frac{a}{b}\right)$.

5. Com um nível alto de predadores, o número de presas diminui $\left(\frac{d N}{d t}<0\right.$, quando $\left.P>\frac{a}{b}\right)$.

6. Uma alimentação abundante produz aumento na população dos predadores $\left(\frac{d P}{d t}>0\right.$, quando $\left.N>\frac{d}{c}\right)$.

7. Com alimentação insuficiente o número de predadores diminui $\left(\frac{d P}{d t}<\mathbf{0}\right.$, quando $\left.N<\frac{d}{c}\right)$.

8. Como as trajetórias são fechadas, podemos predizer que para uma dada população inicial $\left(N_{0}, P_{0}\right) \neq(0,0)$ ou $\left(N_{0}, P_{0}\right) \neq\left(\frac{d}{c}, \frac{a}{b}\right)$ a população de ambas espécies oscilará ciclicamente. Não importa a densidade das populações, nenhuma será extinta e permanecerá constante quando $(N, P)=\left(\frac{d}{c}, \frac{a}{b}\right)$.

A natureza dos pontos de equilíbrio e em consequêencia a estabilidade do sistema (1.5) será analisada no capítulo 2.

\section{Comentários}

Sem conhecer as soluções do sistema (1.3) podemos obter diretamente dele, informações acerca do movimento de um ponto no plano, uma vez que para cada ponto $(x, y)$ no plano de fase de (1.3) conhecemos:

1. A tangente à trajetória passando por $(x, y)$, que coincide com a tangente à solução neste ponto. 
2. A velocidade com que a solução descreve a trajetória: Seja $x(t)$ e $y(t)$ uma « solução de (1.3), quando $t$ varia na reta o ponto $(x(t), y(t))$ se movimenta sobre a trajetória desta solução, sua velocidade na direção do eixo $x$ é $\frac{d x}{d t}$ e a velocidade na direção do eixo $y$ é $\frac{d y}{d t}$. A velocidade é então dada por

$$
v(t)=\sqrt{\left(\frac{d x}{d t}\right)^{2}+\left(\frac{d y}{d t}\right)^{2}}
$$

mas

$$
\frac{d x}{d t}=f(x, y), \quad \frac{d y}{d t}=g(x, y)
$$

portanto a velocidade é dada por $\sqrt{f^{2}+g^{2}}$.

3. $O$ tempo $T$ no qual um ponto se desloca ao longo de um segmento $c$ de uma trajetória $(c: t \in[a, b] \rightarrow(x(t), y(t)))$ é dado por

$$
\begin{aligned}
T & =\int_{c} d t=\int_{c}\left(\frac{d x}{d t}\right)^{-1}\left(\frac{d x}{d t}\right) d t \\
& =\int_{c} \frac{d x}{f(x, y)}
\end{aligned}
$$

De forma alternativa, seja $d s$ o comprimento de um segmento de arco de $c$. Então $d s=\sqrt{d x^{2}+d y^{2}}$ sobre a trajetória e

$$
\begin{aligned}
T & =\int_{c}\left(\frac{d s}{d t}\right)^{-1}\left(\frac{d s}{d t}\right) d t \\
& =\int_{c} \frac{d s}{\sqrt{f^{2}+g^{2}}}
\end{aligned}
$$

dado que

$$
\frac{d s}{d t}=\sqrt{\frac{d x^{2}}{d t^{2}}+\frac{d y^{2}}{d t^{2}}}=\sqrt{\left(\frac{d x}{d t}\right)^{2}+\left(\frac{d y}{d t}\right)^{2}}=\sqrt{f^{2}+g^{2}} .
$$

As integrais acima dependem somente de $f, g$ e da geometria da trajetória, portanto, o tempo está implícito no diagrama de fase. 


\subsubsection{Sistemas Lineares}

Consideremos o sistema autônomo de primeira órdem

$$
\begin{aligned}
& \frac{d x}{d t}=a x+b y \\
& \frac{d y}{d t}=c x+d y
\end{aligned}
$$

com $a, b, c, d$ números reais e $a d-b c \neq 0$. 0 sistema (1.9) é linear e tem $(x, y)=(0,0)$ como o único ponto de equilíbrio.

Podemos reduzir o sistema (1.9) a uma equação diferencial de segunda ordem. Supondo que $b \neq 0$, tiramos o valor de $y$ da primeira equação do sistema (1.9)

$$
y=\frac{1}{b} \frac{d x}{d t}-\frac{a}{b} x
$$

Agora, derivando ambos os membros desta equação e substituindo o valor de $\frac{d y}{d t}$ dado, na primeira equação do sistema (1.9) obtemos

$$
\frac{d^{2} x}{d t^{2}}-(a+d) \frac{d x}{d t}+(a d-b c) x=0
$$

A equação característica associada a esta equação é dada por

$$
p(\lambda)=\lambda^{2}-p \lambda+q=0 \quad \text { onde } \quad p=a+d, \quad q=a d-b c
$$

As raízes da equação característịca (raízes características ou autovalores) são dadas por:

$$
\lambda_{1,2}=\frac{1}{2}\left(p \pm \Delta^{\frac{1}{2}}\right), \quad \Delta=p^{2}-4 q,(\text { discriminante })
$$

o fato de supormos $a d-b c \neq 0$ implica em $\lambda_{1} \neq 0$ e $\lambda_{2} \neq 0$.

\section{Natureza e estabilidade do ponto de equilíbrio}

O ponto de equilíbrio $(x, y)=(0,0)$ é classificado pela natureza das trajetórias no plano de fase numa vizinhança dele, e a estabilidade do ponto de equilíbrio é determinada pelo comportamento das trajetórias nesta vizinhança. Uma variação dos sinais de $\Delta, p$ e $q$ leva a tipos diferentes de estabilidade:

1. As raizes da equação característica são reais e distintas $(\Delta>0)$ 
A solução geral de (1.9) tem a forma

$$
\begin{aligned}
& x(t)=C_{1} r_{1} e^{\lambda_{1} t}+C_{2} s_{1} e^{\lambda_{2} t^{\prime \prime}} \\
& y(t)=C_{1} r_{2} e^{\lambda_{1} t}+C_{2} s_{2} e^{\lambda_{2} t}
\end{aligned}
$$

onde $\left(r_{1}, r_{2}\right)^{T},\left(s_{1}, s_{2}\right)^{T}$ são os autovetores associados aos autovalores $\lambda_{1}, \lambda_{2}$ respectivamente e $C_{1}$ e $C_{2}$ são constantes arbitráriạs.

A equação das trajetórias é dada por

$$
\frac{d y}{d x}=\frac{\lambda_{1} C_{1} r_{2} e^{\lambda_{1} t}+\lambda_{2} C_{2} s_{2} e^{\lambda_{2} t}}{\lambda_{1} C_{1} r_{1} e^{\lambda_{1} t}+\lambda_{2} C_{2} s_{1} e^{\lambda_{2}}}
$$

podemos escrever (1.12) na forma.

$$
\frac{d y}{d x}=\frac{\lambda_{1} C_{1} r_{2}+\lambda_{2} C_{2} s_{2} e^{-\left(\lambda_{1}-\lambda_{2}\right) t}}{\lambda_{1} C_{1} r_{1}+\lambda_{2} C_{2} s_{1} e^{-\left(\lambda_{1}-\lambda_{2}\right) t}}
$$

São possiveis os seguintes casos:

(a) $\lambda_{2}<\lambda_{1}<0 \quad(p<0, q>0)$.

De (1.11) temos que, quando $t \rightarrow \infty, x(t) \rightarrow 0$ e $y(t) \rightarrow 0$.

Para $C_{1}=0$ temos que $s_{1} d y=s_{2} d x$ e as trajetórias se aproximam da origem ao longo da reta $s_{1} y=s_{2} x$ através de duas direções opostas, uma vez que, a origem também é uma trajetória.

As soluções para $C_{2}=0$ dão um outro par de trajetórias que se aproximam da origem em direções opostas ao longo da reta $r_{1} y=r_{2} x$.

Consideremos agora a família de trajetórias para as quais $C_{1} \neq 0 \mathrm{e}$ $C_{2} \neq 0$.

Como

$$
\frac{d y}{d x} \rightarrow \frac{r_{2}}{r_{1}}, \quad \text { quando } \quad t \rightarrow \infty
$$

as trajetórias se aproximam da origem tangenciando a reta $r_{1} y=r_{2} x$. Como

$$
\frac{d y}{d x} \rightarrow \frac{s_{2}}{s_{1}}, \text { quando } t \rightarrow-\infty
$$

as trajetórias se afastam da origem tangenciando a reta $s_{1} y=s_{2} x$. $O$ ponto de equilíbrio $(x, y)=(0,0)$, chamado nó, é estável.

(b) $0<\lambda_{2}<\lambda_{1} \quad(p>0, q>0)$.

Este caso se transforma no anterior ao se substituir $t$ por $-t$. As trajetórias têm a mesma forma geométrica com a diferença de que os pontos se movimentam em sentido contrário.

O ponto de equilibrio $(x, y)=(0,0)$ é um nó instável. 
$\because$ (c) $\lambda_{1}>0, \lambda_{2}<0 \quad(p>0, q<0)$.

Para $C_{1}=0$ temos, $s_{1} d y=s_{2} d x$, e portanto, quando $t \rightarrow \infty$ as trajetórias se aproximam da origem em direções opostas ao longo da reta $s_{1} y=s_{2} x$. Tal reta é chamada separatriz.

Para $C_{2}=0$ temos, $r_{1} d y=r_{2} d x$, e portanto, quando $t \rightarrow \infty$ as trajetórias se afastam da origem em direções opostas ao longo da reta $r_{1} y=r_{2} x$.

Para $C_{1} \neq 0, C_{2} \neq 0$ temos

$$
\frac{d y}{d x} \rightarrow \frac{r_{2}}{r_{1}}, \quad \text { quando } \quad t \rightarrow \infty
$$

e as trajetórias tangenciam a reta $s_{1} y=s_{2} x$.

Além disso,

$$
\frac{d y}{d x} \rightarrow \frac{s_{2}}{s_{1}}, \text { quando } \quad t \rightarrow-\infty
$$

e as trajetórias tangenciam a reta $r_{1} y=r_{2} x$.

As retas $r_{1} y=r_{2} x$ e $s_{1} y=s_{2} x$ são assíntotas para as outras trajetórias.

O ponto de equilíbrio $(x, y)=(0,0)$, chamado ponto de sela, é sempre instável.

2. As raízes da equação característica são complexas $(\Delta<0)$.

Como $\lambda_{1}=\bar{\lambda}_{2}$ temos $r=\bar{s}$. Para obter as soluções reais de (1.9) fazemos $C_{2}=\frac{1}{2}\left(c_{1}+c_{2} i\right)$ e $C_{1}=\bar{C}_{2}$ (isto porque (1.9) é linear).

Fazendo $\lambda_{1}=\bar{\lambda}_{2}=\alpha+i \beta$, podemos escrever (1.11) na forma polar:

$$
\begin{aligned}
x(t) & =e^{\alpha t}\left(\left(C_{1} r_{1}+C_{2} s_{1}\right) \cos \beta t+\left(C_{1} r_{1}-C_{2} s_{1}\right) i \operatorname{sen}(\beta t)\right) \\
& =e^{\alpha t}\left(A_{1} \cos \beta t-B_{1} \operatorname{sen} \beta t\right)
\end{aligned}
$$

onde $A_{1}=C_{1} r_{2}+C_{2} s_{1}$ e $B_{1}=C_{1} r_{1}-C_{2} s_{1}$.

Fazendo $A_{1}=C \cos \gamma$ e $B_{1}=C \operatorname{sen} \gamma$, obtemos

$$
x(t)=C e^{\alpha t} \cos (\beta t+\gamma) \quad \text { onde } C=\sqrt{A_{1}^{2}+B_{1}^{2}} .
$$

Da mesma forma,

$$
\begin{aligned}
y(t) & =e^{\alpha t}\left(\left(C_{1} r_{2}+C_{2} s_{2}\right) \cos \beta t+\left(C_{1} r_{2}-C_{2} s_{2}\right) i \operatorname{sen}(\beta t)\right) \\
& =e^{\alpha t}\left(A_{2} \cos \beta t-B_{2} \operatorname{sen} \beta t\right)
\end{aligned}
$$

onde $A_{2}=C_{1} r_{2}+C_{2} s_{2}$ e $B_{2}=C_{1} r_{2}-C_{2} s_{2}$. 
Fazendo $A_{2}=K \cos \kappa$ e $B_{2}=K \operatorname{sen} \kappa$, obtemos

$$
y(t)=K e^{\alpha t} \cos (\beta t+\kappa) \quad \text { onde } K=\sqrt{A_{2}^{2}+B_{2}^{2}} .
$$

O sistema (1.11) fica na forma

$$
\begin{aligned}
& x(t)=C e^{\alpha t} \cos (\beta t+\gamma) \\
& y(t)=K e^{\alpha t} \cos (\beta t+\kappa)
\end{aligned}
$$

Os seguintes casos são possíveis:

(a) $\alpha \neq 0$ e $\beta \neq 0$.

Dado que as partes trigonométricas de $x(t)$ e $y(t)$ são limitadas, a natureza do ponto de equilíbrio é determinada pelo sinal da parte real das raizes. Se $\alpha<0(p<0)$ temos

$$
\begin{aligned}
& x(t) \rightarrow 0 \text { e } \quad y(t) \rightarrow 0, \text { quando } \quad t \rightarrow \infty \\
& x(t) \rightarrow \infty \text { e } y(t) \rightarrow \infty \text {, quando } \quad t \rightarrow-\infty
\end{aligned}
$$

e o diagrama de fase consiste de curvas espiralando-se em direção à origem, e o ponto $(x, y)=(0,0)$, chamado ponto espiral, é estável. Se $\alpha>0(p>0)$ a origem é instável.

(b) $\alpha=0, \beta \neq 0\left(\lambda_{1}=i \beta, \lambda_{2}=-i \beta\right)$.

De (1.14), obtemos as soluções

$$
\begin{aligned}
& x(t)=C \cos (\beta t+\gamma) \\
& y(t)=K \cos (\beta t+\kappa)
\end{aligned}
$$

elas representam curvas fechadas em volta da origem. As soluções neste caso são ditas periódicas (periodo $T=2 \pi / \beta$ ).

$O$ ponto de equilíbrio $(x, y)=(0,0)$ é chamado Centro.

3. As raízes da equaçã̃o característica não são simples $(\Delta=0)$.

Neste caso, $\lambda_{1}=\lambda_{2}=\lambda$, dois casos são possíveis:

(a) A solução geral tem a forma

$$
\begin{aligned}
& x(t)=\left(C_{1} r_{1}+C_{2} s_{1} t\right) e^{\lambda t} \\
& y(t)=\left(C_{1} r_{2}+C_{2} s_{2} t\right) e^{\lambda t}
\end{aligned}
$$

Seja $\lambda<0$. As soluções com $C_{1}=0$ se aproximam da origem, quando $t \rightarrow \infty$ ao longo da reta $s_{1} y=s_{2} x$ e as soluções com $C_{2}=0$ se aproximam da origem, quando $t \rightarrow \infty$ ao longo da reta $r_{1} y=r_{2} x$. 
Para as soluções com $C_{1} \neq 0$ e $C_{2} \neq 0$ temos

$$
\frac{d y}{d x} \rightarrow \frac{s_{2}}{s_{1}}, \text { quando } \quad t \rightarrow \infty \text {. }
$$

$O$ fator $e^{\lambda t}$ tende rapidamente para zero quando $t \rightarrow \infty$, logo o produto $\left(C_{1} r_{i}+C_{2} s_{i} t\right) e^{\lambda_{t}},(i=1,2)$ tende também a zero, portanto a origem é estável. Neste caso as retas $s_{1} y=s_{2} x$ e $r_{1} y=r_{2} x$ coincidem. $\mathrm{O}$ ponto de equilíbrio $(x, y)=(0,0)$, chamado nó de inflexão, é estável se $\lambda<0$ e instável se $\lambda>0$.

(b) A solução geral tem a forma

$$
\begin{aligned}
& x(t)=C_{1} r_{1} e^{\lambda_{t}} \\
& y(t)=C_{1} r_{2} e^{\lambda t}
\end{aligned}
$$

Dado que $r_{1} d y=r_{2} d x$ temos $r_{1} y=r_{2} x$, como neste caso $r_{1}$ e $r_{2}$ são arbitrários, as trajetórias são semiretas que se aproximam da origem. $O$ ponto de equilíbrio $(x, y)=(0,0)$ é um nó estável se $\lambda<0$, e instável se $\lambda>0$.

Para pequenas perturbações dos coeficientes reais $a, b, c$ e $d$, as raízes múltiplas podem transformar-se num par de raízes complexas conjugadas, ou em um par de raízes reais diferentes, podendo ser então um nó estável ou um ponto espiral estável.

\section{Observação:}

No caso em que $a d-b c=0$, a origem não é o único ponto de equilíbrio. Dois casos são possíveis:

1. Se $\lambda_{1}=0, \lambda_{2} \neq 0 \quad(p \neq 0)$.

A solução geral tem a forma:

$$
\begin{aligned}
& x(t)=C_{1} r_{1}+C_{2} s_{1} e^{\lambda_{2 t}} \\
& y(t)=C_{1} r_{2}+C_{2} s_{2} e^{\lambda_{2 t}}
\end{aligned}
$$

Seja $\lambda_{2}<0$.

Para $C_{1}=0$, temos $s_{1} d y=s_{2} d x$, e as trajetórias se aproximam da origem ao longo da reta $s_{1} y=s_{2} x$. Portanto, a origem é estável.

Para $C_{2}=0$, temos $x(t)=C_{1} r_{1}$ e $y(t)=C_{2} r_{2}$, todos os pontos na reta $r_{1} y=r_{2} x$ são pontos de equilíbrio estáveis. 
Para $C_{1} \neq 0$ e $C_{2} \neq 0$, temos

$$
\frac{d y}{d x} \rightarrow \frac{s_{2}}{s_{1}}, \quad \text { quando } \quad t \rightarrow \infty .
$$

e $x(t) \rightarrow C_{1} r_{1}, y(t) \rightarrow C_{1} r_{2}$ e as trajetórias são retas paralelas que se aproximam do ponto de equilíbrio $(x, y)=\left(C_{1} r_{1}, C_{1} r_{2}\right)$. Portanto, todos os pontos na reta $r_{1} y=r_{2} x$ são pontos de equilíbrio estáveis. Se $\lambda_{2}>0$ todos os pontos de equilíbrio são instáveis.

2. Se $\lambda_{1}=\lambda_{2}=0 \quad(p=0)$.

Dois casos são possíveis:

(a) A solução geral tem a forma

$$
\begin{aligned}
& x(t)=C_{1} \\
& y(t)=C_{2}
\end{aligned}
$$

neste caso todos os pontos são pontos de equilíbrio estáveis.

(b) A solução geral tem a forma

$$
\begin{aligned}
& x(t)=C_{1}+C_{2} t \\
& y(t)=C_{1}^{*}+C_{2}{ }^{*} t
\end{aligned}
$$

Onde $C_{1}{ }^{*}, C_{2}{ }^{*}$ são combinações lineares das constantes arbitrárias $C_{1}$ e $C_{2}$.

Neste caso,

$$
x(t) \rightarrow \infty \text { e } y(t) \rightarrow \infty, \text { quando } \quad t \rightarrow \infty
$$

e, portanto, a origem é instável.

A figura 1.2 mostra a natureza dos ponțos de equilíbrio sobre o plano-pq. 

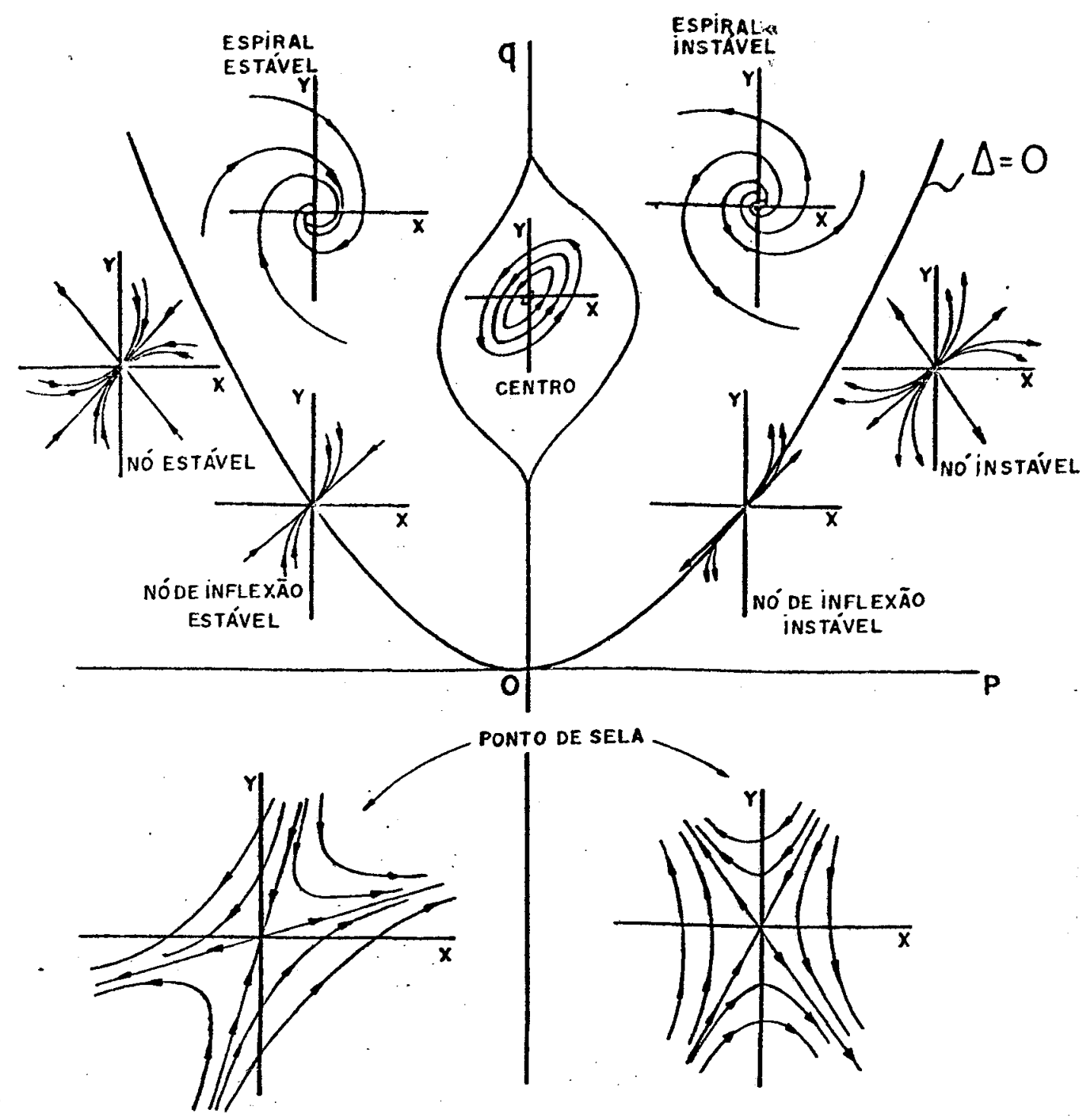

Figura 1.2: Classificação geral dos pontos de equilíbrio. (reproduzida de [26])

$\mathrm{Da}$ análise anterior temos que a estabilidade da solução constante $(x, y)=(0,0)$ do sistema $(1.9)$, é completamente determinada pelos valores das raizes características, conforme o seguinte teorema:

Teorema 1.2.1 Consideremos o sistema linear

$$
\frac{d x}{d t}=a x+b y, \quad \frac{d y}{d t}=c x+d y
$$

com $a, b, c, d$ números reais e $a d-b c \neq 0$. Então, 
1.: Se as raízes da equação característica têm parte real negativa, então, o ponto de equilibrio $(0,0)$ é assintoticamente estável.

2. Se pelo menos uma das raízes da equação característica tem parte real positiva, então, o ponto de equilíbrio $(0,0)$ é instável.

3. Se as raízes da equação característica são imaginárias puras, então, o ponto de equilibrio $(0,0)$ é estável, mas não assintoticamente estável.

\subsubsection{Sistemas Aproximadamente Lineares}

Consideremos o sistema

$$
\frac{d x}{d t}=f(x, y), \quad \frac{d y}{d t}=g(x, y)
$$

onde $f, g$ são funções não lineares. Em contraste com sistemas lineares, o sistema (1.21) não tem a origem como único ponto de equilíbrio. Poincaré (1881) e Lyapunov (1892), desenvolveram um método analítico para a investigação da estabilidade dos pontos de equilíbrio.

Seja $\left(x_{0}, y_{0}\right)$ um ponto de equilíbrio do sistema (1.21). Para analisar o comportamento das trajetórias nas vizinhanças do ponto de equilíbrio podemos, sem perda de generalidade, considerar $x_{0}=0$ e $y_{0}=0$ (se $x_{0} \neq 0$ e $y_{0} \neq 0$ o ponto pode ser levado a origem através de uma traslação conveniente dos eixos).

Suponhamos que as funções $f$ e $g$ possam ser expandidas na forma:

$$
\begin{aligned}
& f(x, y)=a x+b y+P(x, y) \\
& g(x, y)=c x+d y+Q(x, y)
\end{aligned}
$$

onde

$$
\lim _{r \rightarrow 0} \frac{P(x, y)}{\sqrt{x^{2}+y^{2}}}=0, \lim _{r \rightarrow 0} \frac{Q(x, y)}{\sqrt{x^{2}+y^{2}}}=0, r^{2}=x^{2}+y^{2}
$$

e

$$
\begin{array}{ll}
a=\frac{\partial f}{\partial x}(0,0), & b=\frac{\partial f}{\partial y}(0,0) \\
c=\frac{\partial g}{\partial x}(0,0), & d=\frac{\partial g}{\partial y}(0,0)
\end{array}
$$

perturbados.

Sistemas como (1.21) podem ser considerados como sistemàs lineares 
- O sistema linear, associado ao sistema (1.21), será

$$
\begin{aligned}
& \frac{d x}{d t}=a x+b y \\
& \frac{d y}{d t}=c x+d y
\end{aligned}
$$

No caso em que as raizes do polinômio característico têm parte real não nula, a estabilidade dos pontos de equilibrio do sistema (1.21) pode ser determinada através do sistema linear associado, conforme o seguinte teorema:

Teorema 1.2.2 (Lyapunov-Poincaré) Consideremos o sistema (1.21), onde $f$ e $g$ são continuamente diferenciáveis em uma vizinhança da origem, tal que o sistema pode ser aproximado pelo sistema linear (1.23), então:

1. Se a origem é assintoticamente estável para a aproximação linear [As raízes da equação característica têm parte real negativa], então, ela é assintoticamente estável para o sistema não linear.

2. Se pelo menos uma das raízes características na aproximação linear é positiva, ou se ambas raízes são complexas com parte real positiva, então, a origem é instável para o sistema não linear.

Prova: [28, pag.230-233].

A natureza das trajetórias nas vizinhanças dos pontos de equilíbrio do sistema não linear é tambem determinada através do sistema linear associado.

Teorema 1.2.3 Nas hipóteses do teorema (1.2.2), vale:

1. Se para a aproximação linear a origem é um centro [As raízes da equação característica são imaginárias puras], então, a origem pode ser um centro ou uma espiral para o sistema não linear. Além disso, se a origem é uma espiral para a aproximaçấo linear [As raízes da equação característica são complexas], então, também é uma espiral para o sistema näo linear.

2. Se a aproximação linear tem raizes características reais, distintas e não nulas $\lambda_{1}$ e $\lambda_{2}$ entâa as trajetórias do sistema não linear têm, numa vizinhança da origem, a mesma configuração qualitativa das trajetórias da aproximação linear.

Prova: [28, pag.235-238]. 


\subsection{O Método Direto de Lyapunov}

Nos sistemas para os quais os teoremas (1.2.2) e (1.2.3) não podem ser aplicados, a estabilidade do ponto de equilíbrio pode ser determinada usando o método direto de Lyapunov [22], que pode ser aplicado sem a necessidade de se resolver o sistema de equaçōes diferenciais.

Consideremos o sistema autônomo não linear

$$
\frac{d \mathbf{x}}{d t}=f(\mathbf{x}), \quad \mathbf{x} \in \mathcal{R}^{n}
$$

onde $f$ é continuamente diferenciável, definida numa região $\Omega$ que contém a origem, onde (1.24) tem um ponto de equilíbrio.

Definição 1.3.1 Seja $V(\mathbf{x})$ uma função real, continuamente diferenciável, definida em uma região $\Omega$ que contém a origem. $V(\mathbf{x})$ é dita definida positiva em $\Omega$ se, e somente se, $V(\mathbf{0})=0$ e $V(\mathbf{x})>0$ para $\mathbf{x} \neq \mathbf{0}$ e $\mathbf{x} \in \Omega$. $V(\mathbf{x})$ é dita definida negativa se, e somente se, $-V(\mathbf{x})$ é definida positiva.

Teorema 1.3.1 (Lyapunov) Seja $f: \Omega \subset \mathcal{R}^{n} \rightarrow \mathcal{R}^{n}$ um campo continuamente diferenciável, e considere o sistema $\frac{d \mathrm{x}}{d t}=f(\mathbf{x})$. Suponha que exista uma função $V(\mathbf{x})$ definida positiva em $\Omega$. Então,

a) Se grad $V(\mathbf{x}) \cdot f(\mathbf{x}) \leq 0$ para todo $\mathbf{x} \in \Omega, \mathbf{x} \neq \mathbf{0}$, então, o ponto de equilibrio é estável.

b) Se $\operatorname{grad} V(\mathbf{x}) \cdot f(\mathbf{x})<0$ para todo $\mathbf{x} \in \Omega, \mathbf{x} \neq \mathbf{0}$, então, o ponto de equilibrio é assintoticamente estável.

Prova: [4, pag.364-367].

\subsection{Existência de Soluções Periódicas e Ciclos- Limites}

Em sistemas não lineares pode aparecer o seguinte padrão de comportamento: No lugar de um ponto de equilíbrio existe uma solução periódica onde as trajetórias vizinhas em ambos os lados são espirais. A solução periódica é chamada ciclo limite e, um exemplo é mostrado na figura 1.3. 


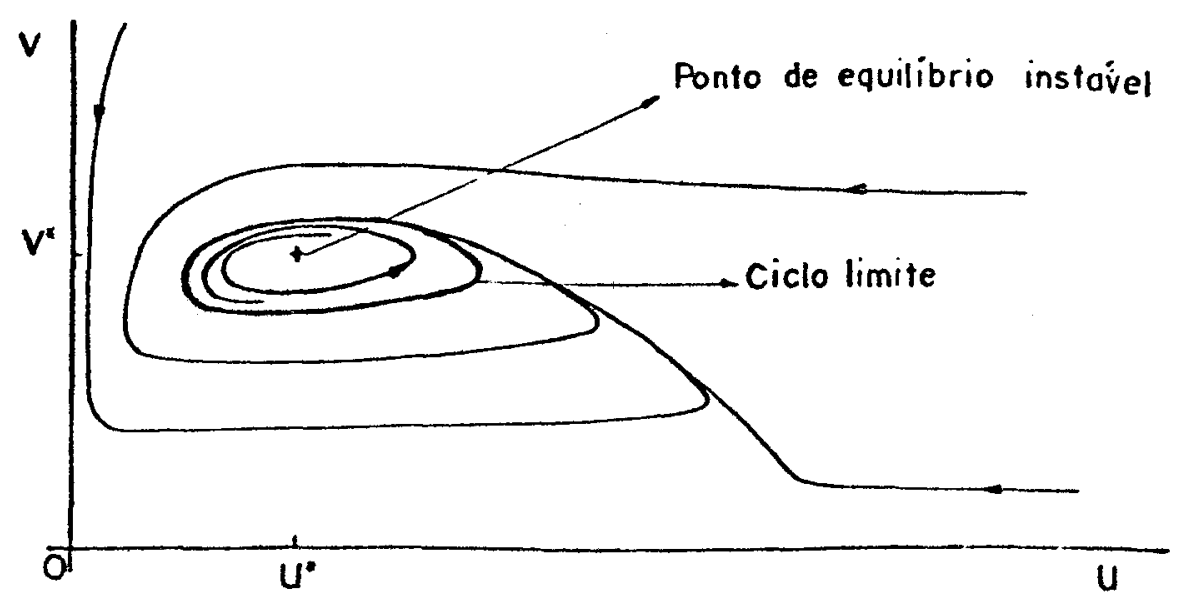

Figura 1.3: Ciclo-limite, para o sistema (2.22) com os parâmetros $a=1.5$, $b=0.04$ e $d=0.3$

Se as trajetórias próximas ao ciclo-limite são espirais que se aproximam do ciclo quando $t \rightarrow \infty$, o ciclo-limite é dito estável e, se as trajetórias são espirais que se afastam dele quando $t \rightarrow \infty$, o ciclo-limite é dito instável.

Lembremos que num sistema linear autônomo quando as raízes da equação característica são imaginărias puras, temos trajetórias fechadas em volta do ponto de equilíbrio $(x, y)=(0,0)$ e as soluções neste caso são periódicas. Contudo quando consideramos sistemas não lineares, cujo sistema linear associado tem estas características, a origem pode ser um centro ou um ponto espiral. Portanto, é importante poder decidir com certeza se existem ou não soluções periódicas e ciclos-limites. O seguinte teorema trata desta questão para sistemas de duas dimensões.

Teorema 1.4.1 (Poincaré-Bendixon) Seja $\mathcal{R}$ uma região fechada e limitada, que contém pontos não singulares do sistema de duas dimensões $\frac{d \mathbf{x}}{d t}=f(\mathbf{x})$. Se alguma semi-trajetória positiva $\mathcal{H}$ está inteiramente contida em $\mathcal{R}$. Então: Ou $\mathcal{H}$ é ela própria uma trajetória fechada, ou se aproxima de uma trajetória fechada ou se aproxima do ponto de equilíbrio.

Prova: [17, pag.321]

O teorema de Poincaré-Bendixon é aplicável somente para sistemas de duas dimensões, para sistemas de dimensão $n>2$, pode ser aplicada a teoria da Bifurcação de Hopf. 
Um outro teorema (W. A. Coppel, [10]) pode ser usado para determinar a não existência de ciclos-limites:

Teorema 1.4.2 Sejam $P$ e $Q$ continuamente diferenciáveis em uma região aberta e conexa $D$, tal que nenhuma trajetória da solução do sistema

$$
\frac{d x}{d t}=P(x, y), \quad \frac{d y}{d t}=Q(x, y)
$$

deixa $D$, e suponha que $D$ contém pelo menos um ponto de equilibrio. Se existe $B(x, y)$ continuamente diferenciável em $D$ tal que

$$
\frac{\partial(B P)}{\partial x}+\frac{\partial(B Q)}{\partial y}
$$

tem o mesmo sinal em $D$. Então, não existem trajetórias fechadas (soluções periódicas) em $D$.

Prova: $[10$, seção 3].

\subsection{Resultados Adicionais}

\subsubsection{Propriedades de Matrizes}

Apresentamos alguns resultados sobre matrizes, [20], [31, cap. 2].

1. Dada uma matriz $n \times n, A=\left(a_{i j}\right)$, dizemos que $A$ é irredutivel se para qualquer subconjunto próprio $S \subset\{1, \ldots, n\}$ existem $i \in S$ e $j \in S^{\prime}$, sendo $S^{\prime}=\{1, \ldots, n\} \backslash S$, tal que $a_{i j} \neq 0$.

2. Se $\lambda_{i} ; 1 \leq i \leq n$ são autovalores de $A$ então o raio espectral, $\rho(A)$, é definido por $\rho(A)=\max _{i}\left|\lambda_{i}\right|$. 0 módulo de estabilidade $S(A)$, é definido por $S(A)=\max _{i} R e \lambda_{i}$, onde $\operatorname{Re} \lambda_{i}$ é a parte real do autovalor $\lambda_{i}$.

3. A matriz $A=\left(a_{i j}\right)$ é dita não negativa $(A \geq 0)$ se, e somente se, $a_{i j} \geq 0$ para todo $i, j$. 
- Da teoria de Perron-Frobenius, tem-se o seguinte resultado:

Teorema 1.5.1 Seja $A \geq 0$ uma matriz $n \times n$ irredutivel. Então:

1. A tem um autovalor real positivo igual a seu raio espectral.

2. Ao raio espectral, $\rho(A)$, corresponde um autovetor $\mathrm{x}>0$ (isto é, $x_{i}>0$, para todo i).

3. $\rho(A)$ é incrementado sempre que qualquer elemento de $A$ é incrementado.

4. $\rho(A)$ é um autovalor simples de $A$.

Prova: [31, pag. 30].

Do teorema (1.5.1), obtém-se o seguinte resultado

Lema 1.5.1 Seja A uma matriz $n \times n$ irredutivel e tal que $a_{i j} \geq 0$ sempre que $i \neq j$. Então: Existe um autovetor $\mathrm{w}$ de $A$ tal que $\mathrm{w}>0$, e o autovalor correspondente é $S(A)$.

Prova: [20].

\section{Observações}

1. $S(A)$ é denominado autovalor de Perron de $A$ e w de autovetor de Perron de $A$.

2. Se $A$ é não negativa e irredutível, a teoria de Perron-Frobenius implica em que ela tem um autovalor real, simples igual a seu raio espectral $\rho(A)$. 0 autovetor correspondente $\mathbf{x}$ é positivo, qualquer outro autovetor não negativo é múltiplo de $\mathbf{x}$, e o raio espectral de $A$ é igual ao autovalor de Perron de $A$.

3. $A$ é irredutivel se, e somente se, a matriz transposta, $A^{T}$, é irredutivel. $S(A)=S\left(A^{T}\right)$. 


\subsubsection{Um Teorema de Ponto Fixo}

Definição 1.5.1 (Sublinearidade) A função $f: \mathcal{R}_{+}^{n} \rightarrow \mathcal{R}_{+}^{n} ; \mathcal{R}_{+}^{n}=[0, \infty)^{n}$ é dita estritamente sublinear se fixando $x \in(0, \infty)^{n}$ e $r \in(0.1)$, existe $\varepsilon>0$ tal que $f(r x) \geq(1+\varepsilon) r f(x)$.

Sublinearidade estrita significa que o gráfico de $f(x)$ com $f(0)=0$ é estritamente côncavo quando o ponto final é fixado em $(0, f(0))$, isto é, $f((1-r) 0+r x) \geq$ $(1+\varepsilon)[(1-r) f(0)+r f(x)]$. Observamos que se $x, y \in \mathcal{R}_{+}^{n}$ então $x \leq y$ se, e somente se, $x_{i} \leq y_{i}, i=1, \ldots, n$. Isto é, o símbolo $\leq$ denota a ordem gerada pelo cone $\mathcal{R}_{+}^{n}$.

Teorema 1.5.2 (De ponto fixo) Seja $f: \mathcal{R}_{+}^{n} \rightarrow \mathcal{R}_{+}^{n}$ uma função contínua, monôtona não decrescente, estritamente sublinear e limitada. Seja $f(0)=0$ e $f^{\prime}(0)$ existe e é irredutivel. Então: $f(x)$ não tem um ponto fixo, não trivial, com pelo menos uma coordenada nula e, além disso, $f(x)$ tem um ponto fixo positivo se, e somente se, $\rho\left(f^{\prime}(0)\right)>1$. Se existe um ponto fixo positivo, então ele é único.

Prova: [12]. 


\section{Capítulo 2}

\section{Interações entre Espécies}

\subsection{Introdução}

Em geral os modelos matemáticos em Biologia assumem a forma de sistemas de Volterra. 0 sistema clássico de Lotka-Volterra para a modelagem de interações entre $n$ espécies é dado pelo sistema de equações diferenciais:

$$
\frac{d N_{i}}{d t}=N_{i}\left(a_{i}+\sum_{j=1}^{n} b_{i j} N_{j}\right), \quad N_{i}(0)>0, \quad(i=1, \ldots, n)
$$

onde $N_{i}$ é a densidade populacional da $i$-ésima espécie. $O$ primeiro termo descreve o comportamento da $i$-ésima espécie na ausência das outras e, o segundo termo descreve a interação da $i$-ésima espécie com todas as outras, em geral $i \neq j$. Classificaremos as interações em três tipos gerais: Predação, Competição e Mutualismo.

Para o estudo das interações populacionais, é necessário conhecer as características específicas de cada uma das populações que estão interagindo. Portanto, iniciaremos este capítulo apresentando os modelos de crescimento populacional para espécies isoladas. Estudaremos a seguir a interação presa-predador (modelo clássico de Lotka-volterra, modelos presa-predador realísticos, modelo presa-predador com comportamento periódico de ciclo-limite, complexidade e estabilidade de sistemas presa-predador), modelos de competição, mutualismo e finalmente o modelo geral para interação entre $n$ espécies. $[2,4,7,24,26,30]$. 


\subsection{Modelos de Crescimento Populacional \\ 《?}

Os modelos que descrevem a variação da densidade populacional de uma espécie no tempo, são da forma

$$
\frac{d N}{d t}=r N f(N)
$$

onde $N$ define a densidade populacional e $r>0$, constante, a taxa de crescimento. A forma da função $f(N)$ depende das características da população. Assim sendo, existem vários modelos dos quais discutiremos somente o modelo de Malthus e o modelo de crescimento logístico ou de Verhulst, dado que serão usados neste trabalho.

A primeira lei de crescimento populacional foi dada por Thomas $R$. Malthus em 1798, quando observou que o crescimento populacional segue uma progressão geométrica em contraste com os meios de subsistência os quais tendem a crescer em progressão aritmética. $O$ crescimento malthusiano para uma população sem restrições pode ser representado pela equação

$$
\frac{d N}{d t}=r N
$$

onde $N(t)$ é a população instantânea da espécie sob consideração e $r$ é o coeficiente de crescimento populacional. A equação (2.3) é conhecida como Lei de Malthus. De acordo com ela uma população cresce exponencialmente, como mostra a solução de (2.3), dada por

$$
N(t)=N_{0} e^{r t}
$$

onde $N_{0}=N\left(t_{0}\right)$ é a população inicial.

Malthus não considerou o fato de que o crescimento populacional pode ser influenciado por fatores externos que o limitam. Contudo a equação é apropriada para medir estimativas de crescimento populacional a curto prazo, como por exemplo, culturas de microorganismos.

Verhulst, em 1837, propôs que o crescimento populacional não podia ser ilimitado como no modelo de Malthus, ele argumentou que fatores tais como: disponibilidade de alimentos, espaço, abrigo etc. influenciam o crescimento. Existe portanto um limitante, digamos $K$, chamado Capacidade de suporte do meio, que é a quantidade em que o tamanho da população se estabiliza. Ele propôs que a taxa de crescimento de uma população era proporcional ao produto da população existente e a diferença entre o total de recursos disponiveis e os recursos ja utilizados pela população presente. 
De acordo com Verhulst, o coeficiente de crescimento populacional é dado por

$$
r_{m}=r\left[\frac{K-N}{K}\right]
$$

Isto significa que, quando $N \ll K$ o crescimento satisfaz a lei de Malthus e quando $N \approx K$, a taxa de crescimento diminui rapidamente. A equação de Verhulst é então,

$$
\frac{d N}{d t}=r N\left[1-\frac{N}{K}\right]
$$

Se $N_{0}=N\left(t_{0}\right)$ é a população inicial, a solução da equação (2.5) é dada pela fórmula

$$
N(t)=\frac{N_{0} K e^{r t}}{\left[K+N_{0}\left(e^{r t}-1\right)\right]}=\frac{K}{\left[\frac{K}{N_{0}}-1\right] e^{-r t}+1}
$$

A curva $N(t)$, chamada Curva de crescimento Logístico é representada na seguinte figura:

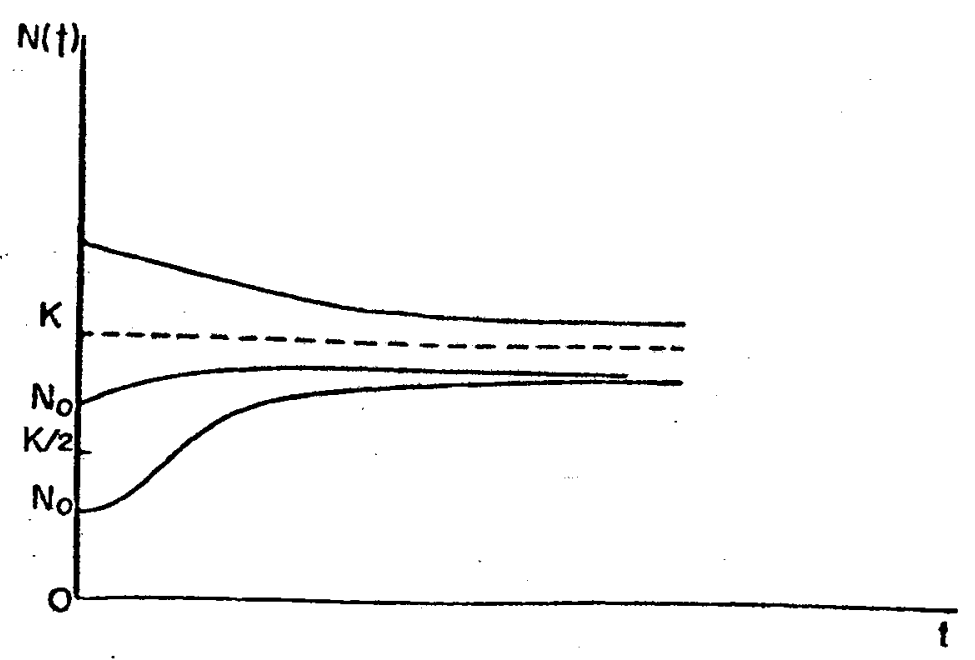

Figura 2.1: Curva de crescimento Logístico

As seguintes observações são pertinentes:

1. Da equação (2.5) temos que o coeficiente de crescimento é negativo quando $N>K$ e positivo quando $N<K$. Desta forma, a população se aproxima de $K$, a densidade equilíbrio, crescendo ou decrescendo.

2. Da equação (2.5) temos que $\frac{d N}{d t}$ como função de $N$ é uma parábola de concavidade para baixo, com ralzes em $N=0$ e $N=K$. $O$ valor máximo 
de $\frac{d N}{d t}$ em relação a $N$ é atingido quando $N(t)=\frac{K}{2}$, ou seja, temos a maior taxa de variação populacional quando a população for igual a metade da população limite.

3. Quando $N_{0} \leq \frac{K}{2}$ a curva $N(t)$ (curva sigmóide) tem um ponto de inflexão, isto porque o crescimento populacional tem um instante de variação máxima dado por

$$
t_{m}=\frac{1}{r} \ln \left|\frac{K-N_{0}}{N_{0}}\right|
$$

a população neste instante é dada por $N\left(t_{m}\right)=\frac{K}{2}$.

\subsection{Predação}

Neste tipo de interação uma espécie, chamada predadora, se alimenta de outra espécie, chamada presa. A população de presas dispõe (em qualquer época) de alimentos em abundância e a população predadora alimenta-se exclusivamente da primeira.

\subsubsection{Modelo Clássico de Lotka-Volterra}

O modelo (descoberto por. Volterra e independentemente por Lotka, em torno de 1925) foi apresentado no capítulo 1, pag. 5. Analisaremos agora a estabilidade do sistema.

Assumindo que as duas espécies são isoladas, as hipóteses do modelo são as seguintes:

1. O encontro de elementos das duas espécies é ao acaso, a uma taxa proporcional ao tamanho das duas populações.

2. $\mathrm{Na}$ ausência do predador, a população das presas cresce segundo a lei de Malthus.

3. Na ausência da presa, o predador morre por inanição, resultando num decaimento exponencial da população.

4. Os efeitos da interação entre as espécies são instantâneos, isto é, o tempo entre o momento em que o predador devora a sua presa e o momento em que a matéria ingerida é convertida em um novo predador é ignorado. 


\section{Análise do modelo}

Para simplificar a análise utilizamos a técnica de Adimensionalização. Esta técnica reduz os parâmetros do modelo a uma dimensão menor, no entanto, esta redução não é aleatória, os parâmetros devem ser agrupados de forma a permitir uma medida dos efeitos de mudançàs nos parâmetros originais sobre o comportamento do sistema. Então, fazendo-se a seguinte substituição de variáveis

$$
u(\tau)=\frac{c N(t)}{d}, v(\tau)=\frac{b P(t)}{a}, \tau=a t, \alpha=\frac{d}{a}
$$

obtém-se

$$
\begin{aligned}
& \frac{d u}{d \tau}=u(1-v)=f(u, v) \\
& \frac{d v}{d \tau}=\alpha v(u-1)=g(u, v)
\end{aligned}
$$

O sistema não linear (2.8) não tem necessariamente uma solução analítica. Portanto, estudaremos as trajetórias da solução no plano de fase $(u, v)$.

Neste modelo e em todos os subsequentes, dado que tratamos com densidades populacionais, a análise será restrita ao quadrante positivo do plano de fase.

\section{Análise da estabilidade dos pontos de equilíbrio}

Os pontos de equilíbrio do sistema $(2.8)$ são: $(0,0)$ e $(1,1)$. Utilizando a teoria discutida no capítulo 1 (pag. 16), o sisterna pode ser linearizado e a natureza dos pontos de equilíbrio determinada pelas raízes do polinômio característico. 0 sistema linear associado ao sistema (2.8) é dado por

$$
\left(\begin{array}{l}
d u / d t \\
d v / d t
\end{array}\right)=A\left(\begin{array}{l}
u \\
v
\end{array}\right)
$$

onde $A$ é a matriz jacobiana avaliada no ponto de equilíbrio $(u, v)=\left(u^{*}, v^{*}\right)$. No que segue, chamaremos $A$ de Matriz de estabilidade.

A matriz jacobiana do sistema (2.8) é dada por

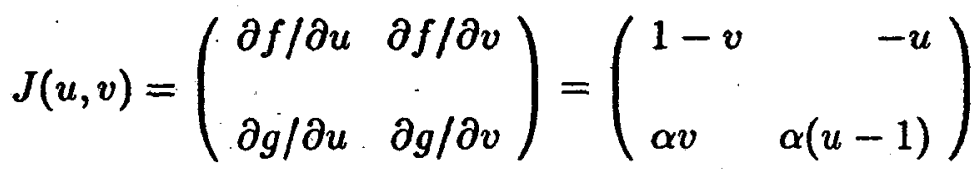


1. Para o ponto $(0,0)$ os autovalores são dados por $\lambda_{1}=1$ e $\lambda_{2}=-\alpha$, portanto, o ponto de equilíbrio é um ponto de sela. *

2. Para o ponto $(1,1)$ os autovalores são dados por $\lambda_{1}=i \sqrt{\alpha}$ e $\lambda_{2}=-i \sqrt{\alpha}$, portanto o ponto de equilíbrio é um centro para o sistema linear, portanto, para o sistema não linear (2.8) a natureza do ponto é indeterminada, podendo ser um centro ou uma espiral. Porém, para este modelo é possível determinar a natureza do ponto, da seguinte maneira:

As trajetórias de fase do sistema (2.8) são as curvas solução da equação

$$
\frac{d v}{d u}=\frac{\alpha v(u-1)}{u(1-v)}
$$

que têm pontos singulares em $(0,0)$ e $(1,1)$. A equação $(2.10)$ é separável e pode ser integrada exatamente, obtendo-se a equação das trajetórias de fase,

$$
f(u, v)=a u+v-\ln \left(u^{\alpha} v\right)=C,(\text { constante) }
$$

e conforme o resultado obtido no exemplo da pag. 5 , as trajetórias dadas por (2.11) são curvas fechadas. Portanto, o ponto de equilibrio $(1,1)$ é um centro para o sistema não linear.

O diagrama de fase para o sistema (2.8), $\operatorname{com} \alpha=1$ é mostrado na figura 2.2.

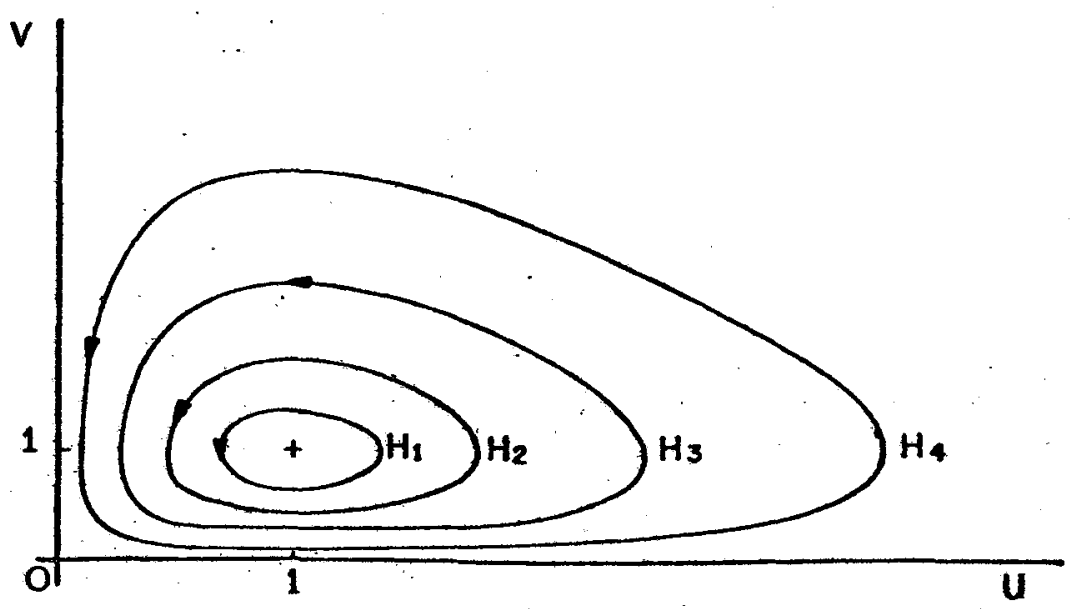

- Figura 2.2: Trajetórias de fase para o sistema (2.9), modelo clássijco de Lotka-Volterra. 


\section{Comentários}

1. Trajetórias fechadas implicam em soluções periódicas, o periodo depende somente da taxa de crescimento das presas e da mortalidade dos predadores.

Prova: As soluções numa vizinhança do ponto de equilíbrio $(u, v)=(1,1)$ são periódicas em $T$ com período $T=\frac{2 \pi}{\sqrt{\alpha}}$, onde $\alpha=\frac{d}{a}$. Temos então que $T=2 \pi \sqrt{\frac{a}{d}}$, isto é, o período é proporcional a raíz quadrada de $\frac{a}{d}$, onde $a$ é a taxa de crescimento das presas e $d$ a taxa de mortalidade dos predadores. Por exemplo, um incremento na taxa de crescimento das presas aumenta o período.

2. Os valores médios da população de presas e da população de predadores ao longo de um período são os mesmos para todas as soluções, embora soluções diferentes tenhaim períodos diferentes.

Prova: [4, pag. 388]. O sistema (2.8) pode ser escrito na forma

$$
\begin{aligned}
& \frac{1}{u} \frac{d u}{d \tau}=(1-v) \\
& \frac{1}{v} \frac{d v}{d \tau}=\alpha(u-1)
\end{aligned}
$$

e integrando ambas equações entre 0 e $\mathrm{T}$, onde $\mathrm{T}$ é o periodo de uma solução particular, obtemos

$$
\begin{aligned}
& \ln u(T)-\ln u(0)=T-\int_{0}^{T} v d \tau \\
& \ln v(T)-\ln v(0)=T-\int_{0}^{T} u d \tau
\end{aligned}
$$

como a solução é periódica temos que $u(T)=u(0)$ e $v(T)=v(0)$, portanto, de (2.13) obtemos

$$
\frac{1}{T} \int_{0}^{T} v d \tau=1, \quad \frac{1}{T} \int_{0}^{T} u d \tau=1
$$

sendo o primeiro membro das equações (2.14) os valores médios das populações de presas e predadores ao longo de um periodo.

Do ponto de vista biológico, a interpretação deste resultado é que os valores médios de ambas populações não dependem das condições iniciais, eles sempre serão iguais aos valores de equilíbrio $(u, v)=(1,1)$. Por exemplo, num sistema em que uma praga (presa) e seu predador natural convivem, para diminuir a praga não resolve aumentar a quantidade de predadores, dado que isto só muda a amplitude do ciclo. 
3:- A retirada uniforme de elementos de ambas populações produz um aumento na população das presas.

Prova: [4, pag. 339]. Considerando uma retirada uniforme de elementos das duas populações, a população será diminuida a uma taxa proporcional ao tamanho desta.

Seja $\epsilon$ a constante de proporcionalidade de retirada, o sistema (2.8) é modificado para

$$
\begin{aligned}
& \frac{d u}{d \tau}=u(1-v)-\epsilon u \\
& \frac{d v}{d \tau}=\alpha v(u-1)-\epsilon v
\end{aligned}
$$

que tem pontos de equilibrio $(0,0)$ e $\left(1+\frac{\epsilon}{\alpha}, 1-\epsilon\right)$, a diferença entre os sistemas (2.8) e (2.15) é a localização dos pontos de equilíbrio e podemos observar que o valor médio das presas aumenta, e diminui o valor médio dos predadores. Por exemplo, num sistema em que uma praga (presa) e seu predador natural convivem, o uso de pesticidas que matam indiscriminadamente tanto presas como predadores, aumentará o valor médio da população das pragas.

4. O modelo de Lotka-Volterra não é estruturalmente estável, dado que, qualquer mudança arbitrariamente pequena, alterará a topologia das trajetórias no plano de fase. Isto pode ser visto diretamente da figura 2.2. Suponha que $(u(0), v(0))$ sejam tais que para $\tau>0,(u(\tau), v(\tau))$ esteja sobre a trajetória $H 4$, perto dos eixos coordenados. Uma pequena perturbação poderá deslocar a solução para uma outra trajetória que não permanece sempre perto da trajetória original $H 4$, sendo esta, a principal objeção ao modelo de Lotka-Volterra.

\subsubsection{Modelos Presa-Predador Realísticos}

No modelo de Lotka-Volterra, apresentado na seção anterior, a população das presas na ausência de predadores cresce segundo a lei de Malthus, ou seja, a densidade populacional é considerada como o único regulador do crescimento.

Em experimentos com populaçōes, Gause(1934), contestou estes resultados, ele disse, que no lugar de soluções periódicas, as oscilações poderiam explodir, seguido de extinção das presas e em conseqüência dos predadores. Gause sustentou que existe um limite no qual um único predador pode reproduzir-se ou capturar uma presa. Portanto; para altas densidades de presas nầo sé pode assumir que a quantidade de presas capturadas e/ou número de descendentes 
seja simplesmente proporcional à densidade das presas. Surgem então, a noção de Resposta Funcional do Predador e Resposta numérica do predador, definidas a seguir.

Resposta Funcional do Predador é a função que relaciona a densidade da presa ao número de presas devoradas por um predador.

Resposta Numérica do Predador é a função que relaciona a eficiência na captura ao incremento na densidade dos predadores.

Os primeiros estudos a este respeito foram publicados em 1959 por Holling e Rashevsky, citados por Metz et al., [24, pag 5-20].

Modelos mais realísticos devem levar em conta as características específicas das populações. Um exemplo é o Modelo de Kolmogorov (1936):

$$
\frac{d N}{d t}=N F(N, P), \quad \frac{d P}{d t}=P G(N, P)
$$

onde as funções $F$ e $G$ dependem somente das espécies e do tipó de interação.

Discutiremos inicialmente a primeira equação do sistema (2.16).

$$
\text { Seja } \frac{d N}{d t}=N F(N, P), \quad F(N, P)=r\left(1-\frac{N}{K}\right)-P R(N)
$$

Aqui a população das presas na ausência do predador obedece ao crescimento logístico, onde $K$ é a capacidade de suporte do meio e $r>0$ é uma constante. Qualquer outro padrão de crescimento particular poderia ser considerado, levando em conta o ajuste à realidade. A população das presas é diminuída pelo termo $P N R(N)$ onde $N R(N)$ é a Resposta funcional do predador. Alguns exemplos para $R(N)$ são:

$$
R(N)=\frac{A}{N+B}, \quad R(N)=\frac{A N}{N^{2}+B^{2}}, \quad R(N)=\frac{A\left[1-e^{-a N}\right]}{N}
$$

onde $A, B$ e $a$ são constantes positivas. Observamos que a resposta funcional do predador geralmente mostra um efeito de saturação para alta densidade das presas.

A segunda equação do sistema (2.16) pode ser feita mais realista do que $G(N, P)=-d+c N$, como no modelo de Lotka-Volterra (1.5). Alguns exemplos para $G(N, P)$ são:

$$
G(N, P)=k\left(1-\frac{h P}{N}\right), \quad G(N, P)=-d+e R(N)
$$


onde $k, h, d$ e $e$ são constantes positivas, e $R(N)$ como em (2.17).

A função $G(N, P)$ é a Resposta numérica do predador. Observamos que na primeira equação em (2.18), a capacidade de suporte do meio do predador é diretamente proporcional à densidade das presas.

\subsubsection{Modelo Presa-Predador com Solução Periódica de Ciclo-Limite: Modelo de Murray}

O modelo a ser discutido é descrito pelo sistema de equações [26]:

$$
\begin{aligned}
\frac{d N}{d t} & =N\left[r\left(1-\frac{N}{K}\right)-\frac{k P}{N+D}\right] \\
\frac{d P}{d t} & =P\left[s\left(1-\frac{h P}{N}\right)\right]
\end{aligned}
$$

onde $r, K, k, D, s$ e $h$ são constantes positivas. $N$ define a densidade das presas e $P$ a densidade dos predadores. No modelo estão incorporados os seguintes fatos.

1. Na ausência de predadores, o crescimento das presas é logístico, $K$ é a capacidade de suporte do meio e $r$ é a taxa em que este limite é atingido.

2. A resposta funcional do predador é dada pela termo $N R(N)$ onde $R(N)=$ $\underset{\text { presas. }}{\frac{k}{+} \text {. Esta função é aproximadamente linear para baixa densidade das }}$

3. O crescimento dos predadores é logístico, e a capacidade de suporte do meio é diretamente proporcional à densidade das presas.

\section{Análise do modelo}

Simplificamos o sistema (2.19), introduzindo variáveis adimensionais:

$$
u(\tau)=\frac{N(t)}{K}, v(\tau)=\frac{h P(t)}{K}, \tau=r t, a=\frac{k}{h r}, \quad b=\frac{s}{r}, d=\frac{D}{K}
$$

e obtemos o sistema

$$
\begin{aligned}
& \frac{d u}{d \tau}=u(1-u)-\frac{a u v}{u+d}=f(u, v) \\
& \frac{d v}{d \tau}=b v\left(1-\frac{v}{u}\right)=g(u, v)
\end{aligned}
$$


; Os pontos de equilíbrio de (2.21) são os pontos $(u, v)=\left(u^{*}, v^{*}\right)$ onde

$$
u^{*}\left(1-u^{*}\right)-\frac{a u^{*} v^{*}}{u^{*}+d}=0, \quad b v^{*}\left(1-\frac{v^{*}}{u^{*}}\right)=0
$$

resolvendo (2.22) obtemos

$$
\begin{gathered}
v^{*}=u^{*}, \quad u^{*^{2}}-(1-d-a) u^{*}-d=0 \\
u_{1,2}^{*}=\frac{(1-a-d) \pm\left\{(1-a-d)^{2}+4 d\right\}^{\frac{1}{2}}}{2}
\end{gathered}
$$

Como somente nos interessam as soluçôes positivas, temos os pontos de equilíbrio

$$
u^{*}=v^{*}, \quad u^{*}=\frac{(1-a-d)+\left\{(1-a-d)^{2}+4 d\right\}^{\frac{1}{2}}}{2}
$$

A análise da estabilidade linear nas vizinhanças dos pontos de equilíbrio é equivalente à análise no plano de fase.

\section{Análise da estabilidade dos pontos de equilíbrio}

Linearizando-se o sistema (2.21) e tomando-se a matriz jacobiana no ponto $\left(u^{*}, v^{*}\right)$, temos a matriz de estabilidade

$$
A=\left(\begin{array}{lr}
u^{*}\left[\frac{a u^{*}}{\left(u^{*}+d\right)^{2}}-1\right] & \frac{-a u^{*}}{u^{*}+d} \\
b & -b
\end{array}\right)
$$

cujos autovalores são dados por

$$
\lambda_{1,2}=\frac{\operatorname{tr} A \pm \sqrt{(\operatorname{tr} A)^{2}-4 \operatorname{det} A}}{2}
$$

que têm parte real negativa se, e somente se, as seguintes condições são satisfeitas:

$$
\text { 1) } \operatorname{tr} A<0 \quad \text { 2) } \operatorname{det} A>0
$$

portanto as condições necessária e suficiente para a estabilidade linear são 


$$
u^{*}\left[\frac{a u^{*}}{\left(u^{*}+d\right)^{2}}-1\right]<b, \quad 1+\frac{a}{u^{*}+d}-\frac{a u^{*}}{\left(u^{*}+d\right)^{2}}>0
$$

respectivamente.

Quando estas condições são satisfeitas, o ponto de equilíbrio é estável, podendo ser um nó ou uma espiral. Substituindo $u^{*}$ de (2.23) nas desigualdades acima, obtemos as condições de estabilidade em termos dos parâmetros $a, b$ e $d$ e em consequêencia em termos dos parâmetros originais $r, k, s, h, K$ e $D$.

Existe uma região no espaço $(a, b, d)$ tal que, se os parâmetros permanecem dentro dela, o ponto $\left(u^{*}, v^{*}\right)$ é instável; para que isto possa acontecer é necessário que ao menos uma das condições de (2.25) não seja satisfeita.

\section{Região de instabilidade}

A segunda condição de $(2.25)$ é sempre satisfeita $(\operatorname{det} A>0)$ ou

$$
1+\frac{a}{u^{*}+d}-\frac{a u^{*}}{\left(u^{*}+d\right)^{2}}=1+\frac{a d}{\left(u^{*}+d\right)^{2}}>0
$$

para todo $a>0, d>0$, portanto a região de instabilidade é determinada somente pela primeira desigualdade de $(2.25)(\operatorname{tr} A<0)$ ou

$$
u^{*}\left[\frac{a u^{*}}{\left(u^{*}+d\right)^{2}}-1\right]<b
$$

usando as condições (2.22)

$$
u^{*}\left(1-u^{*}\right)-\frac{a u^{*} v^{*}}{u^{*}+d}=0 \quad \text { e } \quad v^{*}=u^{*}
$$

e $u^{*}$ como em (2.23), substituindo em (2.26) obtemos a seguinte expressão:

$$
\left[a-\left\{(1-a-d)^{2}+4 d\right\}^{\frac{1}{2}}\right] \frac{\left[(1+a+d)-\left\{(1-a-d)^{2}+4 d\right\}^{\frac{1}{2}}\right]}{2 a}<b
$$

$a \neq 0$, que define uma superfície tridimensional no espaço $(a, b, d)$, com $a, b$ e $d$ sempre positivos. A expressão no segundo colchete em (2.27) é uma função monótona decrescente de $d$ e sempre positiva. A expressão no primeiro colchete também é uma função monótona decrescente com máximo em $d=0$. Assim, para $d=0 \mathrm{em}(2.27)$, obtemos 


$$
b_{d=0}> \begin{cases}2 a-1 & \text { se } 0<a \leq 1 \\ \frac{1}{a} & \text { se } 1 \leq a\end{cases}
$$

portanto para $0<a<\frac{1}{2}$ e para todo $d>0$ a condição de estabilidade (2.26) é satisfeita para qualquer $b>0$, ou seja $\left(u^{*}, v^{*}\right)$ é linearmente estável para todo $0<a<\frac{1}{2}, b>0$ e $d>0$. De outra maneira, se $a>\frac{1}{2}$ existe uma região em $(a, b, d)$ com $b>0, d>0$ onde (2.26) não é satisfeita e portanto a primeira condição de (2.25) não é satisfeita e daqui um dos autovalores $\lambda$ em (2.24) tem $\operatorname{Re} \lambda>0$, isto implica que o ponto de equilibrio $\left(u^{*}, v^{*}\right)$ é instável para pequenas perturbações.

A fronteira desta região é dada por $(2.27)$ e a interseção do plano $b=0$ e da curva $d=d_{m}(a)$ dada pela solução positiva de

$$
a=\left\{\left(1-a-d_{m}\right)^{2}+4 d_{m}\right\}^{\frac{1}{2}}
$$

que é

$$
d_{m}(a)=d_{b=0}=\left(a^{2}+4 a\right)^{\frac{1}{2}}-(1+a) .
$$

$d_{m}(a)$ é uma função monótona crescente, limitada por $d=1$, e também $d<a$ para todo $a>1 / 2$. A região de instabilidade-estabilidade é representada no espaço $(a, b, d)$, na figura 2.3 .

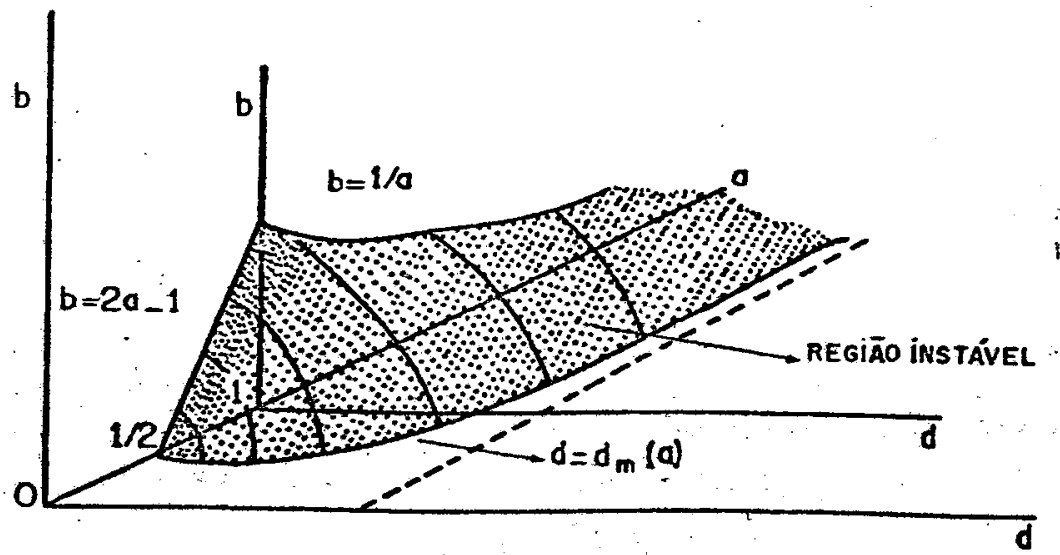

Figura 2.3: Região de instabilidade. (reproduzida de [26]) 


\section{Existência de ciclo-limite}

Quando os parâmetros $a, b, d$ estão dentro da região de instabilidade, o ponto de equilíbrio $\left(u^{*}, v^{*}\right)$ é instável (podendo ser um nó ou uma espiral) e as trajetórias de fase tendem a um ciclo-limite.

Para mostrar isto, determinaremos uma região no plano $(u, v)$ tal como no teorema de Poincaré-Bendixon para a existência de ciclo-limite. Em outras palavras, devemos encontrar uma região limitada no quadrante positivo do plano de fase tal que as trajetórias apontem sempre para dentro da região, ou seja, para todos os pontos na fronteira desta região é necessário que

$$
\mathbf{n} \cdot\left(\frac{d u}{d \tau}, \frac{d v}{d \tau}\right)<0
$$

onde $\mathrm{n}$ é o vetor normal à fronteira no ponto. Se (2.30) é satisfeita, isto significa que o vetor velocidade $\left(\frac{d u}{d \tau}, \frac{d v}{d \tau}\right)$ aponta para dentro da região, e nenhuma trajetória de fase que comece dentro da região pode sair dela. Para encontrar essa região plotamos no plano de fase $(u, v)$ as curvas onde $f(u, v)=\frac{d u}{d \tau}=0$ e $g(u, v)=\frac{d v}{d \tau}=0$. De (2.21) estas curvas são

$$
u=v, \quad v=\frac{1}{a}(1-u)(u+d)
$$

que são mostradas na figura 2.4.

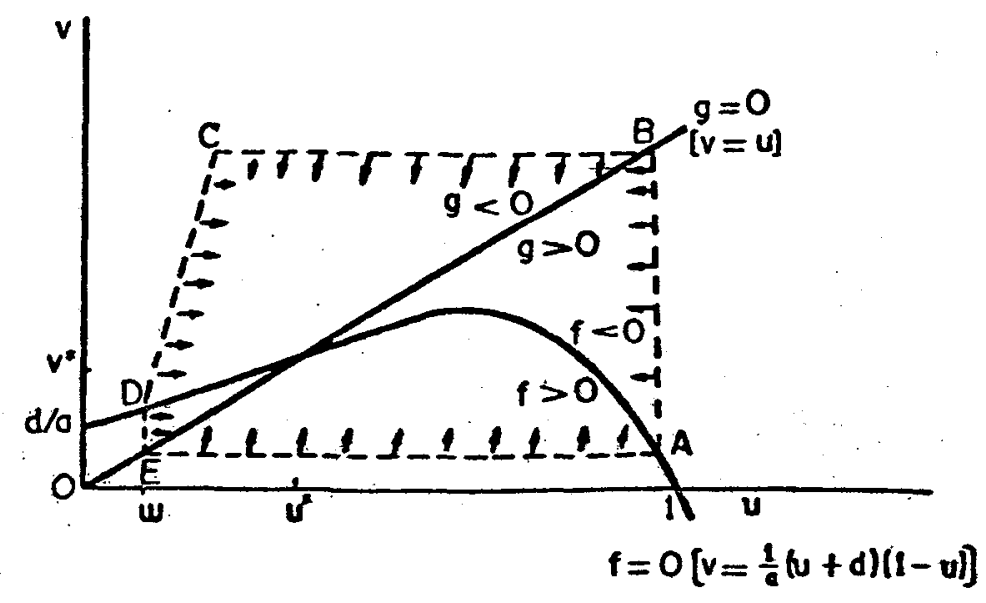

Figura 2.4: Região. limitada em volta de $\left(u^{*}, v^{*}\right)$. (reproduzida de [26])

Consideremos à região $A B C D E A$, sobre os segmentos $A B, B C, D E \mathrm{e}$ $E A$ as trajetórias claramente apontam para dentro da região: 

$1: \operatorname{Par}$ Para o segmento $A B$
2. Para o segmento $B C \quad \mathbf{n}=(0,1), f<0, g<0: \mathbf{n} \cdot(f, g)<0$.
3. Para o segmento $D E \quad \mathbf{n}=(-1,0), f>0, g<0: \mathbf{n} \cdot(f, g)<0$.
4. Para o segmento $E A \quad \mathbf{n}=(0,-1), f>0, g>0: \mathbf{n} \cdot(f, g)<0$.

Se o segmento $D C$ for tomado paralelo ao eixo $V$ obtém-se $\mathbf{n} \cdot(f, g)>0$. Porém é sempre possível escolher o segmento $D C$ tal que $\mathbf{n} \cdot(f, g)<0$ onde $\mathbf{n}=(-1, \alpha), \alpha>0$.

Prova: Seja $C D$ o segmento da reta $v=m u+k$ com coeficiente angular $m$ que passa pelo ponto $\left(w, \frac{1}{a}(w+d)(1-w)\right)$. O vetor unitário perpendicular a $D C$ é dado por $\mathbf{n}=\left(-1, \frac{1}{m}\right)$, onde $m \neq 0$. Observemos que devemos ter $m>0$, dado que se $m<0$, obtemos $\mathbf{n} \cdot(f, g)>0$.

Como

$$
\mathbf{n} \cdot(f, g)=\left(-1, \frac{1}{m}\right) \cdot(f, g)=-u(1-u)+\frac{a u v}{u+d}+\frac{b v}{m}\left(\frac{u-v}{u}\right)
$$

temos que

$$
\mathbf{n} \cdot(f, g)<0 \text { se, e somente se, } m>\frac{g(u, v)}{f(u, v)}
$$

Portanto, podemos escolher $C D$ como o segmento da reta

$$
v=m u+k=m u+\frac{1}{a}(w+d)(1-w)-m w
$$

onde

$$
m>\frac{g(u, v)}{f(u, v)}, \quad \text { e } \alpha=\frac{1}{m}
$$

Temos agora a região apropriada para aplicar o teorema de PoincaréBendixon. Portanto, quando $\left(u^{*}, v^{*}\right)$ é instável, as trajetórias se afastam dele, porém não podem atravessar a região $A B C D E A$ e devem evoluir em uma trajetória ciclo-limite. Na fig. 2.5 é mostrado o diagrama de fase para o sistema (2.21), com os seguintes valores dos parâmetros: $a=1.5, d=0: 3$. Para $b=50$ ponto de equilíbrio é estável e para $b=0.01$ é instável, apresentando ciclo-limite. 

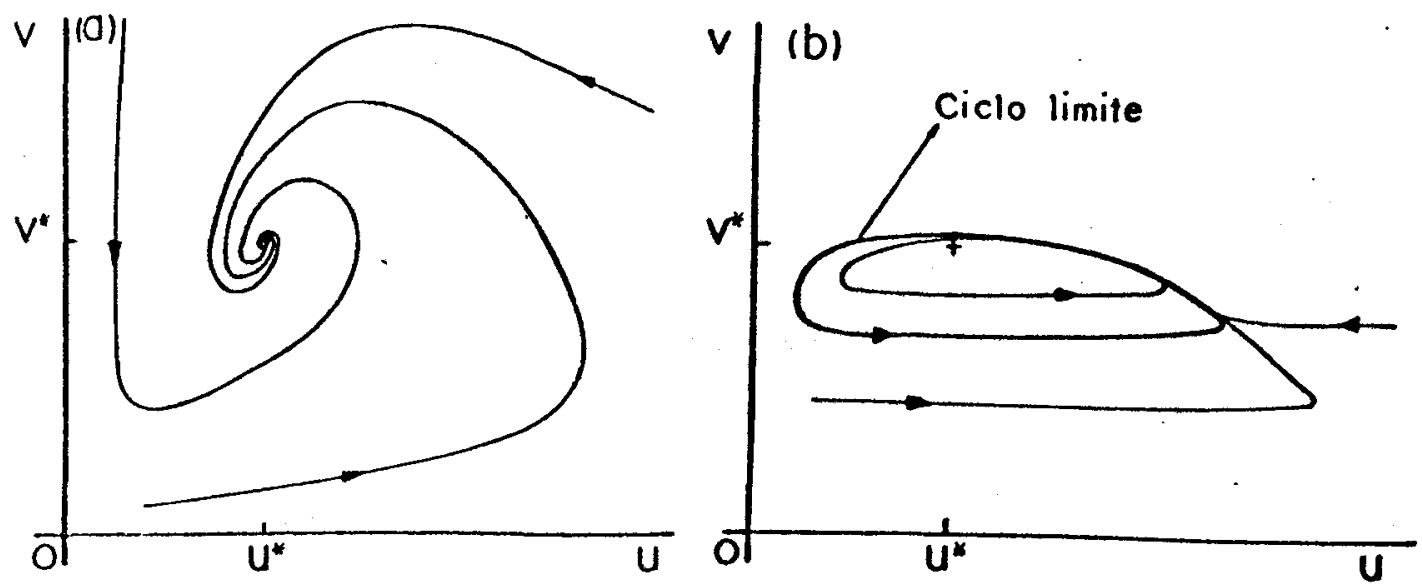

Figura 2.5: Trajetórias de fase para o sistema (2.22): (a) Espiral estável (b) Ciclo limite

\section{Comentários}

Este modelo exibe propriedades de bifurcação quando os parâmetros variam de uma região estável a uma instável. $O$ fato de os parâmetros $a, b$ e $d$ passarem através de valores de bifurcação permite avaliar os efeitos sobre os parâmetros originais $(2.20)$, vejamos

1. $b=\frac{s}{r}$ (razão entre as taxas de crescimento linear das presas e predadores). Se o estado de equilíbrio é instável, podemos observar que quando a taxa de crescimento dos predadores $(s)$ decresce, existe mais probabilidade de comportamento periódico, dado que (b) decresce e, se decresce o suficiente, pode-se entrar num regime de instabilidade.

2. $a=\frac{k h}{r}$, se a taxa de crescimento das presas $(r)$ decresce, $(a)$ é incrementado, se $a>\frac{1}{2}$, existe um domínio finito de instabilidade e aumenta-se a possibilidade de comportamento periódico.

3. $d=\frac{D}{K}$ aumentando a capacidade de suporte do meio das presas, a resposta funcional do predador é diminuída. 


\subsubsection{Complexidade e Estabilidade de Sistemas Presa- Predador}

Um tópico muito explorado em ecologia teórica é a relação complexidadeestabilidade. Para ter uma idéia dos efeitos da complexidade sobre a estabilidade, analisaremos um modelo particular onde o número de espécies predadoras é igual ao número de espécies de presas.

Consideremos o modelo presa-predador de Lotka-Volterra generalizado, [26], onde existem $k$ espécies de presas e $k$ espécies de predadores. Todas as espécies de predadores atacam todas as espécies de presas, porém, com diferente intensidade.

$$
\begin{aligned}
& \quad 0 \text { sistema (1.5) se converte no sistema } \\
& \frac{d N_{i}}{d t}=N_{i}\left[a_{i}-\sum_{j=1}^{k} b_{i j} P_{j}\right], \frac{d P_{i}}{d t}=P_{i}\left[\sum_{j=1}^{k} c_{i j} N_{j}-d_{i}\right],(i=1, \ldots, k)
\end{aligned}
$$

onde todos os $a_{i}, b_{i j}, c_{i j}$ e $d_{i}$ são constantes positivas, não assumimos $b_{i j}=c_{i j}$.

O sistema (2.31) tem dois pontos de equilíbrio, dados pela solução do sistema de equações

$$
N_{i}\left[a_{i}-\sum_{j=1}^{k} b_{i j} P_{j}\right]=0, P_{i}\left[\sum_{j=1}^{k} c_{i j} N_{j}-d_{i}\right]=0,(i=1, \ldots, k)
$$

tais pontos de equilíbrio são:

1. A solução trivial $N_{i}=P_{i}=0$ para todo $i$. A matriz de estabilidade é a matriz diagonal

$$
A=\left[\begin{array}{cccccc}
a_{i} & & 0 & & & 0 \\
& \ddots & & & & \\
0 & & a_{k} & & & \\
& & & -d_{i} & & 0 \\
0 & & & & \ddots & \\
0 & & & 0 & & -d_{k}
\end{array}\right]
$$

onde os $2 k$ autovalores são

$$
\lambda_{i}=a_{i}>0, \quad \lambda_{k+i}=-d_{i}<0,(i=1, \ldots, k)
$$

portanto o ponto de equilibrio é instável, dado que todos os $\lambda_{i}{ }^{\prime \prime}>0$, $(i=1, \ldots, k)$. 
2. A solução não trivial, o vetor $\left(N^{*}, P^{*}\right)$, que satisfaz

$$
\sum_{j=1}^{k} b_{i j} P_{j}^{*}=a_{i}, \quad \sum_{j=1}^{k} c_{i j} N_{j}^{*}=d_{i} \quad(i=1, \ldots, k)
$$

ou em notação matricial, $B P^{*}=\mathrm{a}, C N^{*}=\mathrm{d}$ onde $B \mathrm{e} C$ são as matrizes de dimensão $k \times k$, com elementos $\left(b_{i j}\right)$ e $\left(c_{i j}\right)$ respectivamente. Nesta notação o sistema (2.31) se transforma em

$$
\begin{aligned}
& \frac{d N}{d t}=N^{T}[\mathrm{a}-B P] \\
& \frac{d P}{d t}=P^{T}[C N-\mathrm{d}]
\end{aligned}
$$

onde $N^{T}$ e $P^{T}$ são os transpostos dos vetores $N$ e $P$.

Para analisar o ponto de equilíbrio $\left(N^{*}, P^{*}\right)$, linearizamos numa vizinhança desse ponto. Fazendo a mudança de variável $N=N^{*}+\mathrm{u}, P=P^{*}+\mathrm{v}$ e substituindo em (2.33), obtemos

$$
\begin{aligned}
& \frac{d \mathbf{u}}{d t}=-N^{*^{T}} B \mathbf{v}-\mathbf{u}^{T} B \mathbf{v} \\
& \frac{d \mathbf{v}}{d t}=P^{*^{T}} C \mathbf{u}+\mathbf{v}^{T} C \mathbf{u}
\end{aligned}
$$

a matriz jacobiana do sistema é dado por

$$
J(\mathrm{u}, \mathrm{v})=\left[\begin{array}{lr}
-B \mathrm{v} & -N^{*^{T}} B-\mathbf{u}^{T} B \\
P^{*^{T}} C+\mathbf{v}^{T} C & C \mathrm{u}
\end{array}\right]
$$

e a matriz de estabilidade é dada por

$$
A=\left[\begin{array}{lr}
0 & -N^{*^{T}} B \\
P^{*^{T}} C & 0
\end{array}\right]
$$

Para determinar a natureza do ponto de equilíbrio, é necessário determinar os autovalores da matriz $A$, o que não é trivial. Para matrizes de 
dimensão baixa as condições de estabilidade ou critério de Routh-Hurwitz [26, pag.702] podem ser aplicadas.

Neste caso, contornaremos o problema da seguinte maneira: Da teoria de matrizes, temos que, a soma dos autovalores de $A$ é igual a seu traço $(\operatorname{tr} A)$. Portanto,

$$
\sum_{i=1}^{2 k} \lambda_{i}=\operatorname{tr} A=0
$$

Como os elementos de $A$ são reais, se o polinômio característico tem raízes complexas, elas aparecem em pares conjugados. Desta forma de (2.35) podemos ter:

i) Os autovalores são todos imaginários puros, nesse caso, para todo $\lambda_{i}$, $(i=1, \ldots, 2 k), \operatorname{Re} \lambda_{i}=0$ e o ponto $\left(N^{*}, P^{*}\right)$ é estável para o sistema linearizado.

ii) Se existe $\lambda_{i}$ tal que $\operatorname{Re} \lambda_{i} \neq 0$, existe pelo menos um autovalor com parte real positiva e portanto $\left(N^{*}, P^{*}\right)$ é instável.

Se os autovalores são todos imaginários puros (soluções periódicas), uma pequena perturbação poderia resultar em pelo menos um dos autovalores com parte real não nula e portanto em um ponto de equilíbrio instável.

Concluimos que, em geral, complexidade resulta em instabilidade; May [23] mostrou que nestes casos ou o comportamento é puramente oscilatório (como é sempre o caso de duas espécies) ou o sistema é sempre instável.

\subsection{Competição}

Dizemos que duas espécies estão em competição quando cada espécie afeta negativamente a outra na luta pela sobrevivência. Elas competem por uma fonte comum de recursos, em geral limitados.

Nesta seção examinaremos sob que condições espécies em competição podem coexistir e será mostrado que num ambiente de competição, usualmente uma das espécies tende à extinção. Este fenômeno é conhecido como o Princípio de Exclusão Competitiva ou Lei de Gause. 
- No modelo seguinte, proposto por Lotka e Volterra, e mais tarde estudado por Gause (1934), a competição entre duas espécies é descrita sem referência diretá aos recursos que elas compartilham $[26,7]$.

Consideremos o sistema

$$
\begin{aligned}
& \frac{d N_{1}}{d t}=r_{1} N_{1}\left[1-\frac{N_{1}}{K_{1}}-b_{12} \frac{N_{2}}{K_{1}}\right] \\
& \frac{d N_{2}}{d t}=r_{2} N_{2}\left[1-\frac{N_{2}}{K_{2}}-b_{21} \frac{N_{1}}{K_{2}}\right]
\end{aligned}
$$

onde $r_{1}, K_{1}, r_{2}, K_{2}, b_{12}$ e $b_{21}$ são constantes positivas. $N_{1}$ e $N_{2}$ definem a densidade das populações.

No modelo estão incorporados os seguintes fatos.

1. Cada população $N_{1}$ e $N_{2}$ tem crescimento logístico na ausência da outra, $K_{1}$ e $K_{2}$ são as capacidades de suporte do meio. (competição intraespécie)

2. Devido à competição, as respectivas taxas de crescimento são inibidas pelas duas populações. $r_{1}$ e $r_{2}$ são as taxas de natalidade e $b_{12}, b_{21}$ as medidas dos efeitos da competição de $N_{2}$ sobre $N_{1}$ e de $N_{1}$ sobre $N_{2}$ respectivamente. (competição interespécies)

\section{Análise do Modelo}

Simplificamos o sistema (2.36), introduzindo variáveis adimensionais:

$$
\begin{aligned}
u_{1}(\tau) & =\frac{N_{1}(t)}{K_{1}}, \quad u_{2}(\tau)=\frac{N_{2}(t)}{K_{2}}, \quad \tau=r_{1} t \\
\rho & =\frac{r_{2}}{r_{1}}, \quad a_{12}=b_{12} \frac{K_{2}}{K_{1}}, \quad a_{21}=b_{21} \frac{K_{1}}{K_{2}}
\end{aligned}
$$

e obtemos o sistema

$$
\begin{aligned}
& \frac{d u_{1}}{d \tau}=u_{1}\left(1-u_{1}-a_{12} u_{2}\right)=f_{1}\left(u_{1}, u_{2}\right) \\
& \frac{d u_{2}}{d \tau}=\rho u_{2}\left(1-u_{2}-a_{21} u_{1}\right)=f_{2}\left(u_{1}, u_{2}\right)
\end{aligned}
$$


algébrico

Os pontos de equilíbrio de (2.38) são dados pelas soluções do sistema

$$
\begin{array}{r}
u_{1}\left(1-u_{1}-a_{12} u_{2}\right)=0 \\
\rho u_{2}\left(1-u_{2}-a_{21} u_{1}\right)=0
\end{array}
$$

Obtemos então, os seguintes pontos de equilíbrio:

$$
(0,0),(1,0),(0,1), \quad\left(u_{1}^{*}, u_{2}^{*}\right)=\left(\frac{1-a_{12}}{1-a_{12} a_{21}}, \frac{1-a_{21}}{1-a_{12} a_{21}}\right)
$$

onde $1-a_{12} a_{21} \neq 0$.

Análise de estabilidade dos pontos de equilíbrio

O sistema (2.38) pode ser linearizado, a matriz jacobiana é dada por

$$
J\left(u_{1}, u_{2}\right)=\left(\begin{array}{lr}
1-2 u_{1}-a_{12} u_{2} & -a_{12} u_{1} \\
-\rho a_{21} u_{2} & \rho\left(1-2 u_{2}-a_{21} u_{1}\right)
\end{array}\right)
$$

Analisaremos cada ponto em separado.

1. $(0,0)$. Os autovalores são $\lambda_{1}=1$ e $\lambda_{2}=\rho$, portanto $(0,0)$ é um nó instável.

2. $(1,0)$. Os autovalores são $\lambda_{1}=-1$ e $\lambda_{2}=\rho\left(1-a_{21}\right)$, portanto

$$
(1,0) \dot{e} \begin{cases}\text { nó estável, se } & a_{21}>1 \\ \text { ponto de sela, se } & a_{21}<1\end{cases}
$$

3. $(0,1)$. Os autovalores são $\lambda_{1}=1-a_{12}$ e $\lambda_{2}=-\rho$, portanto

$$
(0,1) \text { é } \begin{cases}\text { nó estável, se } & a_{12}>1 \\ \text { ponto de sela, se } & a_{12}<1\end{cases}
$$

4. Para que o ponto

$$
\left(u_{1}^{*}, u_{2}^{*}\right)=\left(\frac{1-a_{12}}{1-a_{12} a_{21}}, \frac{1-a_{21}}{1-a_{12} a_{21}}\right)
$$


i

esteja no quadrante positivo é necessário que

$$
a_{12}<1, a_{21}<1 \text { ou } a_{12}>1, a_{21}>1
$$

a matriz de estabilidade é dada por

$$
A=\frac{1}{1-a_{12} a_{21}}\left(\begin{array}{lll}
a_{12}-1 & \vdots & a_{12}\left(a_{12}-1\right) \\
\rho a_{21}\left(a_{21}-1\right) & \rho\left(a_{21}-1\right)
\end{array}\right)
$$

e o polinômio característico é dado por

$$
p(\lambda)=\lambda^{2}-\frac{\left[\left(a_{21}-1\right)+\rho\left(a_{21}-1\right)\right]}{1-a_{12} a_{21}} \lambda+\frac{\rho\left(a_{12}-1\right)\left(a_{21}-1\right)}{1-a_{12} a_{21}}
$$

ou, $p(\lambda)=\lambda^{2}-(\operatorname{tr} A) \lambda+\operatorname{det} A$.

Os autovalores são dados por

$$
\lambda_{1,2}=\frac{\operatorname{tr} A \pm \sqrt{(\operatorname{tr} A)^{2}-4 \operatorname{det} A}}{2}
$$

a estabilidade é determinada pelo sinal de $\operatorname{Re} \lambda \mathrm{e}$ isso vai depender dos valores de $a_{12}$ e $a_{21}$. :

Afirmação 2.4.1 1) Os autovalores (2.40) são reais, portanto não existem soluções oscilatórias. 2) $\operatorname{tr} A<0$ e 3) $O$ ponto de equilibrio é um nó estável se $\operatorname{det} A>0$ ou é um ponto de sela se $\operatorname{det} A<0$.

Prova:

1. Os autovalores são reais se $\Delta=(\operatorname{tr} A)^{2}-4 \operatorname{det} A \geq 0$.

$$
\begin{aligned}
\Delta & =\frac{\left[\left(a_{12}-1\right)+\rho\left(a_{21}-1\right)\right]^{2}-4 \rho\left(a_{21}-1\right)\left(a_{12}-1\right)\left(1-a_{12} a_{21}\right)}{\left(1-a_{12} a_{21}\right)^{2}} \\
& =\frac{\left[\left(a_{12}-1\right)-\rho\left(a_{21}-1\right)\right]^{2}+4 \rho a_{12} a_{21}\left(a_{12}-1\right)\left(a_{21}-1\right)}{\left(1-a_{12} a_{21}\right)^{2}}
\end{aligned}
$$

Pelas condições em (2.39), o segundo termo no numerador é sempre positivo e, portanto, os autovalores são reais. 
2. Traço de $A$ sempre menor do que zero.

$$
\operatorname{tr} A=\frac{\left(a_{12}-1\right)+\rho\left(a_{21}-1\right)}{1-a_{12} a_{21}}
$$

Se $a_{12}<1$ e $a_{21}<1$ temos, $a_{12}-1<0, a_{21}-1<0, a_{12} a_{21}<1$ e $1-a_{12} a_{21}>0$. Portanto, $\operatorname{tr} A<0$.

Se $a_{12}>1$ e $a_{21}>1$ temos, $a_{12}-1>0, a_{21}-1>0, a_{12} a_{21}>1 \mathrm{e}$ $1-a_{12} a_{21}<0$. Portanto, $\operatorname{tr} A<0$.

3.

$$
\operatorname{det} A=\frac{\rho\left(a_{12}-1\right)\left(a_{21}-1\right)}{1-a_{12} a_{21}}
$$

Se $a_{12}<1$ e $a_{21}<1$ temos, $a_{12}-1<0, a_{21}-1<0$ e $1-a_{12} a_{21}>0$. Portanto, $\operatorname{det} A>0$. Dado que $\operatorname{tr} A<0$, temos $\lambda_{1}<0$ e $\lambda_{2}<0$, e o ponto de equilibrio é um nó estável.

Se $a_{12}>1$ e $a_{21}>1$ temos, $a_{12}-1>0, a_{21}-1>0$ e $1-a_{12} a_{21}<0$. Portanto, $\operatorname{det} A<0$. Dado que $\operatorname{tr} A<0$, temos $\lambda_{1}>0$ e $\lambda_{2}<0$, e o ponto de equilíbrio é um ponto de sela.

\section{Diagrama de fase}

Se o ponto de interseção das retas

$$
1-u_{1}-a_{12} u_{2}=0, \quad 1-u_{2}-a_{21} u_{1}=0
$$

estiver no primeiro quadrante (as condições em (2.39) são satisfeitas), existem quatro pontos de equilíbrio. Caso contrário, existem somente três. Dependendo da posição relativa destas retas tem-se quatro configuraçóes distintas que são representadas na figura 2.6 , onde $S=\left(u_{1}^{*}, u_{2}^{*}\right)$. 

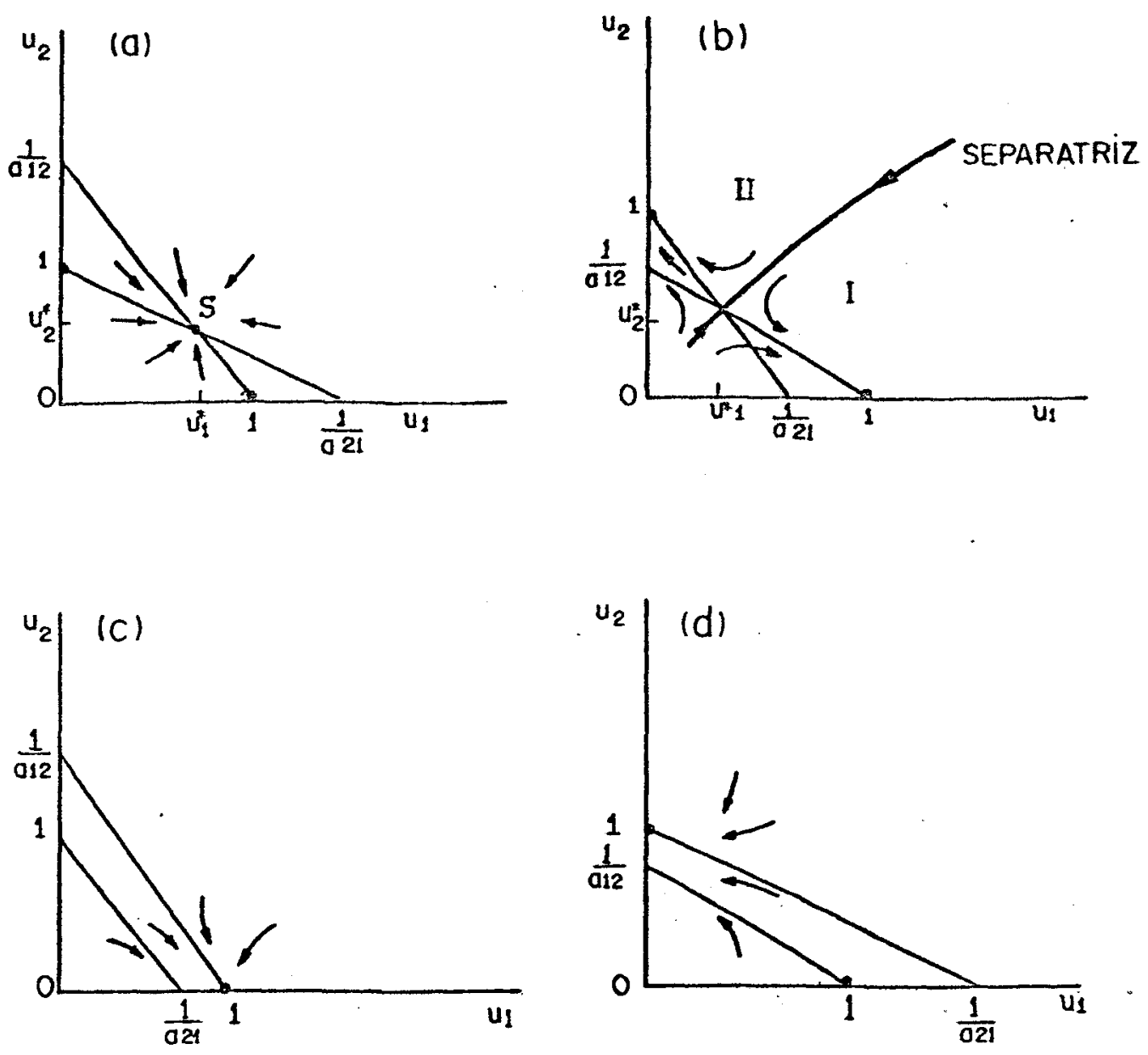

Figura 2.6: Trajetórias de fase: Competição. (reproduzida de [26])

\section{Interpretação dos resultados}

Caso I. (Fig 2.6 a) $a_{12}<1$ e $a_{21}<1$.

Neste caso $(0,0)$ é um nó instável, $(1,0)$ e $(0,1)$ são pontos de sela e $\left(u_{1}^{*}, u_{2}^{*}\right)$ é um nó estável. Para qualquer condição inicial, $u_{1}>0, u_{2}>0$ as trajetórias de fase se aproximam assintoticamente do ponto de equilíbrio $\left(u_{1}^{*}, u_{2}^{*}\right)$.

As espécies $N_{1}$ e $N_{2}$ sobrevivem, e as populações tendem a $u_{1}^{*}$ e $u_{2}^{*}$, respectivamente. Neste caso a competição é fraca, isto porque $1-a_{12} a_{21}>0 \leftrightarrow$ $1-b_{12} \dot{b}_{21}>0$. Portanto, os fatores de competição interespécies são pequenos. 


\section{Caso II. (Fig 2.6 b) $a_{12}>1$ e $a_{21}>1$.}

Neste caso $(0,0)$ é um nó instável, $(1,0)$ e $(0,1)$ são nós estáveis e $\left(u_{1}^{*}, u_{2}^{*}\right)$ é um ponto de sela. Dependendo das condições iniciais, $u_{1}>0, u_{2}>0$ a competição é tal que as três situações de equilíbrio podem acontecer. Na figura podemos observar que a separatriz divide o plano em duas regiões.

Se a condição inicial estiver na região I, $u_{2} \rightarrow 0$ e $u_{1} \rightarrow 1$, isto é, $N_{1} \rightarrow K_{1}$, a capacidade de suporte do meio da espécie $N_{1}$. Esta competição elimina a população $\mathrm{N}_{2}$.

Se a condição inicial estiver na região II, $u_{1} \rightarrow 0$ e $u_{2} \rightarrow 1$, isto é, $N_{2} \rightarrow K_{2}$, a capacidade de suporte do meio da espécie $N_{2}$. Esta competição elimina $N_{1}$.

As espécies podem coexistir somente se o ponto inicial estiver na separatriz, porém, uma pequena perturbação causará a extinção de uma das espécies. $\mathrm{O}$ resultado da competição dependerá da vantagem inicial de cada espécie.

Caso III. (Fig 2.6 c) $a_{12}<1$ e $a_{21}>1$.

Neste caso $(0,0)$ é um nó instável, $(0,1)$ é ponto de sela e $(1,0)$ nó estável. Para qualquer condição inicial, $u_{1}>0, u_{2}>0$ as trajetórias de fase tendem para o ponto de equilíbrio $(1,0)$, isto é, $u_{2} \rightarrow 0 \leftrightarrow N_{2} \rightarrow 0$ e a espécie $N_{2}$ tende a extinção. $u_{1} \rightarrow 1 \leftrightarrow N_{1} \rightarrow K_{1}$ e a espécie $N_{1}$ sobrevive e tende ao limite máximo sustentável.

Em termos dos parâmetros $a_{12}$ e $a_{21}$ na competição interespécies, a espécie $u_{1}$ domina a espécie $u_{2}$ e esta tenderá a extinção. portanto, a competição é forte.

\section{Caso IV. (Fig 2.6 d) $a_{12}>1$ e $a_{21}<1$.}

Neste caso $(0,0)$ é um nó instável, $(1,0)$ é ponto de sela e $(0,1)$ nó estável. Para qualquer condição inicial, $u_{1}>0, u_{2}>0$ as trajetórias de fase tendem para o ponto de equilíbrio $(0,1)$, isto é, $u_{1} \rightarrow 0 \leftrightarrow N_{1} \rightarrow 0$ e a espécie $N_{1}$ tende a extinção. $u_{2} \rightarrow 1 \leftrightarrow N_{2} \rightarrow K_{2}$ e a espécie $N_{2}$ sobrevive e tende ao limite máximo sustentável.

Em termos dos parâmetros $a_{12}$ e $a_{21}$ na competição interespécies a espécie $u_{2}$ domina a espécie $u_{1}$ e esta tenderá a extinção. portanto, a competição é forte.

\section{Comentários}

O Princípio de Exclusão Competitiva ou Lei de Gause estabelece que duas espécies não podem coexistir em estado de competição forte, uma delas sempre será extinta. 
Embora nem todos os casos resultem em extinção de uma das espécies, nos casos III e IV isto sempre acontece. $\mathrm{O}$ caso II depende das condições iniciais, que dependem somente dos parâmetros $a_{12}$ e $a_{21}$ que por sua vez envolvem a medida de interação interespécies e a capacidade de suporte do meio de ambas as populações. Portanto, a exclusão competitiva depende somente destes parâmetros. Observamos que $\rho=\frac{r_{2}}{r_{1}}$ (razão entre as taxas de crescimento) não afeta os resultados sobre a estabilidade do sistema.

0 modelo discutido pode ser usado para descrever interações de quaisquer organismos em competição.

\subsection{Mutualismo}

Dizemos que duas espécies estão em mutualismo quando a interação é vantajosa para ambas. Embora não seja necessária para garantir a sobrevivência ela é importante na preservação das espécies. Um exemplo típico é o das plantas com os dispersadores de suas sementes.

Um modelo simples de mutualismo é dado pelo sistema

$$
\begin{aligned}
& \frac{d N_{1}}{d t}=r_{1} N_{1}+a_{1} N_{1} N_{2} \\
& \frac{d N_{2}}{d t}=r_{2} N_{2}+a_{2} N_{1} N_{2}
\end{aligned}
$$

onde $N_{1}$ e $N_{2}$ definem a densidade das populações $r_{1}, r_{2}$ são as respectivas taxas de crescimento e $a_{1}$ e $a_{2}$ as medidas de interação entre as duas espécies.

Neste modelo assume-se que cada população, na ausência da outra, cresce segundo a lei de Malthus. Dado que $\frac{d N_{1}}{d t}>0$ e $\frac{d N_{2}}{d t}>0$ ambas as populaçóes crescem sem limite.

Um modelo mais realístico, incorporando o fator de inibição do crescimento populacional é o analisado por Murray [26]:

$$
\begin{aligned}
& \frac{d N_{1}}{d t}=r_{1} N_{1}\left[1-\frac{N_{1}}{K_{1}}+b_{12} \frac{N_{2}}{K_{1}}\right] \\
& \frac{d N_{2}}{d t}=r_{2} N_{2}\left[1-\frac{N_{2}}{K_{2}}+b_{21} \frac{N_{1}}{K_{2}}\right]
\end{aligned}
$$

onde $r_{1}, r_{2}, K_{1}, K_{2}, b_{12}$ e $b_{21}$ são constantes positivas, $N_{1}$ e $N_{2}$ definem as densidades das populações. 
No modelo estão incorporados os seguintes fatos:

1. Cada população $N_{1}$ e $N_{2}$ tem crescimento logístico na ausência da outra, $K_{1}$ e $K_{2}$ são as capacidades de suporte do meio.

2. Devido à interação, as respectivas taxas de crescimento são incrementadas de uma maneira linear pelas duas populações, $r_{1}$ e $r_{2}$ são as taxas de crescimento e $b_{12}, b_{21}$ as medidas dos efeitos da interação de $N_{2}$ sobre $N_{1}$ e de $N_{1}$ sobre $N_{2}$ respectivamente.

\section{Análise do Modelo}

Simplificamos o sistema (2.42) introduzindo variáveis adimensionais:

$$
\begin{aligned}
u_{1}(\tau) & =\frac{N_{1}(t)}{K_{1}}, \quad u_{2}(\tau)=\frac{N_{2}(t)}{K_{2}}, \quad \tau=r_{1} t \\
\rho & =\frac{r_{2}}{r_{1}}, \quad a_{12}=b_{12} \frac{K_{2}}{K_{1}}, \quad a_{21}=b_{21} \frac{K_{1}}{K_{2}}
\end{aligned}
$$

e obtemos o sistema

$$
\begin{aligned}
& \frac{d u_{1}}{d \tau}=u_{1}\left(1-u_{1}+a_{12} u_{2}\right)=f_{1}\left(u_{1}, u_{2}\right) \\
& \frac{d u_{2}}{d \tau}=\rho u_{2}\left(1-u_{2}+a_{21} u_{1}\right)=f_{2}\left(u_{1}, u_{2}\right)
\end{aligned}
$$

Os pontos de equilíbrio de (2.44) são dados pelas soluções do sistema algébrico

$$
\begin{array}{r}
u_{1}\left(1-u_{1}+a_{12} u_{2}\right)=0 \\
\rho u_{2}\left(1-u_{2}+a_{21} u_{1}\right)=0
\end{array}
$$

obtemos então, os seguintes pontos de equilíbrio:

$$
(0,0), \quad(1,0), \quad(0,1), \quad\left(u_{1}^{*}, u_{2}^{*}\right)=\left(\frac{1+a_{12}}{1-a_{12} a_{21}}, \frac{1+a_{21}}{1-a_{12} a_{21}}\right)
$$

onde $1-a_{12} a_{21} \neq 0$. 
Análise da estabilidade dos pontos de equilíbrio.

O sistema (2.44) pode ser linearizado, a matriz jacobiana é dada por

$$
J\left(u_{1}, u_{2}\right)=\left(\begin{array}{lr}
1-2 u_{1}+a_{12} u_{2} & a_{12} u_{1} \\
\rho a_{21} u_{2} & \rho\left(1-2 u_{2}+a_{21} u_{1}\right)
\end{array}\right) .
$$

Analisaremos cada ponto em separado.

1. $(0,0)$. Os autovalores são $\lambda_{1}=1$ e $\lambda_{2}=\rho$, portanto, $(0,0)$ é um nó instável.

2. $(1,0)$. Os autovalores são $\lambda_{1}=-1$ e $\lambda_{2}=\rho\left(1+a_{21}\right)$, portanto, $(1,0)$ é um ponto de sela.

3. $(0,1)$. Os autovalores são $\lambda_{1}=1+a_{12}$ e $\lambda_{2}=-\rho$, portanto, $(0,1)$ é um ponto de sela.

4. Para que o ponto

$$
\left(u_{1}^{*}, u_{2}^{*}\right)=\left(\frac{1+a_{12}}{1-a_{12} a_{21}}, \frac{1+a_{21}}{1-a_{12} a_{21}}\right) .
$$

esteja no primeiro quadrante é necessário que $1-a_{12} a_{21}>0$.

A matriz de estabilidade é dada por

$$
A=\frac{1}{1-a_{12} a_{21}}\left(\begin{array}{cc}
-\left(1+a_{12}\right) & a_{12}\left(1+a_{12}\right) \\
\rho a_{21}\left(1+a_{21}\right) & -\rho\left(1+a_{21}\right)
\end{array}\right)
$$

e o polinômio característico é dado por

$$
p(\lambda)=\lambda^{2}+\frac{\left[\left(1+a_{12}\right)+\rho\left(1+a_{21}\right)\right]}{1-a_{12} a_{21}} \lambda+\frac{\rho\left(1+a_{12}\right)\left(1+a_{21}\right)}{1-a_{12} a_{21}}
$$

ou, $p(\lambda)=\lambda^{2}-(\operatorname{tr} A) \lambda+\operatorname{det} A$.

Os autovalores são dados. por

$$
\lambda_{1,2}=\frac{\operatorname{tr} A \pm \sqrt{(\operatorname{tr} A)^{2}-4 \operatorname{det} A}}{2}
$$


Afirmação 2.5.1 1) Os autovalores (2.46) são reais, portanto não existem soluções oscilatórias. 2) $\operatorname{det} A>0$ e 3) $\operatorname{tr} A<0$ e o ponto de equilíbrio um nó estável.

Prova:

1. Os autovalores são reais se $\Delta=(\operatorname{tr} A)^{2}-4 \operatorname{det} A \geq 0$.

$$
\begin{aligned}
\Delta & =\frac{\left[\left(1+a_{12}\right)+\rho\left(1+a_{21}\right)\right]^{2}-4 \rho\left(1+a_{21}\right)\left(1+a_{12}\right)\left(1-a_{12} a_{21}\right)}{\left(1-a_{12} a_{21}\right)^{2}} \\
& =\frac{\left[\left(1+a_{12}\right)-\rho\left(1+a_{21}\right)\right]^{2}+4 \rho a_{12} a_{21}\left(1+a_{12}\right)\left(1+a_{21}\right)}{\left(1-a_{12} a_{21}\right)^{2}}
\end{aligned}
$$

que resulta sempre maior que zero. Portanto, os autovalores são reais.

2. Determinante de $A$ maior que zero.

$$
\operatorname{det} A=\frac{\rho\left(1+a_{12}\right)\left(1+a_{21}\right)}{1-a_{12} a_{21}}
$$

como $1-a_{12} a_{21}>0$, temos $\operatorname{det} A>0$.

3. Traço de $A$ sempre menor do que zero.

$$
\operatorname{tr} A=\frac{-\left(1+a_{12}\right)-\rho\left(1+a_{21}\right)}{1-a_{12} a_{21}}=\frac{-\left[\left(1+a_{12}\right)+\rho\left(1+a_{21}\right)\right]}{1-a_{12} a_{21}}
$$

como $1-a_{12} a_{21}>0$ temos $\operatorname{tr} A<0$ e.

Dado que $\operatorname{tr} A<0$ e $\operatorname{det} A>0$ temos, $\operatorname{Re} \lambda_{1}<0$ e $\operatorname{Re} \lambda_{2}<0$, e portanto, o ponto de equilíbrio é um nó estável.

\section{Diagrama de fase}

Se o ponto de interseção das retas

$$
1-u_{1}+a_{12} u_{2}=0, \quad 1-u_{2}+a_{21} u_{1}=0
$$

estiver no primeiro quadrante $\left(1-a_{12} a_{21}>0\right)$ existem quatro pontos de equilíbrio, caso contrário, existem somente três. As duas configurações são representadas na figura 2.7 , onde $S=\left(u_{1}^{*}, u_{2}^{*}\right)$. 

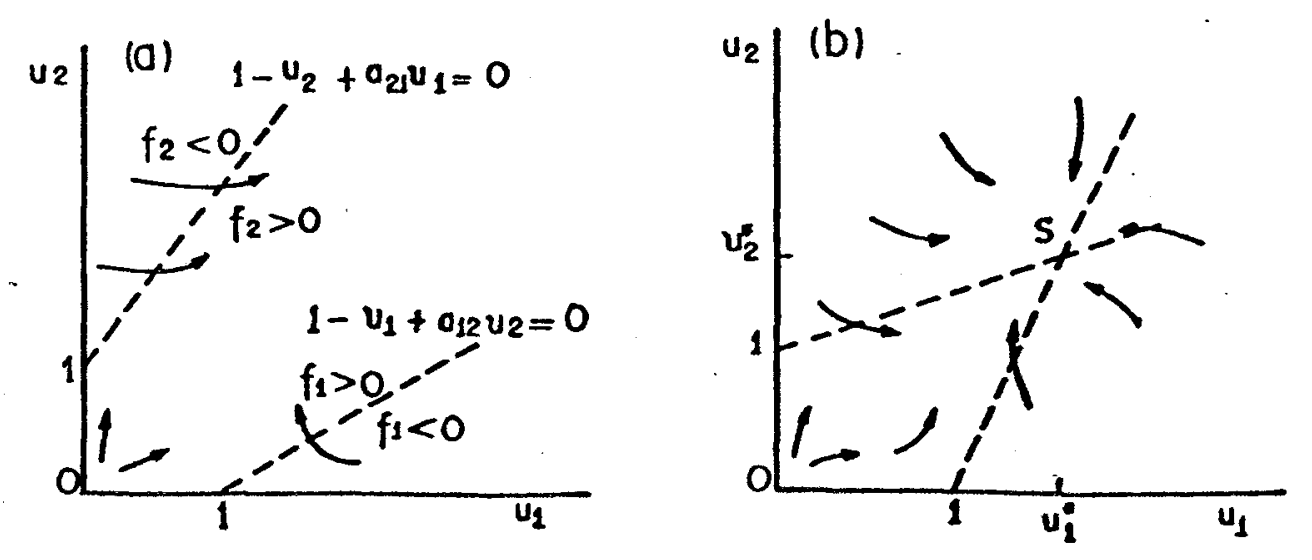

Figura 2.7: Trajetórias de fase: Mutualismo. (reproduzido de [26])

\section{Interpretação dos resultados}

Caso I. (Fig 2.7 a) $\left(1-a_{12} a_{21}<0\right)$.

Neste caso $(0,0)$ é um nó instável, $(1,0)$ e $(0,1)$ são pontos de sela. Para qualquer condição inicial $u_{1}>0, u_{2}>0$, as trajetórias de fase tendem ao infinito, $u_{1} \rightarrow \infty$ e $u_{2} \rightarrow \infty$. Neste caso o crescimento populacional é ilimitado.

Caso II. (Fig 2.7 b) $\left(1-a_{12} a_{21}>0\right)$.

Neste caso $(0,0)$ é um nó instável, $(1,0)$ e $(0,1)$ são pontos de sela e $\left(u_{1}^{*}, u_{2}^{*}\right)$ é um nó estável. Para quaisquer condição inicial $u_{1}>0, u_{2}>0$, as trajetórias de fase se aproximam assintoticamente do estado de equilíbrio $\left(u_{1}^{*}, u_{2}^{*}\right)$. Observemos que $u_{1}^{*}>1$ e $u_{2}^{*}>1$.

$$
\begin{aligned}
& u_{1}^{*}>1 \leftrightarrow \frac{N_{1}}{K_{1}}>1 \rightarrow N_{1}>K_{1} \\
& u_{2}^{*}>1 \leftrightarrow \frac{N_{2}}{K_{2}}>1 \rightarrow N_{2}>K_{2}
\end{aligned}
$$

e portanto, a capacidade de suporte do meio de cada população é incrementada.

\section{Comentários}

Neste modelo a possibilidade de crescimento ilimitado da população ou a existência de um estado de equilíbrio finito, depende unicamente da desigualdade 
$a_{12} a_{21}<1$ ou $b_{12} b_{21}<1$ em termos dos parâmetros originais. Portanto, se o mutualismo é muito grande, esta última condição é violada e como consequêencia as populações crescem sem limite.

\subsection{Modelos para n Espécies}

Em complexos sistemas biológicos, existem interações entre muitas espécies, e os três tipos gerais de interação discutidos nas seções anteriores podem acontecer. Uma questão importante a ser respondida é saber se alguma das espécies pode ser extinta. As comunidades ecológicas podem perder sua permanência se uma espécie predadora, competidora ou mutualista é removida. Isto é, as espécies restantes podem não coexistir por muito tempo.

Os modelos gerais que descrevem tais sistemas biológicos são da forma

$$
\frac{d \mathbf{u}}{d t}=f(\mathbf{u}) \quad \text { ou } \quad \frac{d u_{i}}{d t}=f_{i}\left(u_{1}, \ldots, u_{n}\right), i=1, \ldots, n
$$

onde $\mathbf{u}$ é um vetor n-dimensional de densidade populacional e $f(\mathbf{u})$ descreve a interação não linear entre as espécies, ela reune os parâmetros que caracterizam as leis de crescimento e as características da interação do sistema sob investigação. $f_{i}\left(u_{1}, \ldots, u_{n}\right)$ especifica as informações sobre a i-ésima espécie.

\section{Estabilidade do sistema}

A estabilidade dos pontos de equilíbrio é determinada por linearização na vizinhança dos pontos de equilíbrio $\mathbf{u}^{*}$ onde $f\left(\mathbf{u}^{*}\right)=0$ e examinando os autovalores da matriz de estabilidade.

$$
A=\left(a_{i j}\right)=\left(\frac{\partial f_{i}}{\partial u_{j}}\right)_{\mathbf{u}_{=\mathbf{u}^{*}}}
$$

A condição necessária e suficiente para que os autovalores $\lambda$, soluções do polinômio característico $|A-\lambda I|=0$, tenham $\operatorname{Re} \lambda>0$ são dadas pelas condições de Routh-Hurwitz [26, pag. 702-704].

Se o ponto de equilíbrio é instável então a solução u pode crescer sem limite ou evoluir èm um outro ponto de equilibrio ou apresentar um compòrtamento oscilatório estável como um ciclo-limite. 
Para modelos de duas espécies, a técnica do plano de fase pode ser usada, como ja foi mostrado nas seções anteriores. Para três ou mais espécies não existe uma teoria geral. Alguns resultados para soluções que perdem a estabilidade numa vizinhança do ponto de equilibrio, podem ser encontrados usando a teoria da bifurcação de Hopf.

A matriz de estabilidade $A$, definida em (2.48) tem um significado biológico direto: Cada elemento $a_{i j}$ mede o efeito da j-ésima espécie sobre a i-ésima perto do ponto de equilíbrio. Por exemplo:

Se $w_{i}$ é uma perturbação do ponto de equilíbrio $u_{i}{ }^{*}$ a equação para $w_{i}$ é

$$
\frac{d w_{i}}{d t}=\sum_{j=1}^{n} a_{i j} w_{j}
$$

de fato, seja w uma perturbação do ponto de equilíbrio $\mathbf{u}^{*}$, então, para $i$, temos

$$
f_{i}\left(\mathbf{u}^{*}+\mathbf{w}\right)=f_{i}\left(\mathbf{u}^{*}\right)+\frac{\partial f_{i}}{\partial u_{1}} w_{1}+\frac{\partial f_{i}}{\partial u_{2}} w_{2}+\cdots+\frac{\partial f_{i}}{\partial u_{n}} w_{n}+\text { termos de ordem } 2 .
$$

De (2.47), (2.48) e dado que $f_{i}\left(\mathbf{u}^{*}\right)=0$, obtemos

$$
\frac{d w_{i}}{d t}=f_{i}\left(\mathbf{u}^{*}+\mathbf{w}\right)=\left(\sum_{j=1}^{n} \frac{\partial f_{i}}{\partial u_{j}} w_{j}\right)_{u=\mathbf{u}^{*}}=\sum_{j=1}^{n} a_{i j} w_{j} .
$$

Assim, $a_{i j} w_{j}$ é o efeito da espécie $w_{j}$ sobre o crescimento de $w_{i}$. Se $a_{i j}>0$ então, $w_{j}$ acentua diretamente o crescimento de $w_{i}$ e, quando $a_{i j}<0$ o diminui. Se $a_{i j}>0$ e $a_{j i}>0$ então, $w_{i}$ e $w_{j}$ acentuam mutuamente seu crescimento e portanto, a interação entre elas é mutualista. Se $a_{i j}<0$ e $a_{j i}<0$ então, a interação é de competição.

Têm sido feitos muitos estudos considerando a matriz de estabilidade com caracteristicas especiais, por exemplo, simetria ou antisimetria, e têm sido obtidos alguns resultados gerais a respeito dos autovalores e em consequência da estabilidade do sistema. Porém, isto tem muito pouco valor prático, uma vez que, nos modelos para ecossistemas reais, a matriz de estabilidade dificilmente apresenta essas propriedades.

\subsection{Comentários}

O uso de modelos para estudar os efeitos da interferência artificial num ecossistema é muito recomendável, dado que podem ser extremamente ilustrativos 
sobre o seu comportamento. Hufbauer et al., [15], têm estudado os efeitos estabilizadores de espécies predadoras e competidoras sobre comunidades ecológicas. Várias questões surgem a este respeito, por exemplo, se uma espécie predadora estabiliza uma comunidade, então pode ser interessante construir métodos que especifiquem o número mínimo de espécies predadoras necessário para estabilizar o sistema.

No estudo de ecossistemas complexos, podem ser usados os chamados Ecossistemas de laboratório, compostos de diversos tipos de microorganismos, e que permitem identificar a natureza das interações que poderiam estar presentes em um sistema complexo, como por exemplo, um lago. Tais modelos são a ponte entre modelos matemáticos e ecossistemas reais. Seu valor principal reside em que permitem verificar os resultados teóricos e o aparecimento de fenômenos não esperados. Existem muitos artigos publicados a este respeito, veja-se por exemplo Butler et al., [6].

Modelos em ecologia também têm mostrado ser de utilidade na procura de soluções para problemas relacionados com o meio ambiente. Um problema típico é a poluição ambiental originada pelo uso de substâncias tóxicas na agricultura. Pesquisas na área mostram que tal situação pode se evitada através do controle natural, que propôe o uso de inimigos naturais das pragas.

De nosso estudo de modelos em interação populacional vimos que a estabilidade de um sistema pode ser mudada se certos parâmetros são mudados apropriadamente passando através de valores de bifurcação. Porém, antes de fazer qualquer perturbação externa num sistema, deve ser feito um estudo científico considerável para evitar resultados indesejáveis. 


\section{Capítulo 3}

\section{Dinâmica Populacional das Doenças Transmissíveis}

\subsection{Introdução}

A aplicação da teoria matemática às interações populacionais, tem motivado o uso de modelos para o estudo de muitas questões de interesse científico, ligadas às populações. Por exemplo, na relação entre epidemiologia e dinâmica populacional, as doenças são consideradas como um dos fatores que regulam - crescimento populacional, isto é, além da predação, competição intra e inter espécies, agentes causadores de doenças, podem controlar o crescimento. Outra questão de interesse médico imediato, é o papel predominante da teoria no esclarecimento do impacto das doenças nas populações e a habilidade para controlá-las. Sendo esta última questão a abordada neste trabalho.

Discutiremos neste capítulo varios modelos epidêmicos, os quais incorporam aspectos gerais da transmissão de doenças infecciosas e as condições sob as quais elas podem evoluir para epidemias. $[4,7,9,10,13,26]$.

\subsection{Terminologia}

As doenças infecciosas são causadas por microorganismos como bactérias, fungos, vírus etc. Biológicamente distinguimos duas categorias gerais de transmissão de doenças: a transmissão horizontal onde o contagio se dá por contato físico direto ou através de material contaminado, como no caso da gripe, varíola entre outros; e a transmissão vertical quando o contágio ocorre dos progenitores para os filhos, em geral durante a gestação, e citamos como exemplos a rubeóla 
congénita, AIDS e doença de Chagas.

Ainda, é possível se distinguir o processo de transmissão das doenças em relação a presença de vetores: a transmissão é dita direta quando não existe a participação de hospedeiro intermediário (vetor) e dita indireta quando, no processo de transmissão ocorre a participação de um vetor no qual o agente infeccioso desenvolve uma etapa de seu ciclo vital. Exemplos deste tipo são: a febre amarela (vetor Anopheles sp), doença de Chagas (vetor: Triatoma Infestans), e dengue (vetor: Aedes Aegypti). No caso de transmissão indireta, ressalta-se a necessidade de uma interação populacional interespécies.

No presente trabalho consideramos somente trasnmissão horizontal e direta. Para descrever a dinâmica de transmissão é conveniente dividir a população em classes disjuntas cujo tamanho pode mudar com o tempo. A classe susceptível (S) contém os indivíduos não infectados que podem contrair a doença, a classe infecciosa (I) que contém os indivíduos infectados que podem transmitir a doença, a classe exposta (E) que contém os indivíduos infectados que estão em período latente, isto é, não são ainda infecciosos, a classe dos removidos (R) que contém todos os indivíduos que foram retirados da interação susceptível-infecciosa por recuperação com imunidade permanente ou temporária, por isolação ou por morte.

Existem vários tipos de modelos epidêmicos, uma sequeência de letras, tal como SEIR, descreve o movimento de indivíduos entre as classes: $O$ susceptivel vem a ser latente, logo torna-se infeccioso e finalmente se recupera com imunidade permanente.

Além disso, outros fatores podem ser considerados na construção de modelos, entre eles, a influência dos nascimentos e mortes naturais dentro da população (dinâmica vital). Neste aspecto, as doenças epidêmicas, caracterizadas por rápida propagação, atingindo grande número de indivíduos, não são influenciadas pela dinâmica vital devido a sua curta duração; o que não acontece com doenças endêmicas, cuja duração é maior, sendo necessário considerar a dinâmica vital.

Para a modelagem de doenças que conferem imunidade permanente e são endêmicas, devido ao nascimento de novos susceptíveis, podem ser usados modelos SIR ou SEIR com ou sem dinâmica vital. Os modelos tipo SIRS ou SEIRS são usados para modelar doenças que permanecem endèmicas devido ao fato de que a imunidade é temporaria. Doenças nas quais a recuperação não confere imunidade são descritas por modelos SIS ou SEIS e, finalmente, para doenças nas quais os infecciosos não se recuperam, pode ser usado o modelo SI.

Um conceito básico em epidemiologia é a existência de limiares; estes, são os valores críticos para quantidades tal como: tamanho da população que deve ser excedido para que uma doença seja considerada epidêmica.. · • 


\section{Distribuição da doença na população}

Os modelos epidêmicos convencionais assumem que dentro de uma população a doença se propaga homogeneamente, com indivíduos infectados e susceptíveis se misturando como as moléculas de um gás ideal. Uma alternativa mais realista, assume que tal propagação é heterogênea, isto é, atinge preferencialmente determinados grupos da população, no entanto dentro destes grupos a doença continua a se propagar homogeneạmente. Tais modelos são conhecidos na literatura por Modelos para populações heterogêneas ou Modelos epidêmicos com subpopulações.

\section{Hipóteses gerais}

Os modelos, para populações não heterogêneas, aqui apresentados [10], satisfazem as seguintes hipóteses gerais:

1. A população considerada tem tamanho constante $N$, suficientemente grande para que o tamanho de cada classe possa ser considerada uma variável contínua. Se o modelo inclui dinâmica vital, então assume-se que nascimentos e mortes ocorrem a taxas iguais e todos os recém-nascidos são considerados susceptiveis. Indivíduos são retirados por morte de cada classe a uma taxa proporcional ao tamanho da classe com constante de proporcionalidade $\mu$, denominada taxa de remoção por morte. $O$ tempo médio de vida é $1 / \mu$.

2. A população é uniforme e homogeneamente distribuída. A taxa de contato $\beta$ é o número médio de contatos por infeccioso por unidade de tempo. Um contato de um infeccioso é uma interação que resulta em infecção de outro indivíduo, se ele é susceptível. O número médio de susceptíveis infectados por um indivíduo infeccioso é $\beta S$, e o número médio de susceptiveis infectados pela classe dos infecciosos com tamanho $N I$ é $\beta N I S$ por unidade de tempo. A taxa de contato $\beta$ é fixa e não varia com a estação. $O$ tipo de contato direto ou indireto adequado para a transmissão depende especificamente da doença.

3. Indivíduos se recuperam e são retirados da classe dos infecciosos a uma taxa proporcional ao número de infecciosos com constante de proporcionalidade $\boldsymbol{\gamma}$ denominada taxa de remoção por recuperação. O período latente (período entre o instante da exposição e o instante em que o indivíduo se torna infeccioso) é nulo e o período médio de infecciosidade é $1 / \gamma$. 
A taxa de remoção da classe dos infecciosos por morte e recuperação é $\gamma+\beta$, assim, o período médio de infecciosidade é $\frac{1}{\gamma+\mu}$. Portanto, o número médio de contatos (com susceptíveis e outros) de um infeccioso durante seu período de infecciosidade é $\sigma=\frac{\beta}{\gamma+\mu}$, denominado número de contatos infecciosos (alguns autores o denominam taxa básica de reprodutividade da infecção) Dado que o número médio de susceptíveis infectados por um infeccioso durante seu periodo de infecciosidade é $\sigma S$, a quantidade $\sigma S$ é denominada número de infecciosos substituídos.

\section{Considerações gerais sobre os modelos}

1. Todos os parâmetros na equação diferencial são não negativos e somente são consideradas as soluções não negativas, dado que soluções negativas não têm significado epidemiológico.

2. O tamanho da população $(N)$ não figura explicitamente nas equações, isto é, consideramos somente as fraçôes em $N$ de indivíduos em cada classe, de modo que a soma de todas as classes é igual à unidade.

3. Embora alguns símbolos na notação, já foram usados nos capítulos anteriores, eles são redefinidos na terminologia epidemiológica.

\subsection{O Modelo SIS}

Consiste de uma doença na qual o indivíduo ao recuperar-se, torna-se novamente susceptível à doença, não existe periodo de latência e os indivíduos infecciosos não são isolados $(R=0)$. Por exemplo: gripe.

Das hipóteses gerais, obtemos sistema de equações diferenciais [10]:

$$
\begin{aligned}
& \frac{d S}{d t}=-\beta I S+\gamma I+\mu-\mu S \\
& \frac{d I}{d t}=\beta I S-\gamma I-\mu I
\end{aligned}
$$

Com as condições iniciais:

$$
S(0)=S_{0}>0, I(0)=I_{0}>0, S(t)+I(t)=1
$$


onde $\beta$ é positivo. $O$ termo $-\beta I S$ dá a taxa de movimentação da classe dos susceptíveis para a classe dos infecciosos. $O$ termo $-\gamma I$ dá a taxa na qual os infecciosos se recuperam (sem imunidade) e retornam à classe dos susceptíveis. Os termos $\mu S \mathrm{e}-\mu I$ correspondem às mortes nas classes de susceptiveis e infecciosos respectivamente.

\section{Análise do Modelo}

Os pontos de equilíbrio de (3.1) são

$$
(1,0) \quad e \quad\left(S^{*}, I^{*}\right)=\left(\frac{\gamma+\mu}{\beta}, 1-\frac{\gamma+\mu}{\beta}\right)
$$

O sistema (3.1) é não linear e, dado que $S(t)=1-I(t)$, é suficiente considerar o PVI para $I(t)$. A equação diferencial para $I(t) \operatorname{com} S=1-I$ é

$$
\frac{d I}{d t}=[\beta-(\gamma+\mu)] I-\beta I^{2}, \quad I(0)=I_{0}>0
$$

que pode ser resolvida explicitamente pelo método de separação de variáveis, obtendo-se a solução

$$
I(t)=\left\{\begin{array}{lll}
e^{k t} /\left[\beta\left(e^{k t}-1\right) / k+1 / I_{0}\right] & \text { se } & k \neq 0 \\
1 /\left(\beta t+1 / I_{0}\right) & \text { se } & k=0
\end{array}\right.
$$

onde $k=\beta-(\gamma+\mu)$.

0 comportamento assintótico de $I(t)$ quando $t \rightarrow \infty$ é obtido diretamente da expressão acima. Observamos que $k<0$ se $\sigma=\frac{\beta}{\gamma+\mu} \leq 1$ e $k>0$ se $\sigma>1$.

Para $k \leq 0, I(t) \rightarrow 0$ quando $t \rightarrow \infty$, e $S \rightarrow 1$, portanto o ponto de equilíbrio $(S, I)=(1,0)$ é estável.

Para $k>0, I(t) \rightarrow 1-\frac{\gamma+\mu}{\beta}$ quando $t \rightarrow \infty$, e $S(t) \rightarrow \frac{\gamma+\mu}{\beta}$, portanto o ponto de equilíbrio $\left(S^{*}, I^{*}\right)=\left(\frac{\gamma+\mu}{\beta}, 1-\frac{\gamma+\mu}{\beta}\right)$ é estável.

Podemos agora enunciar os seguintes resultados [10]

Teorema 3.3.1 A solução $I(t)$ de (3.1), (3.2) aproxima-se de $1-\frac{1}{\sigma}$ quando $t \rightarrow \infty$ se $\sigma=\frac{\beta}{\gamma+\mu}>1$ e aproxima-se de zero quando $t \rightarrow \infty$, se $\sigma \leq 1$. 
Corolário 3.3.1 Em uma doença sem imunidade, com qualquer fração inicial de infecciosos, a fração de infecciosos aproxima-se de um valor endêmico constante se o número de contatos infecciosos excede a 1; de outra forma a fração de infecciosos tende a zero.

\section{Comentários}

1. O ponto de equilíbrio $(S, I)=(1,0)$ corresponde à extinção da doença.

2. O ponto de equilíbrio $(S, I)=\left(\frac{1}{\sigma}, 1-\frac{1}{\sigma}\right)$, corresponde à existência endêmica da doença.

3. No ponto de equilíbrio endêmico, a fração susceptível $(S)$ da população é igual a $\frac{1}{\sigma}$, de modo que o número de infecciosos substituídos satisfaz $\sigma S=1$. Assim, 1 é o limiar para o número de contatos que determina se a doença se extingue $(\sigma<1)$ ou se permanece endêmica $(\sigma>1)$. Mudanças dos parâmetros em $\sigma$ permitem analisar o comportamento assintótico de $I(t)$. $\mathrm{O}$ número de contatos depende tanto da doença como da população, por exemplo: pode ser maior que $1 \mathrm{em}$ uma população e menor que 1 em outra.

4. Quando fazemos $\mu=0$, temos o modelo SIS sem dinâmica vital.

5. Um valor limiar para o modelo SI é obtido do teorema (3.3.1), fazendo-se a taxa de remoção $\gamma=0$. Fazendo-se $\mu=0$ temos o modelo SI sem dinâmica vital.

6. Embora o comportamento assintótico seja similar para o modelo SIS com ou sem dinâmica vital, isto não é verdadeiro para os modelos SIR, que serão analisados na seção seguinte.

\subsection{O Modelo SIR}

Consiste de uma doença na qual indivíduos são retirados da interação susceptível-infeccioso, por recuperação com imunidade permanente, isolação ou por morte devido à doença. Por exemplo: Sarampo. 


\subsubsection{Modelo SIR sem Dinâmica Vital}

O modelo, conhecido como modelo de Kermak-McKendric (1927), é descrito pelo sistema de equações [10]:

$$
\begin{aligned}
\frac{d S}{d t} & =-\beta I S \\
\frac{d I}{d t} & =\beta I S-\gamma I \\
\frac{d R}{d t} & =\gamma I
\end{aligned}
$$

Com as condições iniciais:

$$
S(0)=S_{0}>0, I(0)=I_{0}>0, \quad R(0) \geq 0, \quad S(t)+I(t)+R(t)=1
$$

Este é um modelo simples, porém, permite conclusões gerais importantes acerca de epidemias. A questão chave numa situação epidêmica é: determinar se a infecção se espalhará ou não dados $\beta, \gamma$ e os valores iniciais $S_{0}$ e $I_{0}$ e, se o fizer, como será seu crescimento e declínio em relação ao tempo.

\section{Análise do Modelo}

Dado que $R(t)=1-S(t)-I(t)$ podemos considerar o PVI no plano $(S, I)$. A equação das trajetórias é.

$$
\frac{d I}{d S}=\frac{\beta I S-\gamma I}{-\beta I S}=-1+\frac{\gamma}{\beta S}
$$

cuja solução é

$$
I(S)=1-S+\frac{1}{\sigma} \ln \left(\frac{S}{S_{0}}\right)
$$

da equação (3.7) vem que

$$
\frac{d I}{d S}>0 . \quad \text { se } \frac{1}{\sigma S}>1, \text { ou seja, se } S<\frac{1}{\sigma}
$$

portanto, $I(S)$ é uma função crescente se $S<\frac{1}{\sigma}$. O valor máximo para $I(S)$ acontece em $S=\frac{1}{\sigma}(d I / d S=0)$, substituindo este valor em (3.8) obtemos

$$
I_{\max }=1-\frac{1}{\sigma}-\frac{1}{\sigma} \ln \left(\sigma S_{0}\right)
$$


$I(S)$ é decrescente quando $S>\frac{1}{\sigma}$, e dado que $I=0$ é uma linha de singularidades, em tơdas as trajetórias tem-se que $I(t) \rightarrow 0$ quando $t \rightarrow \infty$. Como $I_{0}>0$, existe pelo menos um valor de $S$ para o qual $I=0$, seja $S=S_{\infty}$ este valor, podemos calcular $S_{\infty}$ analisando o PVI no plano $(S, R)$. De (3.5) temos

$$
\frac{d S}{d R}=-\frac{\beta S}{\gamma}=-\sigma S
$$

cuja solução é

$$
S(t)=S_{0} e^{-\sigma R}>0
$$

observamos que $0<S_{\infty}<1$ e $0<S_{\infty}<\frac{1}{\sigma}$.

Dado que $I_{\infty}=0$, temos $R_{\infty}=1-S_{\infty}$ e, de (3.11),

$$
S_{\infty}=S_{0} e^{-\sigma\left(1-S_{\infty}\right)}
$$

portanto $S_{\infty}$ é a raíz positiva no intervalo $0<z<\frac{1}{\sigma}$ da equação

$$
z=S_{0} e^{-\sigma(1-z)}
$$

O número total de susceptíveis que podem contrair a doença no curso da epidemia é $I_{0}+S_{0}-S_{\infty}$

Voltando à análise no plano $(S, I)$, das duas primeiras equações do sistema (3.5) temos que: $I=0$ é ponto de equilíbrio, $S(t)$ é sempre decrescente, dado que

$$
\begin{aligned}
& \frac{d S}{d t}<0 \quad \text { para } \quad S \neq 0 \quad \text { e } \quad I \neq 0, \\
& \frac{d I}{d t}>0 \quad \text { se } \quad S>\frac{1}{\sigma} \quad \text { e } \quad \frac{d I}{d t}<0 \quad \text { se } \quad S<\frac{1}{\sigma}
\end{aligned}
$$

quando $t$ cresce o ponto $(S, I)$ se move ao longo da trajetória dada por (3.7). Se $S_{0}>\frac{1}{\sigma}, I$ cresce e decresce se $S_{0}<\frac{1}{\sigma}$, ao passo que $S$ é sempre decrescente (dado que os susceptiveis tornam-se infecciosos, e não existem novos susceptíveis). Observamos que quanto maior for a taxa de remoção $(\gamma)$ relativamente à taxa de infeção, mais rapidamente a epidemia cessará. Na figura 3.1 é mostrado o diagrama de fase para o sistema (3.5) no plano- $S I$, com valores dos parâmetros: $\gamma=0.04$ e $\beta=0.1$. 


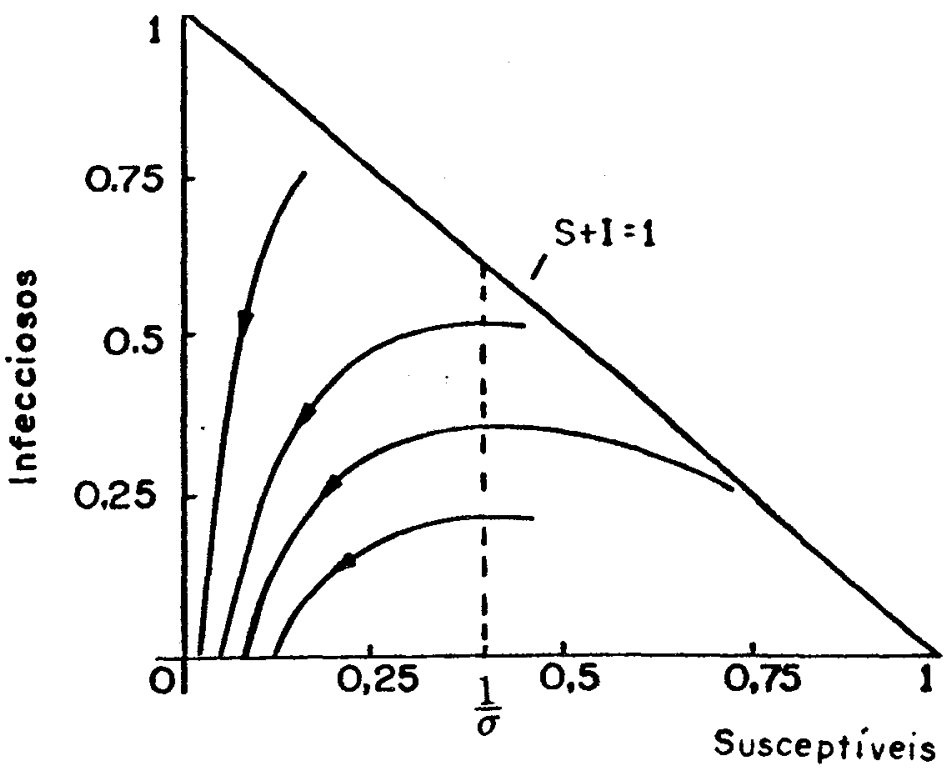

Figura 3.1: Trajetórias de fase: Modelo SIR sem dinâmica vital.

Quando $R(0)=0$, todas as trajetórias começam sobre a linha $S+I=1$, e permanecem dentro do triângulo dado por $0<S+I<1$ para todo $t$.

Da análise feita, enunciamos os seguintes resultados [10].

Teorema 3.4.1 Seja $(S(t), I(t))$ a solução de (3.5), (3.6). Se $\sigma S_{0} \leq 1$, então $I(t) \rightarrow 0$ quando $t \rightarrow \infty$; se $\sigma S_{0}>1$, então $I(t)$ inicialmente cresce até o valor máximo igual a $1-\frac{1}{\sigma}-\frac{1}{\sigma} \ln \left(\sigma S_{0}\right)$ e então decresce para zero quando $t \rightarrow \infty$. A fração de susceptíveis $S(t)$ é uma função decrescente, e o valor limite $S_{\infty}$ é a única raíz em $\left(0, \frac{1}{\sigma}\right)$ da equação

$$
1-z+\frac{1}{\sigma} \ln \left(\frac{z}{s_{0}}\right)=0
$$

Corolário 3.4.1 Em uma doença considerando-se dinâmica vital, onde a recuperação confere imunidade permanente, se o número inicial de infecciosos substituidos é maior que 1, então a fração de infecciosos cresce até o ponto máximo e então decresce para zero; caso contrário, a fração de infecciosos tende para zero. A propagação da infeç̧ão cessa porque o número de infecciosos substituídos tornase menor que 1 quando a fração de susceptiveis se torna pequena; entretanto, a população final de susceptíveis não é nula.

Na maioria das epidemias é difícil determinar os novos infectados porque em geral, somente os retirados da interação podem ser contados. Assim para 
aplicar o modelo a uma tal situação epidêmica particular é necessário conhecer o número de removidos por unidade de tempo, ou seja, $\frac{d R}{d t}$ como função do tempo $t$ (conhecida como curva epidêmica).

De (3.5) e (3.11) temos

$$
\frac{d R}{d t}=\gamma I=\gamma[1-R-S]=\gamma\left[1-R-S_{0} e^{-\sigma R}\right]
$$

Embora seja possivel resolver esta equação exatamente, a expressão resultante é muito complicada, olharemos portanto, para uma solução aproximada. Expandindo o termo exponencial de (3.12) em série de Taylor em uma vizinhança de $R(0)=0$, obtemos:

$$
e^{-\sigma R}=1-(\sigma R)+\frac{1}{2}(\sigma R)^{2}-\frac{1}{6}(\sigma R)^{3}+\cdots
$$

Observamos que, se a aproximação linear for considerada, obtemos

$$
R(t)=\frac{I_{0}}{\sigma\left(S_{0}-1 / \sigma\right)}\left[e^{\gamma \sigma\left(S_{0}-1 / \sigma\right) t}-1\right]
$$

e, se $S_{0}>\frac{1}{\sigma}$, temos que $R(t) \rightarrow \infty$ quando $t \rightarrow \infty$, isto implica que o número de removidos tende para o infinito, o que contradiz as hipóteses do modelo.

Tomando-se a aproximação até o termo quadrático e substituindo em (3.12) obtemos

$$
\frac{d R}{d t}=\gamma\left[I_{0}+\left(\sigma S_{0}-1\right) R-\frac{S_{0}}{2} \sigma^{2} R^{2}\right]
$$

Cuja solução é:

$$
\begin{aligned}
& \begin{aligned}
R(t) & =\frac{1}{\sigma^{2} S_{0}}\left[\sigma S_{0}-1+a \tanh \left(\frac{a \gamma t}{2}-\phi\right)\right]^{-} \\
\text {onde } & \\
\qquad & =\sqrt{\left.\left(\sigma S_{0}-1\right)^{2}+2 \sigma^{2} S_{0} I_{0}\right)} \\
\phi & =\tanh ^{-1}\left[\frac{\sigma S_{0}-1}{a}\right]
\end{aligned}
\end{aligned}
$$

A curva epidêmica é agora dada pela expressão

$$
\frac{d R}{d t}=\frac{\gamma a^{2}}{2 \sigma^{2} S_{0}}\left[\operatorname{sech}\left(\frac{a \gamma t}{2}-\phi\right)\right]^{2}
$$


que nos dá a taxa de remoção. A curva epidêmica registra a taxa na qual a doença se propaga na população, e involve somente os parâmetros: $\beta, \gamma$ e os valores iniciais $S_{0}$ e $I_{0}$.

A expressão (3.15) descreve uma função que atinge o máximo em $t=\frac{2 \phi}{a \gamma}$. $\mathrm{Na}$ seguinte figura é representada a forma da curva (3.15).

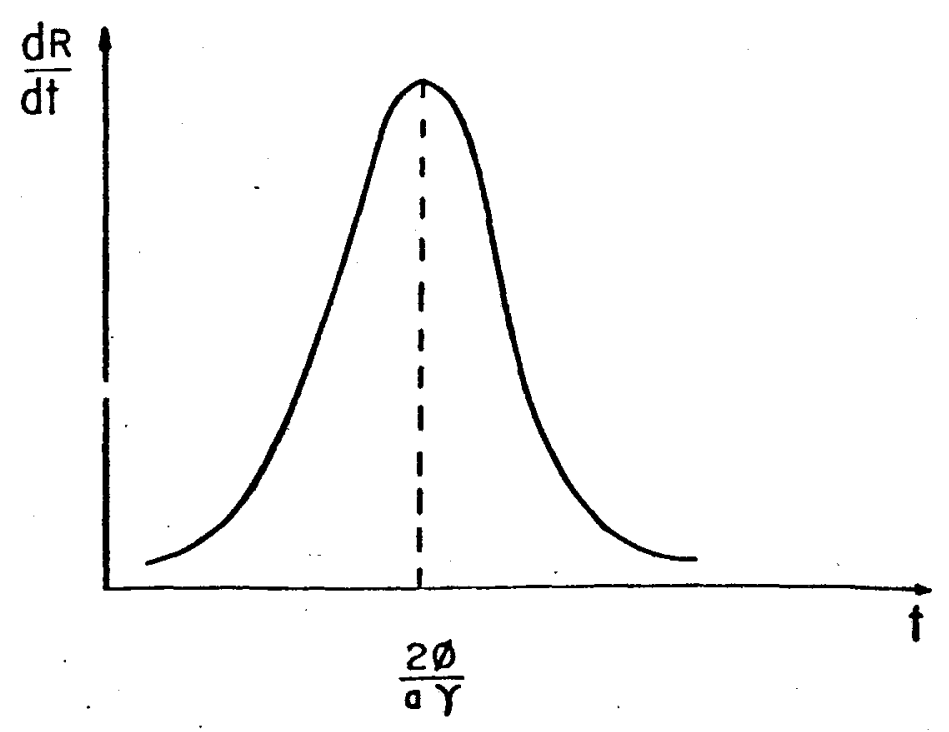

Figura 3.2: Curva epidêmica

$\mathrm{Na}$ figura observamos que as ocorrências aumentam quando $t$ cresce, e atingem o máximo em $t=\frac{2 \phi}{a \gamma}$ e então decrescem até a extinção.

Desejamos investigar o comportamento assintótico da epidemia quando $t \rightarrow \infty$. Dado que existe somente um número finito de indivíduos na população e a doença confere imunidade permanente, a epidemia será extinta. Além disso, quando a epidemia termina os indivíduos serão susceptiveis ou removidos, não haverá infecciosos. Portanto examinaremos a quantidade

$$
\lim _{t \rightarrow \infty} R(t)=R_{\infty}=\frac{1}{\sigma^{2} S_{0}}\left[\sigma S_{0}-1+a\right]
$$

Assumindo que a epidemia é iniciada por um pequeno grupo de infecciosos com

$$
2 \sigma^{2} S_{0} I_{0} \ll \sigma S_{0}-1: \quad S_{0}>\frac{1}{\sigma}
$$


então, da definição de $a$ em (3.14), temos $a \approx \sigma S_{0}-1$ e, substituindo em (3.16), obtém-se

$$
R_{\infty} \approx \frac{2\left(S_{0}-1 / \sigma\right)}{\sigma S_{0}}
$$

A condição para um surto epidêmico da doença é $S_{0}>\frac{1}{\sigma}$. Assumindo que $S_{0}=\frac{1}{\sigma}+\varepsilon$, onde $0<\varepsilon \ll \frac{1}{\sigma}$, substituindo na equação para $R_{\infty}$ temos

$$
R_{\infty} \approx \frac{2 \varepsilon}{1+\varepsilon \sigma} \approx 2 \varepsilon
$$

Isto significa que, para uma população que inicialmente tem $S_{0}=\frac{1}{\sigma}+\varepsilon$ susceptíveis, quando a epidemia se extingue, existirá $S_{\infty}=\frac{1}{\sigma}-\varepsilon$ susceptiveis restantes $\left(S_{\infty}=S_{0}-R_{\infty}\right)$. Em outras palavras, o número final de susceptíveis fica abaixo do limiar para uma epidemia. Este resultado é conhecido como o Teorema do Limiar de Kermack-McKendric.

\subsubsection{Modelo SIR com Dinâmica Vital}

O modelo é descrito pelo sistema de equações [10]:

$$
\begin{aligned}
& \frac{d S}{d t}=-\beta I S+\mu-\mu S \\
& \frac{d I}{d t}=\beta I S-\gamma I-\mu I \\
& \frac{d R}{d t}=\gamma I-\mu R
\end{aligned}
$$

Com as condições iniciais:

$$
S(t)+I(t)+R(t)=1, S(0)=S_{0}>0, I(0)=I_{0}>0, R(0) \geq 0
$$

Dado que $R(t)=1-S(t)-I(t)$, é suficiente considerar o PVI no plano $(S, I)$.

Os pontos de equilíbrio são:

$$
(1,0) \quad e \quad\left(S^{*}, I^{*}\right)=\left(\frac{1}{\sigma} ; \frac{\mu(\sigma-1)}{\sigma(\gamma+\mu)}\right), \text { onde } \sigma=\frac{\beta}{\gamma+\mu}
$$


Consideramos o comportamento assintótico das soluções de (3.17) no triângulo $D$, limitado pelos eixos $S$ e $I$, e a reta $S+I=1$. Uma regiãa assintoticamente estável para um ponto de equilíbrio é uma regiáo tal que todas as trajetórias que nela se originam, aproximam-se do ponto de equilibrio quando $t \rightarrow \infty$.

Os seguintes resultados são obtidos como um caso particular $(\alpha=0)$ do modelo SIRS com dinâmica vital, analisado na seção seguinte.

Teorema 3.4.2 Seja $(S(t), I(t))$ uma solução da equação diferencial em (3.17), (3.18). Se $\sigma>1$ então $D \backslash\{(S, 0): 0 \leq S \leq 1\}$ é uma região assintoticamente estável para o ponto de equilibrio $\left(\frac{1}{\sigma}, \frac{\mu(\sigma-1)}{\sigma(\gamma+\mu)}\right)$, onde $\sigma=\frac{\beta}{\gamma+\mu}$. Se $\sigma \leq 1, D$ é uma região assintoticamente estável para o ponto de equilibrio $(1,0)$.

Corolário 3.4.2 Em uma doença sem considerar dinâmica vital, onde a recuperação confere imunidade permanente, se o número de contatos infecciosos excede a 1, então as frações de susceptiveis e infecciosos eventualmente se aproximam de um valor endêmico constante e positivo, exceto no caso trivial quando inicialmente não há infecciosos. Se o número de contatos infecciosos é menor que 1, entäo a fração de infecciosos aproxima-se de zero e a fração de removidos também aproxima-se de zero (devido à morte de indivíduos removidos), de modo que a população inteira é eventualmente susceptível devido ao nascimento de novos susceptíveis.

\section{Comentário}

Comparando os teoremas (3.4.1) e (3.4.2) e seus corolários, é claro que o comportamento assintótico para o modelo SIR com ou sem dinâmica vital são muito diferentes. O modelo SIR sem dinâmica vital é apropriado para descrever um ataque epidêmico, ao passo que o modelo com dinâmica vital descreve melhor uma doença endêmica. Doenças com agente viral tais como sarampo, catapora, cachumba e variola podem ter surtos epidêmicos em certas comunidades e permanecer endêmicas em baixo nível em grandes grupos populacionais.

\subsection{O Modelo SIRS com Dinâmica Vital}

Neste modelo, a recuperação confere imunidade temporária. O modelo é apropriado para doençàs tais como tétano, cólera e febre tifóide.' Ássumimos que a taxa na qual indivíduos removidos perdem a imunidade e tornan-se 
novamente susceptíveis é proporcional ao número de indivíduos removidos com taxa de proporcionalidade $\alpha$, denominada taxa diária de perda da imunidade. 0 periodo médio de imunidade é $\frac{1}{\alpha}$, e para $\alpha=0$ tem-se imunidade permanente (modelo SIR).

0 modelo é descrito pelo sistema de equações [10]:

$$
\begin{aligned}
& \frac{d S}{d t}=-\dot{\beta} I S+\mu-\mu S+\alpha R \\
& \frac{d I}{d t}=\beta I S-\gamma I-\mu I \\
& \frac{d R}{d t}=\gamma I-\mu R-\alpha R
\end{aligned}
$$

Com as condições iniciais:

$$
S(t)+I(t)+R(t)=1, S(0)=S_{0}>0, I(0)=I_{0}>0, R(0) \geq 0
$$

onde $\beta, \gamma+\mu$ e $\mu+\alpha$ são positivos. A hipótese $\gamma+\mu>0$ significa que deve existir um fluxo para fora da classe dos infecciosos, e $\gamma+\alpha>0$ significa que existe um fluxo para dentro da classe dos susceptíveis.

\section{Análise do Modelo}

Dado que $R(t)=1-S(t)-I(t)$ é suficiente considerar o PVI no plano $(S, I)$. Seja $D$ o triângulo $D=\{(S, I): S \geq 0, I \geq 0, S+I \leq 1\}$. Os pontos de equilibrio de (3.19) são dados pelas soluções do sistema algébrico

$$
\begin{array}{r}
-\beta I S+(\mu+\alpha)-(\mu+\alpha) S-\alpha I=0 \\
\beta I S-\gamma I-\mu I=0
\end{array}
$$

Obtemos então, os seguintes pontos de equilíbrio:

$$
(1,0) \quad e \quad\left(S^{*}, I^{*}\right)=\left(\frac{1}{\sigma}, \frac{(\mu+\alpha)(\sigma-1)}{\beta+\alpha \sigma}\right)
$$




\section{Análise da estabilidade dos pontos de equilíbrio}

O sistema (3.19) pode ser linearizado, a matriz jacobiana é dada por

$$
J(S, I)=\left(\begin{array}{lr}
-\beta I-(\mu+\alpha) & -\beta S-\alpha \\
\beta I & \beta S-(\gamma+\mu)
\end{array}\right)
$$

Analisaremos cada ponto em separado.

1. $(1,0)$. Os autovalores são $\lambda_{1}=-(\mu+\alpha)$ e $\lambda_{2}=(\gamma+\mu)(\sigma-1)$, portanto

$$
(1,0) \text { é } \begin{cases}\text { nó estável, se } & \sigma<1 \\ \text { ponto de sela, se } & \sigma>1\end{cases}
$$

Se $\sigma=1$, o método do plano de fase não pode ser aplicado. Contudo $\sigma=1$ implica em $\beta=\gamma+\mu$ e, da segunda equação em (3.19)

$$
\frac{d I}{d t}=\beta I(S-1) \leq 0 \quad \text { na região } \quad D
$$

com $\frac{d I}{d t}=0$ se, e somente se, $I=0$, portanto todas as trajetórias se aproximam de $I=0$, porém, dado que $I=0$ é solução, as trajetórias devem se aproximar do ponto $(1,0)$. Portanto $D$ é uma região assintoticamente estável para $(1,0)$ se $\sigma \leq 1$.

2. O ponto $\left(S^{*}, I^{*}\right)=\left(\frac{1}{\sigma}, \frac{(\mu+\alpha)(\sigma-1)}{\beta+\alpha \sigma}\right)$ está no quadrante positivo, se e somente se, $\sigma>1$.

A matriz de estabilidade é dada por

$$
A=\left(\begin{array}{cc}
\frac{-\sigma(\mu+\alpha)(\beta+\alpha)}{\beta+\alpha \sigma} & \frac{-(\beta+\alpha)}{\sigma} \\
\frac{\beta(\mu+\alpha)(\sigma-1)}{\beta+\alpha \sigma} & 0
\end{array}\right)
$$


e o polinômio característico é dado por

$$
p(\lambda)=\lambda^{2}+\frac{\sigma(\mu+\alpha)(\beta+\alpha)}{\beta+\alpha \sigma} \lambda+\frac{\beta(\beta+\alpha)(\mu+\alpha)(\sigma-1)}{\sigma(\beta+\alpha \sigma)}
$$

ou, $p(\lambda)=\lambda^{2}-(\operatorname{tr} A) \lambda+\operatorname{det} A$.

Os autovalores são dados por

$$
\lambda_{1,2}=\frac{\operatorname{tr} A \pm \sqrt{(\operatorname{tr} A)^{2}-4 \operatorname{det} A}}{2}
$$

Afirmação 3.5.1 1) Não existem trajetórias fechadas, 2) $\operatorname{det} A>0$, 3) $\operatorname{tr} A<0$ e o ponto de equilibrio é estável.

Prova:

1. Isto pode ser mostrado usando o teorema (1.4.2) com $B=1 / I$, que claramente é continuamente diferenciável em $D$.

2.

$$
\operatorname{det} A=\frac{(\beta+\alpha)(\mu+\alpha)(\gamma+\mu)^{2}(\sigma-1)}{\beta(\gamma+\mu+\alpha)}
$$

dado que $\sigma>1, \operatorname{det} A>0$.

3.

$$
\operatorname{tr} A=\frac{-\sigma(\mu+\alpha)(\beta+\alpha)}{\beta+\alpha \sigma}=\frac{-(\mu+\alpha)(\beta+\alpha)}{\gamma+\underline{\mu}+\alpha}
$$

e, dado que todos os parâmetros são positivos, $\operatorname{tr} A<0$.

Portanto, o ponto de equilíbrio é estável, podendo ser um nó ou uma espiral.

Na figura 3.3 é mostrado o diagrama de fase para o sistema (3.19) com os seguintes valores dos parâmetros: $\mu=0.0001, \gamma=0.1999, \alpha=0.4$. Para $\beta=0.1$, obtém-se $\sigma=0.4997$ e para $\beta=0.4, \sigma=1.999$. 

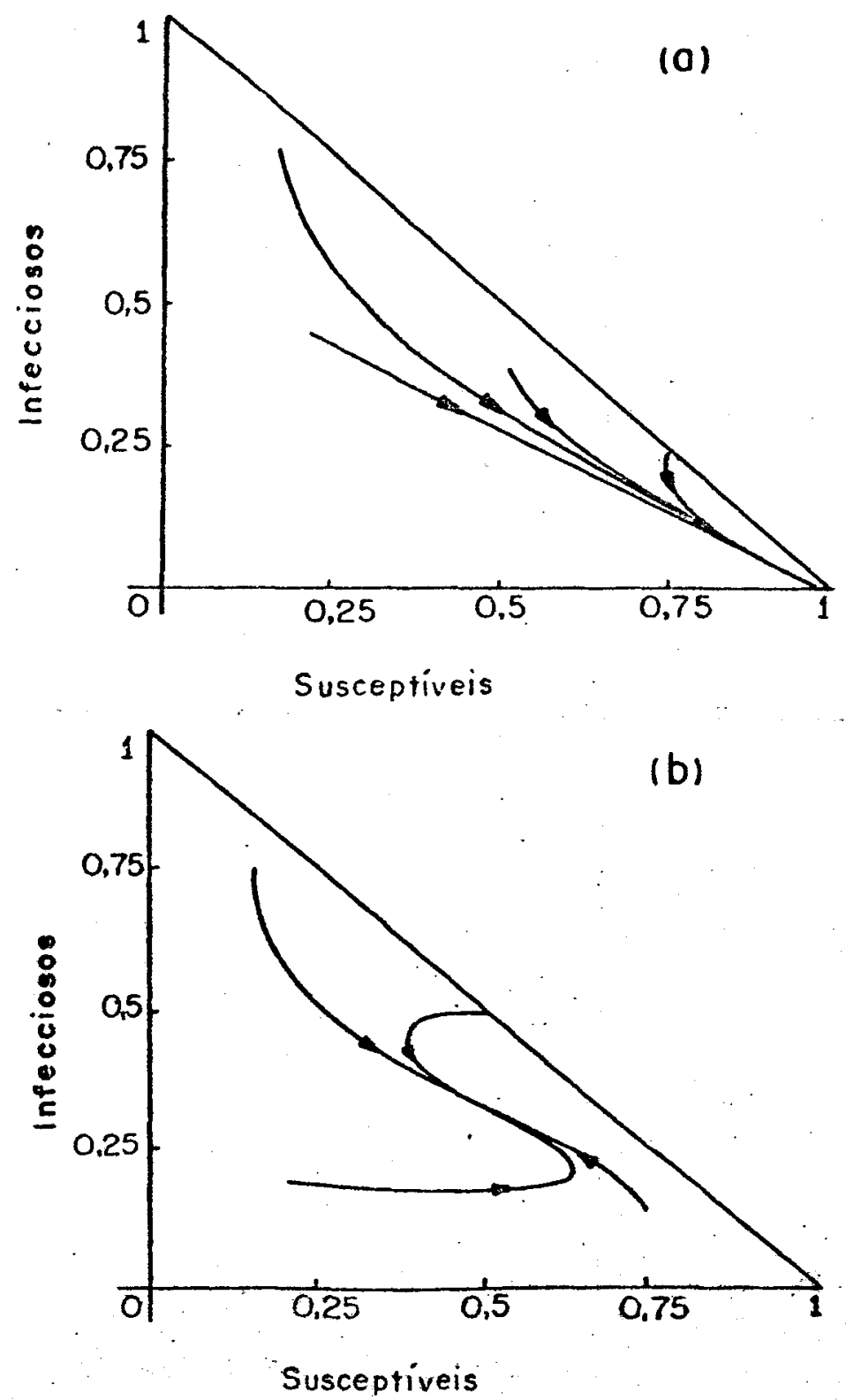

Figura 3.3: Trajetórias de fase para o modelo SIRS: a) Epidemia $(\sigma<1)$, b) Endemia $(\sigma>1)$ 
Da análise anterior, enunciamos os seguintes resultados [10].

Teorema 3.5.1 Seja $(S(t), I(t))$ solução de (3.19), (3.20). Se $\sigma>1$ então $D \backslash\{(S, 0): 0 \leq S \leq 1\}$ é uma região assintoticamente estável para o ponto de equilibrio

$$
\left(\frac{1}{\sigma}, \frac{(\mu+\alpha)(\sigma-1)}{\beta+\alpha \sigma}\right)
$$

Se $\sigma \leq 1$, então $D$ é uma região assintoticamente estável para o ponto de equilibrio $(1,0)$.

Corolário 3.5.1 Em uma doença considerando dinâmica vital, onde a recuperaçâa confere imunidade temporária, se o número de contatos infecciosos excede a 1, então as frações de susceptíveis e infecciosos se aproximam de valores endêmicos constantes para um tempo longo; caso contrário, a fração de susceptíveis cresce quando a fração de infecciosos decresce para zero até que a população inteira torne a ser susceptível.

\section{Comentário}

Considerando $\alpha=0$, temos o modelo SIR com dinâmica vital. Um resultado importante é que imunidade temporária, no lugar de permanente, não muda o critério do limiar.

\subsection{Um Modelo para Populações Heterogêneas}

O modelo a ser agora analisado é uma simplificação do modelo para populações heterogêneas, de Hethcote e Van Ark [13]. Para a análise do modelo usaremos resultados de modelos epidêmicos com n grupos apresentados nas referências: $[11,12,20,27]$, e resultados apresentados no capítulo 1 , pagina 20 .

\subsubsection{O Modelo SIR com n Grupos}

Neste modelo, a população é dividida em n grupos de tamanho $N_{i}$, cada grupo dividido em três classes disjuntas, que podem mudar com o tempo. As três 
classes que formam o grupo $i$ são denotadas por $S_{i}(t), I_{i}(t)$ e $R_{i}(t)$ (a fração em $N_{i}$ de susceptíveis, infecciosos e removidos)

As hipóteses do modelo são as seguintes.

1. 0 tamanho do grupo $i$, denotado por $N_{i}$ é constante e suficientemente grande tal que, em cada classe, as variáveis podem ser consideradas contínuas. Nascimentos e mortes ocorrem com taxas iguais e todos os recémnascidos são considerados susceptíveis. Indivíduos são retirados por morte de cada classe do grupo $i$ com uma taxa proporcional ao tamanho da classe e cuja constante de proporcionalidade é $\mu_{i}$, denominada taxa de remoção por morte.

2. No grupo $i$, individuos se recuperam e são transferidos da classe dos infecciosos para a classe dos removidos com uma taxa proporcional ao tamanho da classe e cuja constante de proporcionalidade é $\gamma_{i}$, denominada taxa de remoção por re superação. O período médio de infecciosidade é $\frac{1}{\gamma_{i}+\mu_{i}}$.

3. A população é heterogênea, porém, dentro de cada grupo é considerada homogênea, no sentido de que todos os indivíduos têm o mesmo período infeccioso e a mesma taxa de contato com indivíduos de outros grupos. $\mathrm{O}$ contato de um infeccioso é uma interação que resulta em infeç̧ão de outro individuo se ele é susceptível (contato efetivo). A taxa de contato $\beta_{i j}>0$ é o número de contatos por unidade de tempo de um indivíduo infeccioso do grupo $j$ com indivíduos do grupo $i$, esta taxa não depende somente do número de encontros, porém, também da frequêencia dos encontros, da infecciosidade dos indivíduos do grupo $j$ e da susceptibilidade ou resistência dos indivíduos do grupo $i$. Notemos que $\beta_{i j} S_{i}$ é a fração de contatos que resultam em transmissão e, $\beta_{i j} S_{i} N_{j} I_{j}$ é o número médio de susceptíveis do grupo $i$ infectados, por unidade de tempo, por $N_{j} I_{j}$ infecciosos no grupo $j$.

Das hipóteses acima, obtemos o sistema de equações diferenciais

$$
\begin{aligned}
& \frac{d\left(N_{i} S_{i}(t)\right)}{d t}=-\left[\sum_{j=1}^{n} \beta_{i j}\left(N_{j} I_{j}\right)\right] S_{i}+\mu_{i} N_{i}-\mu_{i} S_{i} N_{i} \\
& \frac{d\left(N_{i} I_{i}(t)\right)}{d t}=\left[\sum_{j=1}^{n} \beta_{i j}\left(N_{j} I_{j}\right)\right] S_{i}-\gamma_{i} I_{i} N_{i}-\mu_{i} I_{i} N_{i} \\
& \frac{d\left(N_{i} R_{i}(t)\right)}{d t}=\gamma_{i} I_{i} N_{i}-\mu_{i} R_{i} N_{i}
\end{aligned}
$$

para $i=1, \ldots, n$. 
Dado que $N_{i}$ é constante, e dado que $S_{i}(t)+I_{i}(t)+R_{i}(t)=1$ para cada $i$ e para todo $t$, a equação diferencial para $R_{i}(t)$ não é necessária ${ }_{\text {« }} \mathrm{O}$ sistema (3.22) se converte no sistema

$$
\begin{aligned}
\frac{d S_{i}}{d t} & =-\left[\sum_{j=1}^{n}\left(\frac{\beta_{i j} N_{j}}{N_{i}}\right) I_{j}\right] S_{i}+\mu_{i}-\mu_{i} S_{i}=f_{i}(S, I) \\
\frac{d I_{i}}{d t} & =\left[\sum_{j=1}^{n}\left(\frac{\beta_{i j} N_{j}}{N_{i}}\right) I_{j}\right] S_{i}-\gamma_{i} I_{i}-\mu_{i} I_{i}=g_{i}(S, I)
\end{aligned}
$$

para $i=1, \ldots, n$.

Com as condições iniciais:

$$
S_{i}(0)=S_{i 0} \geq 0, \quad I_{i}(0)=I_{i 0} \geq 0, \quad R_{i}(t)=1-S_{i}(t)-I_{i}(t)
$$

\subsubsection{Análise do Modelc}

\section{A Região de Estabilidade}

Consideramos o comportamento assintótico das soluções de (3.23) na região $2 n$-dimensional

$$
D=\left\{\left(S_{1}, \ldots, S_{n}, I_{1}, \ldots, I_{n}\right): S_{i} \geq 0, I_{i} \geq 0, S_{i}+I_{i} \leq 1\right\}
$$

O seguinte lema, mostra que o modelo descrito por (3.23) e (3.24) é bem posto, dado que as trajetórias de suas soluções permanecem em $D$. As soluções de (3.23) e (3.24) existem em $[0, \infty)$ e são únicas, dado que $f_{i}(S, I)$ e $g_{i}(S, I)$ são funções lipschitzianas em $D$.

Lema 3.6.1 O conjunto $D$ é positivamente invariante para o sistema (3.23).

Prova: Nagumo, (Hethcote [13]) mostrou que um conjunto compacto é invariante se o campo de direções da equação diferencial é tangente ou aponta para dentro da região em cada ponto da fronteira. Pode ser mostrado diretamente que o produto interno de $f_{i}$ e $g_{i}$ em (3.23) com as normais aos três hiperplanos que limitam $D$ é menor que zero.

Assumimos que todos os grupos interagem, isto é, cada par de grupos está ligado de forma que a presença de infecciosos em um grupo ocasiona a infeç̧ão 
no outro. Além disso, $\gamma_{i}+\mu_{i}>0$ para todo $i$, de modo que existe sempre um fluxo para fora da classe dos infecciosos por recuperação ou por morte.

O lema abaixo dá as condições sob as quais existirá em cada grupo um número positivo de indivíduos susceptíveis, infecciosos e removidos. A fronteira n-dimensional de $D$ definida por $I_{i}=0$, para cada $i$ corresponde à situação trivial onde não existem indivíduos infecciosos em qualquer grupo.

Lema 3.6.2 Seja $\gamma_{i}+\mu_{i}>0$ para todo i. Se a solução de (3.23) começa na fronteira, $\partial D$, de $D$ porém não sobre a parte da fronteira correspondente à não existência de infecciosos em qualquer grupo, então não permanece sobre $\partial D$ para qualquer intervalo de tempo positivo.

Prova: Lajmanovich e Yorke [20]

\section{Análise da estzbilidade dos pontos de equilíbrio.}

Os pontos de equilíbrio do sistema (3.23) são:

1. O ponto de equilíbrio correspondente à extinção da doença (ponto de equilíbrio em extinção)

$$
\left(S_{1}^{*}, \ldots, S_{n}^{*}, 0, \ldots, 0\right) \quad \text { onde } \quad S_{i}^{*}=1
$$

2. Os pontos de equilíbrio correspondentes à existência endêmica da doença (pontos de equilíbrio endêmico) são da forma $\left(S_{1}^{e}, \ldots, S_{n}^{e}, I_{1}^{e}, \ldots, I_{n}^{e}\right)$, onde

$$
S_{i}^{e}=\frac{\mu_{i}}{\mu_{i}+\sum_{j=1}^{n}\left(\frac{\beta_{i j} N_{j}}{N_{i}}\right) I_{j}^{e}}
$$

e $I_{i}^{e}$ são os pontos fixos positivos da equação

$$
I_{i}=\frac{\sum_{j=1}^{n}\left(\frac{\beta_{i j} N_{j}}{\left(\gamma_{i}+\mu_{i}\right) N_{i}}\right) I_{j}}{1+\frac{\gamma_{i}+\mu_{i}}{\mu_{i}} \sum_{j=1}^{n}\left(\frac{\beta_{i j} N_{j}}{\left(\gamma_{i}+\mu i\right) N_{i}}\right) I_{j}}=f_{i}(I)
$$

Assim, $I^{e}$ é um ponto fixo positivo de $f$ dada por

$$
I=f(I)
$$


Analisaremos cada ponto em separado.

1) $O$ ponto de equilíbrio em extinção é levado à origem fazendo a mudança de variável $S_{i}=S_{i}^{*}-X_{i}$. Obtendo-se o sistema

$$
\begin{aligned}
\frac{d X_{i}}{d t} & =\left[\sum_{j=1}^{n}\left(\frac{\beta_{i j} N_{j}}{N_{i}}\right) I_{j}\right]\left(S_{i}^{*}-X_{i}\right)-\mu_{i} X_{i} \\
\frac{d I_{i}}{d t} & =\left[\sum_{j=1}^{n}\left(\frac{\beta_{i j} N_{j}}{N_{i}}\right) I_{j}\right]\left(S_{i}^{*}-X_{i}\right) \div\left(\gamma_{i}+\mu_{i}\right) I_{i}
\end{aligned}
$$

para $i=1, \ldots, n$.

A região $D$ fica então

$$
D^{*}=\left\{\left(X_{1}, \ldots, X_{n}, I_{1}, \ldots, I_{n}\right): 0 \leq I_{i} \leq 1-\left(S_{i}^{*}-X_{i}\right) \leq 1\right\}
$$

A formulação matricial de (3.28) é

$$
\left(\begin{array}{c}
d X / d t \\
d I / d t
\end{array}\right)=\left(\begin{array}{rr}
-U & L \\
0 & B
\end{array}\right)\left(\begin{array}{c}
X \\
I
\end{array}\right)-\left(\begin{array}{c}
F \\
F
\end{array}\right)
$$

onde

$$
\begin{aligned}
& U=\operatorname{diag}\left(\mu_{i}\right), \quad G=\operatorname{diag}\left(\gamma_{i}\right), \quad L=\left(\frac{\beta_{i j} N_{j}}{N_{i}}\right) \\
& F=\left(\sum_{j=1}^{n}\left(\frac{\beta_{i j} N_{j}}{N_{i}}\right) I_{j} X_{i}\right) \quad \text { e } \quad B=L-G-U
\end{aligned}
$$

A matriz de estabilidade é dada por

$$
A=\left(\begin{array}{rr}
-U & L \\
0 & B
\end{array}\right)
$$

Dado que todos os grupos estão ligados, as matrizes $\left(\beta_{i j}\right), L$ e $B$ são irredutíveis. Os $2 n$ autovalores da matriz $A$ é a união dos autovalores das matrizes $-U$ e $B$. A matriz $-U$ contribui com autovalores com parte real negativa: $-\mu_{i}$, $i=1, \ldots, n$. Portanto a estabilidade do ponto de equilíbrio é determinada pelos autovalores da matriz $B$. Seja $S(B)$ o módulo de estabilidade da matriz $B$, se $S(B)<0$ então todos os autovalores de $A$ têm parte real negativa, de modo que a origem no espaço $(X, I)$ é localmente assintoticamente estável. Se $S(B)>0$ a origem é instável.

Para analisar a estabilidade do ponto de equilíbrio quando $S(B)^{*}=0$, usaremos a teoria da estabilidade de Lyapunov. O subconjunto $C^{*}$ de $D^{*}$ tal que 
$X_{i} \geq 0$ para todo $i$ é positivamente invariante para o sistema (3.28). Segue então de (3.28) que para todai $i$ as trajetórias da solução que começam no subconjunto de $D^{*}$ definido por $X_{i} \leq 0$ devem entrar no subconjunto de $D^{*}$ definido por $X_{i}>0$ ou se aproximam da origem quando $t \rightarrow \infty$. Assim, é suficiente mostrar que $C^{*}$ é uma região assintoticamente estável na origem para (3.28).

Consideremos a função continuamente diferenciável $V=w I$ onde w é o autovetor de $B^{T}$ no lema (1.5.1).

$\operatorname{Em} C^{*}$

$$
\begin{aligned}
\operatorname{grad} V(I) \cdot \frac{d I}{d t} & =\mathbf{w} \cdot B I-\mathbf{w} \cdot F \\
& =B^{T} \mathbf{w} \cdot I-\mathbf{w} \cdot F \\
& =S(B) \mathbf{w} \cdot I-\mathbf{w} \cdot F \\
& \leq 0
\end{aligned}
$$

e portanto, $V$ é uma função de Lyapunov. $O$ maior conjunto invariante de (3.28) no conjunto onde $d V / d t=0$ é o conjunto $M$ para o qual todos os $I_{i}$ são nulos, pelo Teorema da Invariança de LaSalle [22, pag. 58], todas as trajetórias em $C^{*}$ devem aproximar-se de $M$; contudo, elas não podem aproximar-se de qualquer ponto de $M$, exceto da origem, desde que todas as trajetórias em $M$ aproximam-se da origem.

Portanto para $S(B) \leq 0$, a região $D$ é uma região localmente assintoticamente estável para o ponto de equilíbrio em extinção.

2) Para os pontos de equilibrio endêmico $\left(S^{e}, I^{e}\right)$ provaremos inicialmente a existência e unicidade da solução de (3.27) em $\mathcal{R}_{+}^{n}$ e que este ponto existe se, e somente se $S(B)>0$. Assim, o ponto de equilíbrio endêmico é único. Este desenvolvimento segue o dado por Hethcote e Thieme em [12].

Dado que $S_{i}(t)+I_{i}(t)+R_{i}(t)=1$ para cada $i$, as equações em (3.23), (3.24) podem ser reformuladas em termos de $I_{i}$ e $R_{i}$ como segue:

$$
\begin{aligned}
\frac{d I_{i}}{d t} & =\left[\left(1-I_{i}-R_{i}\right) \sum_{j=1}^{n} \lambda_{i j} I_{j}\right]-\left(\gamma_{i}+\mu_{i}\right) I_{i} \\
\frac{d R_{i}}{d t} & =\gamma_{i} I_{i}-\mu_{i} R_{i}
\end{aligned}
$$

para $i=1, \ldots, n$.

Com as condições iniciais

$$
I_{i}(0)=I_{i 0} \geq 0, \quad R_{i}(0)=R_{i 0} \geq 0, \quad I_{i 0}+R_{i 0} \leq 1
$$

e $\lambda_{i j}=\frac{\beta_{i j} N_{j}}{N_{i}}$ 
Resolvendo a segunda equação em (3.32) no ponto de equilíbrio para $R_{\mathrm{i}} \mathrm{e}$ substituindo na primeira, após algumas operações algébricas obtém-se o problema de ponto fixo (3.26) na forma

$$
I_{i}=\frac{\sum_{j=1}^{n} \alpha_{i j} I_{j}}{1+\frac{\gamma_{i}+\mu_{i}}{\mu_{i}} \sum_{j=1}^{n} \alpha_{i j} I_{j}}=f_{i}(I)
$$

onde $\alpha_{i j}=\frac{\beta_{i j} N_{j}}{\left(\gamma_{i}+\mu i\right) N_{i}}$.

Assim, os pontos de equilíbrio são os pontos fixos positivos de $f$ dados por

$$
I=f(I), \quad f: \mathcal{R}_{+}^{n} \rightarrow \mathcal{R}_{+}^{n}
$$

Aplicamos agora o teorema (1.5.2) para provar a existência e unicidade do ponto de equilíbrio endêmico. Neste caso $f: \mathcal{R}_{+}^{n} \rightarrow \mathcal{R}_{+}^{n}$ é continuamente diferenciável e monôtona não decrescente, sendo estritamente sublinear com

$$
\varepsilon=\min _{i} \frac{(1-r) \frac{\gamma_{i}+\mu_{i}}{\mu_{i}} \sum_{j=1}^{n} \alpha_{i j} I_{j}}{1+\frac{\gamma_{i}+\mu_{i}}{\mu_{i}} r \sum_{j=1}^{n} \alpha_{i j} I_{j}}
$$

e limitada, dado que cada $f_{i}(I)$ é limitada superiormente por $\frac{\gamma_{i}+\mu_{i}}{\mu_{i}}$. Além disso $f(0)=0$ e $f^{\prime}(0)=\left(\alpha_{i j}\right)$. Dado que, por hipótese, $\left(\beta_{i j}\right)$ é irredutível, então $\left(\alpha_{i j}\right)$ é também irredutível.

O teorema (1.5.2) implica que o modelo (3.32), (3.33) tem um único ponto de equilíbrio endêmico se, e somente se, o raio espectral da matriz $\left(\alpha_{i j}\right)$ é maior que 1.

onde

De (3.31) tem-se $B=L-G-U$, que pode ser. escrita na forma $B=\left(b_{i j}\right)$

$$
\begin{aligned}
b_{i j} & =\left(\gamma_{j}+\mu_{j}\right)\left(\frac{\beta_{i j} N_{j}}{\left(\gamma_{j}+\mu_{j}\right) N_{i}}-\delta_{i j}\right) \\
& =\left(\gamma_{j}+\mu_{j}\right)\left(\alpha_{i j}-\delta_{i j}\right)
\end{aligned}
$$

sendo $\delta_{i j}$ o delta de Kronecker (isto é, $\delta_{i j}=1$ se $i=j, \delta_{i j}=0$ se $i \neq j$ ).

Lema 3.6.3 Se B é irredutivel, então $S(B)$ tem o mesmo sinal que $\left[\rho\left(\left(\alpha_{i j}\right)\right)-1\right]$.

Prova: Nold [27, lema 3.2] mostrou que se $B$ é uma matriz irredutivel com elementos não diagonais não negativos e $D$ é uma matriz diagonal posițiva, então, os autovalores de Perron de $B$ e $D B$ têm o mesmo sinal (mesmos resultados para $B$ e $B D)$. Usando este resultado e $D=\left(d_{i j}\right), d_{i j}=\left(\gamma_{j}+\mu_{j}\right)^{-1}$ temos que.

$$
S(B D)=S\left(\left(\alpha_{i j}\right)-1\right)=S\left(\left(\alpha_{i j}\right)\right)-1=\rho\left(\left(\alpha_{i j}\right)\right)-1
$$


dado que $S(B)$ e $S(B D)$ têm o mesmo sinal, a prova está completa.

Assim, se $S(B)>0$, o' raio espectral de $\left(\alpha_{i j}\right)$ é maior que 1 , portanto, pelo teorema (1.5.2), a equação (3.34) tem um único ponto fixo positivo correspondente ao equilíbrio endêmico, no caso em que $S(B)>0$.

Provaremos agora que, se existe um ponto de equilíbrio endêmico, então ele é localmente assintoticamente estável. Consideremos o sistema (3.32) e o ponto de equilíbrio endêmico $E=\left(I_{1}^{e}, \ldots, I_{n}^{e}, R_{1}^{e}, \ldots, R_{n}^{e}\right)$; fazendo as mudanças de variáveis $I_{i}=I_{i}^{e}+X_{i}$ e $R_{i}=R_{i}^{e}+Y_{i}$, obtemos o sistema

$$
\begin{aligned}
\frac{d X_{i}}{d t} & =\left(1-I_{i}^{e}-R_{i}^{e}\right) \sum_{j=1}^{n} \lambda_{i j} X_{j}-\left(\gamma_{i}+\mu_{i}\right) X_{i}-\left(X_{i}+Y_{i}\right) \sum_{j=1}^{n} \lambda_{i j} I_{j}^{e} \\
\frac{d Y_{i}}{d t} & =\gamma_{i} X_{i}-\mu_{i} Y_{i}
\end{aligned}
$$

ou em notação matricial

$$
\left(\begin{array}{l}
d X / d t \\
d Y / d t
\end{array}\right)=\left(\begin{array}{ll}
A_{1} & A_{2} \\
A_{3} & A_{4}
\end{array}\right)\left(\begin{array}{c}
X \\
Y
\end{array}\right)
$$

onde

$$
\begin{aligned}
& A_{1}=\left(1-I_{i}^{e}-R_{i}^{e}\right) \lambda_{i j}-\left[\left(\gamma_{i}+\mu_{i}\right)+\sum_{j=1}^{n} \lambda_{i j} I_{j}^{e}\right] \delta_{i j} \\
& A_{2}=\operatorname{diag}\left(-\sum_{j=1}^{n} \lambda_{i j} I_{j}^{e}\right) \\
& A_{3}=\operatorname{diag}\left(\gamma_{i}\right) \text { e } A_{4}=\operatorname{diag}\left(\mu_{i}\right)
\end{aligned}
$$

Lembrando que, se $\frac{d u}{d t}=f(u)$ é um sistema $n \times n$ de equações diferenciais e $E \in \mathcal{R}_{+}^{n}$ é um ponto de equilíbrio, então a estabilidade assintótica de $E$ é geralmente mostrada provando que a equação linearizada $\frac{d w}{d t}=f^{\prime}(E) w$ não tem soluções da forma $w(t)=W e^{z t}$ onde $W \in \mathcal{C}, z \in \mathcal{C}, \operatorname{Rez} \geq 0$. Isto é, $z W=f^{\prime}(E) W$ com $W \in \mathcal{C}^{n} \backslash\{0\}$ implica que Rez<0.

Procedendo desta maneira, consideremos as equaçōes

$$
\begin{aligned}
z X_{i} & =\left[\left(1-I_{i}^{e}-R_{i}^{e}\right) \sum_{j=1}^{n} \lambda_{i j} X_{j}\right]-\left(\gamma_{i}+\mu_{i}\right) X_{i}-\left(X_{i}+Y_{i}\right) \sum_{j=1}^{n} \lambda_{i j} I_{j}^{e} \\
z Y_{i} & =\gamma_{i} X_{i}-\mu_{i} Y_{i}
\end{aligned}
$$

para $i=1, \ldots, n . \quad X_{i}, Y_{i}, z \in \mathcal{C}$ e $I_{i}^{e}, R_{i}^{e}$ são as coordenadas do ponto de equilíbrio endêmico. Vamos supor que $R e z \geq 0$ e trataremos de obter uma contradição. 
Resolvendo a segunda equação em (3.38) para $Y_{i}$ e substituindo este resultado na primeira equação, após algumas operações algébricas obtém-se

$$
\left[1+\eta_{i}(z)\right] X_{i}=(H X)_{i}
$$

onde

$$
\eta_{i}=\frac{1}{\gamma_{i}+\mu_{i}}\left[z+\frac{z+\gamma_{i}+\mu_{i}}{z+\mu_{i}} \sum_{j=1}^{n} \lambda_{i j} I_{j}^{e}\right]
$$

e a matriz $H=\left(h_{i j}\right)$, onde

$$
h_{i j}=\frac{\lambda_{i j}\left(1-I_{i}^{e}-R_{i}^{e}\right)}{\gamma_{i}+\mu_{i}}
$$

Notemos que $H$ é uma matriz não negativa e que $I^{e}=H I^{e}$.

Tomando-se valores absolutos em (3.39), obtemos

$$
[1+\eta(z)]|X| \leq H|X|
$$

$\operatorname{com}|X|=\left(\left|X_{1}\right|, \ldots,\left|X_{n}\right|\right) \mathrm{e}$

$$
\eta(z)=\inf \left\{\operatorname{Re} \eta_{i}(z), i=1, \ldots, n\right\}
$$

Um cálculo elementar mostra que se $\operatorname{Re} z \geq 0$, então $\operatorname{Re} \eta_{i}(z)>0$ para todo $i$, de modo que $\eta(z)>0$. A prova usa agora a estratégia de Krasnoselskii em uma outra versão [18, teorema 2.11].

Seja $r$ o menor número tal que $|X| \leq r I^{e}$. Dado que $I^{e}$ é um vetor estritamente positivo, $r<\infty$. Agora por (3.42),

$$
\begin{aligned}
{[1+\eta(z)]|X| } & \leq H|X| \leq r H I^{e}=r I^{e} \\
|X| & \leq \frac{r I^{e}}{1+\eta(z)}
\end{aligned}
$$

Dado que $\eta(z)>0$ se Re $z \geq 0$, obtemos uma contradição da minimalidade de $r$. Portanto Re $z<0$ e o ponto de equilíbrio endêmico é localmente assintoticamente estável.

Os resultados anteriores são resumidos no seguinte teorema [13].

Teorema 3.6.1 Assuma $B$ irredutivel. Se $S(B) \leq 0$ então, todas as soluçōes do problema de valor inicial (3.23), (3.24) aproximam-se do ponto de equilibrio (3.25), correspondente à extinção da doença. Se $S(B)>0$ e existe alguma infecção inicial, então, as soluções do problema de valor inicial (3.23), (3.24) não se aproximam do ponto de equilibrio (3.25) e existe um único ponto de equilibrio endêmico positivo, localmente assintoticamente estável, correspondente à persistência da doença em todos os grupos. 
Os resultados de estabilidade do teorema (3.6.1) podem ser reformulados em termos de uma matriz que involve o número de contatos ou taxa básica de reprodutividade da infeç̧ão: $\sigma_{i j}=\frac{\beta_{i j}}{\gamma_{j}+\mu_{j}}$.

Definimos a matriz de transmissão $R=\left(r_{i j}\right)$, onde $r_{i j}$ é o número médio de contatos efetivos com indivíduos do grupo $i$ feitos por um único indivíduo infeccioso do grupo $j$ durante seu periodo de infecciosidade. Isto é, $r_{i j}$ representa o número médio de novos casos produzidos no grupo $i$ por um único infeccioso do grupo $j$, se todos no grupo $i$ são susceptíveis.

Para o modelo (3.23), a matriz de transmissão é a matriz $n \times n$ dada por

$$
R=\left(r_{i j}\right)=\left(\frac{\beta_{i j} N_{j}}{\left(\gamma_{j}+\mu_{j}\right) N_{i}}\right)
$$

Dado que a matriz $\left(\beta_{i j}\right)$ é irredutivel, $R$ é também irredutível. De (3.31) temos $B=L-G-U$, que pode ser escrita na forma $B=\left(b_{i j}\right)$ onde

$$
\begin{aligned}
b_{i j} & =\frac{\beta_{i j} N_{j}}{N_{i}}-\delta_{i j}\left(\gamma_{i}+\mu_{i}\right) \\
& =\left(\gamma_{j}+\mu_{j}\right)\left(\frac{\beta_{i j} N_{j}}{\left(\gamma_{j}+\mu_{j}\right) N_{i}}-\delta_{i j}\right) \\
& =\left(\gamma_{j}+\mu_{j}\right)\left(r_{i j}-\delta_{i j}\right)
\end{aligned}
$$

Sendo $B$ e $R$ matrizes irredutíveis temos que $S(B)=\rho(B)$ e $S(R)=$ $\rho(R)$. Pelo lema (3.6.3), tomando-se $D=(G+U)^{-1}$, tem-se que $S(B)$ tem o mesmo sinal que $S(R)-1$. Isto implica que no teorema (3.6.1), $S(B) \leq 0$ é equivalente a $S(R) \leq 1$ e $S(B)>0$ é equivalente a $S(R)>1$.

Concluimos esta seção, observando que o módulo de estabilidade da matriz de transmissão, $S(R)=1$, é o novo limiar epidêmico. Isto é, $S(B)>0$ implica na existência de um surto epidêmico e $S(B)>0$ se, e somente se, $S(R)>1$. A taxa de crescimento da doença é uma função crescente de $S(R)$ e portanto, um programa de controle da doença deverá levar $S(R)$ abaixo do limiar epidêmico: Abordamos este tópico no próximo capítulo. 


\section{Capítulo 4}

\section{Aplicação: Controle de Doenças por Vacinação}

\subsection{Introdução}

O controle das doenças é um importante problema prático, e o uso de modelos epidêmicos para avaliar os resultados de programas de vacinação é fundamental. A imunização pode reduzir a incidência da infecção, ainda que somente uma parte da população receba tratamento. Os indivíduos serão protegidos da infecção e além disto eles não têm mais participação na transmissão da doença, o número de infecciosos é diminuido e a probabilidade de que um indivíduo não vacinado entre em contato com a doença é mínima (imunização indireta). Uma política ótima de vacinação é aquela que consegue controlar a propagação da doença, vacinando o menor número de indivíduos. $[1,11,13]$

Para a aplicação da teoria na vacinação, usaremos o modelo para populações heterogêneas apresentado no capítulo 3: O modelo SIR com n grupos, com dinâmica vital. Além das hipóteses gerais (pag. 74) consideramos a seguinte:

Os recém-nascidos (razoavelmente definidos como crianças com até 18 meses de idade) são retirados da fração de susceptiveis do grupo $i$ a uma taxa proporcional à taxa de natalidade $\mu_{i}$, com constante de proporcionalidade não negativa $p_{i}\left(p_{i}<1\right)$, sendo $p_{i}$ taxa de imunização com sucesso, em geral, mais baixa que a taxa de vacinação.

Assim, temos o sistema (3.23) modificado: 


$$
\begin{aligned}
\frac{d S_{i}}{d t} & =-\left[\sum_{j=1}^{n}\left(\frac{\beta_{i j} N_{j}}{N_{i}}\right) I_{j}\right] S_{i}+\left(1-p_{i}\right) \mu_{i}-\mu_{i} S_{i} \\
\frac{d I_{i}}{d t} & =\left[\sum_{j=1}^{n}\left(\frac{\beta_{i j} N_{j}}{N_{i}}\right) I_{j}\right] S_{i}-\gamma_{i} I_{i}-\mu_{i} I_{i}
\end{aligned}
$$

para $i=1, \ldots, n$.

Com as condições iniciais:

$$
R_{i}(t)=1-S_{i}(t)-I_{i}(t), S_{i}(0)=S_{i 0} \geq 0, I_{i}(0)=I_{i 0} \geq 0
$$

\subsection{O modelo para um grupo $(n=1)$}

Assumimos que $\gamma+\mu>0$ de modo que existe algum fluxo para fora da classe dos infecciosos por recuperação ou por morte. (o subscrito 1 é omitido nesta seção). $O$ modelo é descrito pelo sistema de equaçóes

$$
\begin{aligned}
& \frac{d S}{d t}=-\beta I S+(1-p) \mu-\mu S \\
& \frac{d I}{d t}=\beta I S-\gamma I-\mu I
\end{aligned}
$$

Com as condições iniciais:

$$
R(t)=1-S(t)-I(t), S(0)=S_{0} \geq 0, I(0)=I_{0} \geq 0
$$

Os pontos de equilíbrio de (4.2) no plano- $S I$ são $\left(S^{*}, 0\right)$ e

$$
\left(\frac{1}{\sigma}, \frac{\mu\left(\sigma S^{*}-1\right)}{(\gamma+\mu) \sigma}\right), \quad S^{*}=(1-p)
$$

onde $\sigma=\frac{\beta}{\gamma_{+} \mu}$ é o número de contatos infecciosos.

Seja $D$ o triângulo $D=\{(S, I): S \geq 0, I \geq 0, S+I \leq 1\}$. A prova do seguinte teorema é similar a do teorema (3.4.1) para o modelo sem imunização.

Teorema 4.2.1 Se $\sigma S^{*} \leq 1$ então $D$ é uma região assintoticamente estável para o ponto de equilibrio $\left(S^{*}, 0\right)$. Se $\sigma S^{*} \geq 1$, então $D \backslash\{(S, 0): 0 \leq S \leq 1\}$ é uma região assintoticamente estável para o ponto de equilibrio (4.5). 
0 valor principal do teorema (4.2.1) é que ele indica a relação entre a

- fração de imunização $p$ e o número de contatos infecciosos $\sigma$ que deve ser satisfeita para extinguir a doença. Para isto, a fração vacinada $p$ deve satisfazer $p \geq 1-\frac{1}{\sigma}$. A quantidade limiar $\sigma S^{*}$ é o número médio de casos secundários produzidos por um único infeccioso durante seu periodo de infecciosidade em uma população com uma fração $S^{*}$ de susceptíveis.

\section{Comentários}

1. A doença se extingue sem qualquer imunização quando $\sigma \leq 1$.

2. Quando a doença se extingue, existe uma fração restante de susceptíveis. Além disso, se a imunização é continuada nos mesmos níveis, a doença não pode voltar à população, devido a imunização indireta. Se não existe imunização e a doença se extingue, então as mortes e os nascimentos de novos susceptíveis ocasiona um incremento na fração de susceptiveis, até que a população inteira torne a ser susceptível. Por exemplo: Se a imunização para varíola for interrompida porque ela foi erradicada do mundo, então, após várias gerações, toda a população mundial será susceptível à variola.

3. Quando a doença permanece endêmica, o ponto de equilíbrio é dado por (4.5). Lembrando que o número de infecciosos substituídos $\sigma S(t)$ é o número médio de susceptíveis infectados por um infeccioso durante seu período de infecciosidade, então no ponto de equilíbrio endêmico $\sigma\left(S_{\infty}\right)=1$. A fração susceptível endêmica $S_{\infty}$ é usado como uma estimativa para $\frac{1}{\sigma}$. Portanto para extinguir a doença, a fração vacinada $p$ de recém-nascidos deve exceder $1-S_{\infty}$.

\subsection{O modelo para $n>1$ grupos}

Consideramos o comportamento assintótico das soluçóes de (4.1), (4.2) na região $D$ considerada no modelo sem imunização.

Os pontos de equilíbrio do sistema (4.1) são:

1. O ponto de equilíbrio em extinção

$$
\left(S_{1}^{*}, \ldots, S_{n}^{*}, 0, \ldots, 0\right) \quad \text { onde } \quad S_{i}^{*}=1-p_{i} \quad \cdot(4.6)
$$


2. $O$ ponto de equilibrio endêmico $\left(S_{1}^{e}, \ldots, S_{n}^{e}, I_{1}^{e}, \ldots, I_{n}^{e}\right)$, onde

$$
S_{i}^{e}=\frac{\left(1-p_{i}\right) \mu_{i}}{\mu_{i}+\sum_{j=1}^{n}\left(\frac{\beta_{i j} N_{j}}{N_{i}}\right) I_{j}^{e}}
$$

e $I_{i}^{e}$ é o único ponto fixo positivo da equação

$$
I_{i}=\frac{\sum_{j=1}^{n}\left(\frac{\beta_{i j} N_{j} S_{i}^{*}}{\left(\gamma_{i}+\mu_{i}\right) N_{i}}\right) I_{j}}{1+\frac{\gamma_{i}+\mu_{i}}{\mu_{i}\left(1-p_{i}\right)} \sum_{j=1}^{n}\left(\frac{\beta_{i j} N_{j} S_{i}^{*}}{\left(\gamma_{i}+\mu_{i}\right) N_{i}}\right) I_{j}}
$$

Os resultados sobre a estabilidade dos pontos de equilíbrio são similares aos obtidos para o modelo sem imunização: A doença tende a extinção se $S\left(B^{*}\right) \leq 0$ e permanecerá endêmica se $S\left(B^{*}\right)>0$, onde $B^{*}=L^{*}-G-U$ e

$$
U=\operatorname{diag}\left(\mu_{i}\right), \quad G=\operatorname{diag}\left(\gamma_{i}\right), \quad L^{*}=\left(l_{i j}\right)=\left(\frac{\beta_{i j} N_{j}\left(1-p_{i}\right)}{N_{i}}\right)
$$

Observamos que, se $S\left(B^{*}\right) \leq 0$, a doença se extingue sem qualquer imunização. Portanto considerando $S\left(B^{*}\right)>0$, a doença é controlada vacinando uma fração $p_{i}$ de susceptíveis em cada grupo que faça $S\left(B^{*}\right) \leq 0$ (Problema de Programação Matemática).

Se a fração imunizada é a mesma em cada grupo, $\left(p_{i}=p\right.$, para todo $\left.i\right)$, tem-se um programa de vacinação uniforme.

\subsection{Aspectos de Políticas de Vacinação}

A maioria das pesquisas nesta área se concentram no problema de como fazer que uma política de vacinação leve o sistema abaixo do limiar epidêmico (isto é, fazer $S(R)<1$ ). Uma política de vacinação ótima é então a que usa a menor quantidade de vacina.

Um problema alternativo, proposto por Andrew J. [1], consiste em ligar a política de vacinação à taxa de crescimento inicial da epidemia. Procura-se políticas de vacinação dependentes do tempo, por exemplo: Uma política de vacinação que minimize a taxa de crescimento de uma epidemia que ainda não começou. O problema se reduz a minimizar $S(R(t))$ onde $R(t)$ é a matriz de transmissão, $R$, modificada de acordo com a vacinação executada até o instante $t$. Desta forma o problema clássico se converte no seguinte: Qual o mínimo $t$ tal que exista uma política de vacinação que faça $S(R(t))=1$. No restante deste capítulo apresentaremos esta teoria. 


\subsubsection{Formulação do Problema}

Suponha que podemos vacinar um indivíduo por unidade de tempo começando em $t=0$, e suponha que a doença será introduzida em algum instante $t_{0}$, ou que se tem vacina suficiente para vacinar $t_{0}$ indivíduos.

Seja $N=\left(N_{1}, \ldots, N_{n}\right)$ onde $N_{i}$ é a população do grupo $i$. Definimos o vetor $\mathbf{v}=\left(v_{1}, \ldots, v_{n}\right)^{T}$ como uma política de vacinação se $\mathbf{v} \cdot N=1(\mathbf{v} \geq 0)$, onde $v_{i}$ representa a fração do grupo $i$ a ser vacinadà por unidade de tempo, e $\mathbf{v}$ pode ser uma função do tempo, digamos $\mathbf{v}(t)$, de modo que $w_{i}=\int_{0}^{t} v_{i}(s) d s$ é a fração do grupo $i$ vacinada até o instante $t$. A definição formal de uma política de vacinação é então:

Definição 4.4.1 Dizemos que $\mathbf{v}(t)$ é uma política de vacinação válida se satisfaz as seguintes condições:

$$
\left.\begin{array}{l}
\mathbf{v}(t) \geq 0 \\
\mathbf{v}(\mathbf{t}) \cdot N=1 \\
\int_{0}^{t} \mathbf{v}(s) d s \leq 1 \\
\mathbf{v}(s) \text { é contínua à direita } \\
\mathbf{v}(s) \text { é integrável }
\end{array}\right\} \quad \forall t \in\left[0, t_{0}\right]
$$

onde $t_{0}=N_{1}+N_{2}+\cdots+N_{n}$ é o instante quando todos os grupos têm sido completamente vacinados.

Seja $\mathcal{V}$ o conjunto de todas as políticas de vacinação que satisfazem (4.8). Para cada $v \in \mathcal{V}$ e para cada $t \in\left[0, t_{0}\right]$, seja $w(t)=\int_{0}^{t} \mathrm{v}(s) d s$ e seja $R_{\mathrm{v}}(t)=\left(r_{i j}\left[1-w_{i}(t)\right]\right)$, a matriz de transmissão efetiva, dado que, para cada $i$ a fração $w_{i}(t)$ tem sido vacinada até o instante $t$.

Definição 4.4.2 Seja $\bar{S}(\mathrm{v} ; t)=S\left(R_{\mathrm{v}}(t)\right)$. Dizemos que $\mathrm{v} \in \mathcal{V}$ é ótima para o instante $t$ se $\bar{S}(\mathbf{v} ; t)=$ inf $\{\bar{S}(\mathbf{u} ; t): \mathbf{u} \in \mathcal{V}\}$.

Seja $\phi(t)=\inf \{\bar{S}(\mathbf{u} ; t): \mathbf{u} \in \mathcal{V}\}$. Claramente $\phi$ é continua, e dado que uma política de vacinação uniforme tem $S\left(R_{\mathrm{v}}(t)\right)$ decrescendo linearmente, $\phi(t)$ é decrescente.

Dado que $R_{\mathrm{v}}(t)$ é uma perturbação da matriz de transmissão, $R$, o seu módulo de estabilidade, $S\left(R_{\mathrm{v}}(t)\right)$, pode ser calculado, utilizando a teoria da perturbação de matrizes [21, capítulo 7].

Observemos que

$$
R_{\mathrm{v}}(t)=(I-W(t)) R \text { onde } W(t)=\operatorname{diag}\left(w_{i}(t)\right)
$$


o lema abaixo nos dá uma expressão para $S\left(R_{\mathrm{V}}(t)\right)$, quando $R_{\mathrm{v}}(t)$ pode ser escrita na forma $R_{v}(t)=[I-V(t)] R,\left(V=\operatorname{diag}\left(v_{i}\right)\right)$ onde $\mathbf{v}$ é uma política de vacinação qualquer:

Lema 4.4.1 Seja $B$ uma matriz positiva com autovalores $\lambda_{1}>\lambda_{2}>\cdots>\lambda_{n}$, autovetores à direita $\mathbf{x}_{1}, \mathbf{x}_{2}, \ldots, \mathbf{x}_{n}$ e autovetores à esquerda $\mathbf{y}_{1}, \mathbf{y}_{2}, \ldots, \mathbf{y}_{n}$, de modo que temos $B \mathrm{x}_{i}=\lambda_{i} \mathbf{x}_{i}$ e $B^{T} \mathbf{y}_{i}=\lambda_{i} \mathbf{y}_{i}$, para $i=1, \ldots, n$ e $\mathbf{x}_{i}^{T} \mathbf{y}_{i}=\delta_{i j}$. Seja $B(t)=(I+H t) B$. Então

$$
\lambda(t)=S(B(t))=\lambda_{1}+\psi t+\phi t^{2}+o\left(t^{3}\right)
$$

onde

$$
\psi=\lambda_{1} \mathbf{y}_{1}^{T} H \mathbf{x}_{1} \quad e \quad \phi=\sum_{i=2}^{n} \lambda_{1} \lambda_{i}\left(\lambda_{1}-\lambda_{i}\right)^{-1}\left(\mathbf{y}_{i}^{T} H \mathbf{x}_{1}\right)\left(\mathbf{y}_{1}^{T} H \mathbf{x}_{i}\right)
$$

Prova: Para $t$ suficientemente pequeno, temos os autovalores e autovetores correspondentes para $B(t)$ :

$$
B(t) \mathbf{x}_{i}(t)=\lambda_{i}(t) \mathbf{x}_{i}(t) \quad \text { e } \quad B(t)^{T} \mathbf{y}_{i}(t)=\lambda_{i}(t) \mathbf{y}_{i}(t)
$$

com

$$
\begin{aligned}
& \lambda_{i}(t)=\lambda_{i}+\psi_{i} t+\phi_{i} t^{2}+o\left(t^{3}\right) \\
& \mathbf{x}_{i}(t)=\mathbf{x}_{i}+\mathbf{a}_{i} t+\mathbf{b}_{i} t^{2}+o\left(t^{3}\right) \\
& \mathbf{y}_{i}(t)=\mathbf{y}_{i}+\mathbf{p}_{i} t+\mathbf{q}_{i} t^{2}+o\left(t^{3}\right)
\end{aligned}
$$

com $\mathbf{x}_{i}(t)$ normalizado tal que $\mathbf{x}_{i}(t)^{T} \mathbf{y}_{i}(t)=1$ e $\mathbf{x}_{i}(t)^{T} \mathbf{y}_{j}(t)=\delta_{i j}[21$, teorema 7.7.1]. Temos também $\mathbf{y}_{i}^{T} \mathbf{a}_{i}=0$ e $\mathbf{y}_{i}^{T} \mathbf{b}_{i}=0$. Agora $B(t) \mathbf{x}_{1}(t)=\lambda_{1}(t) \mathbf{x}_{1}(t)$, implica que

$$
(B I+H B t)\left(\mathrm{x}_{1}+\mathrm{a}_{1} t+\mathrm{b}_{1} t^{2}\right)=\left(\lambda_{1}+\psi_{1} t+\phi_{1} t^{2}\right)\left(\mathrm{x}_{1}+\mathrm{a}_{1} t+\mathrm{b}_{1} t^{2}\right)+o\left(t^{3}\right)
$$

Igualando os coeficientes em $t$ e $t^{2}$, obtém-se:

$$
\begin{aligned}
\left(H B-\psi_{1} I\right) \mathbf{x}_{1} & =\left(\lambda_{1} I-B\right) \mathbf{a}_{1} \\
\phi_{1} \mathbf{x}_{1} & =\left(H B-\psi_{1} I\right) \mathbf{a}_{1}+\left(B-\lambda_{1} I\right) \mathbf{b}_{1}
\end{aligned}
$$
$\lambda_{1} \mathbf{y}_{1}^{T} H \mathbf{x}_{1}$.

Da equação (4.10), dado que $\mathbf{y}_{1}^{T} \mathbf{x}_{1}=1$, obtem-se $\psi_{1}=\mathbf{y}_{1}^{T} H B \mathbf{x}_{1}=$ 
Desenvolvendo a equação (4.11) obtemos uma expressão para $\phi_{1}$. Observamos que podemos escrever $\mathbf{a}_{1}$ como $\sum_{j=1}^{n} a_{1 j} \mathbf{x}_{j}$ e usando a equação (4.10) obtemos $a_{11}=0$ e $a_{1 j}=\lambda_{1}\left(\lambda_{1}-\lambda_{j}\right)^{-1} \mathbf{y}_{i}^{T} H x_{1}$. Assim

$$
\begin{aligned}
\phi_{1}=\phi_{1} \mathbf{y}_{1}^{T} \mathbf{x}_{1} & =\mathbf{y}_{1}^{T}\left(H B-\psi_{1} I\right) \mathbf{a}_{1} \\
& =\mathbf{y}_{1}^{T}\left(H B-\psi_{1} I\right) \sum_{i=1}^{n} a_{1 i} \mathbf{x}_{i} \\
& =\sum_{i=2}^{n} a_{1 i} \lambda_{i} \mathbf{y}_{1}^{T} H \mathbf{x}_{i} \\
& =\sum_{i=2}^{n} \lambda_{1} \lambda_{i}\left(\lambda_{1}-\lambda_{i}\right)^{-1}\left(\mathbf{y}_{i}^{T} H \mathbf{x}_{1}\right)\left(\mathbf{y}_{1}^{T} H \mathbf{x}_{i}\right)
\end{aligned}
$$

\subsubsection{A Política de Vacinaçāo Ótima para o Modelo SIR com n Grupos}

A matriz de transmissão para o modelo (3.23) é a matriz $n \times n$ dada por

$$
R=\left(r_{i j}\right)=\left(\frac{\beta_{i j} N_{j}}{\left(\gamma_{j}+\mu_{j}\right) N_{i}}\right)
$$

Para procurar a política de vacinação ótima, por simplificação consideramos a população distribuída proporcionalmente ao nível de atividade $[1,13,27]$. Neste caso particular, assume-se que o número de contatos efetivos entre dois grupos é proporcional aos níveis de atividade relativa dos dois grupos. Assim, os indivíduos em grupos mais ativos terão maior quantidade de contatos efetivos. A vantagem deste tipo de aproximação é que se reduz o número de parâmetros de $n^{2}$ taxas de contato a $n$ níveis de atividade.

Seja $a_{j}$ o nível de atividade no grupo $j$, definido como o número médio de contatos efetivos de um indivíduo do grupo $j$ por dia. Assim, $1 / a_{j}$ é o tempo médio entre contatos. Seja $m_{i j}$ a fração de contatos efetivos feitos por uma média de infecciosos do grupo $j$ com o grupo $i$. Notemos que a soma dos elementos de cada coluna da matriz $M=\left(m_{i j}\right)$ é 1 . Segue desta definição, que o número médio de contatos efetivos por dia de um único infeccioso do grupo $j$ com indivíduos susceptíveis no grupo $i$ é $\beta_{i j}=a_{j} m_{i j}$.

Definimos o número médio de contatos efetivos por dia na população por $D=\sum_{i=1}^{n} a_{i} N_{i}$, o nivel de atividade fracional do grupo $i$ por $b_{i}=a_{i} N_{i} / D$, sendo $b_{i}$ a medida de interação relativa do grupo $i$. Notemos que $\sum_{i=1}^{n} b_{i}=1$. 
A distribuição proporcional assume que o número de contatos efetivos individuais são distribuídos proporcionalmente aos níveis de atividade fracional. Isto é, $m_{i j}=b_{i}$, para todo $i, j$.

0 número de contatos, $k_{j}$, para o grupo $j$, definido como o número de contatos efetivos de um indivíduo infeccioso do grupo $j$ durante seu período de infecciosidade $\left(\frac{1}{\gamma_{j}+\mu_{j}}\right)$, satisfaz $k_{j}=\frac{a_{j}}{\gamma_{j}+\mu_{j}}$.

$\mathrm{O}$ número médio de contatos, $\bar{K}$, para o modelo SIR com $\mathbf{n}$ grupos e distribuição proporcional é

$$
\bar{K}=\sum_{i=1}^{n} b_{i} k_{i}
$$

A matriz de transmissão fica então:

$$
R=\left(r_{i j}\right)=\left(\frac{b_{i}}{k_{i}} k_{j} N_{j}\right)
$$

Para calcular $S(\bar{R})$, usamos a seguinte estratégia [13]. Observemos que

$$
(R-\lambda I)=\operatorname{diag}\left(\frac{b_{i}}{N_{i}}\right)\left(\begin{array}{lllll}
k_{1} N_{1}-\lambda & k_{2} N_{2} & \cdots & k_{n-1} N_{n-1} & k_{n} N_{n} \\
k_{1} N_{1} & k_{2} N_{2}-\lambda & & k_{n-1} N_{n-1} & k_{n} N_{n} \\
\vdots & & \ddots & & \vdots \\
k_{1} N_{1} & k_{2} N_{2} & & k_{n-1} N_{n-1}-\lambda & k_{n} N_{n} \\
k_{1} N_{1} & k_{2} N_{2} & \cdots & k_{n-1} N_{n-1} & k_{n} N_{n}-\lambda
\end{array}\right)
$$

e portanto,

$$
|R-\lambda I|=\prod_{i=1}^{n} \frac{b_{i}}{N_{i}}\left|\begin{array}{lllll}
-\lambda & 0 & \cdots & 0 & \lambda \\
0 & -\lambda & & 0 & \lambda \\
\vdots & & \ddots & & \vdots \\
0 & 0 & & -\lambda & \lambda \\
k_{1} N_{1} & k_{2} N_{2} & \cdots & k_{n-1} N_{n-1} & k_{n} N_{n}-\lambda
\end{array}\right|
$$

Usando a expansão por menores e indução matemática na primeira coluna, obtém-se

$$
|R-\lambda I|=\prod_{i=1}^{n}(-\lambda)+\sum_{i=1}^{n} b_{i} k_{i} \prod_{\substack{j=1 \\ j \neq i}}^{n}(-\lambda)=(-1)^{n} \lambda^{n}-\bar{K} \lambda^{n-1}
$$

A equação característica é então

$$
|R-\lambda I|=(-1)^{n} \lambda^{n-1}(\lambda-\bar{K})=0
$$


e daí

$$
S(R)=\bar{K}
$$

Sob uma política de vacinação $\mathrm{v}, \mathbf{v} \geq 0, \mathbf{v} \cdot N=1$, vt $\leq 1$, tem-se

$$
R_{\mathrm{v}}(t)=\left(\frac{b_{i}}{N_{i}} k_{j} N_{j}\left(1-v_{i} t\right)\right)
$$

Assim,

$$
\begin{aligned}
\left|R_{\mathrm{v}}(t)-\lambda I\right| & =(-1)^{n} \lambda^{n}-\sum_{i=1}^{n} b_{i} k_{i}\left(1-v_{i} t\right) \lambda^{n-1} \\
& =(-1)^{n} \lambda^{n}-\left(\bar{K}-\sum_{i=1}^{n} b_{i} k_{i} v_{i} t\right) \lambda^{n-1} \\
& =(-1)^{n} \lambda^{n-1}\left[\lambda-\left(\bar{K}-t \sum_{i=1}^{n} b_{i} k_{i} v_{i}\right)\right]
\end{aligned}
$$

Portanto

$$
S\left(R_{v}(t)\right)=S(R)-t \sum_{i=1}^{n} b_{i} k_{i} v_{i}
$$

Para minimizar $S\left(R_{\mathrm{v}}(t)\right)$, devemos maximizar $\sum_{i=1}^{n} b_{i} k_{i} v_{i}$ sobre $\mathrm{v}$, sujeito à $\mathrm{v} \geq 0$, $\mathbf{v} \cdot N=1$, vt $\leq 1$. Como o problema é linear em $\mathbf{v}$, uma solução ótima ocorre num ponto extremo da região factivel.

$\operatorname{De} N^{T} \mathrm{v}=N_{1} v_{1}+N_{2} v_{2}+\cdots+N_{r} v_{r}+\cdots+N_{n} v_{n}=1$, pondo $v_{r}$ em evidência tem-se

$$
v_{r}=\left(1-\sum_{\substack{i=1 \\ i \neq r}}^{n} N_{i} v_{i}\right) \frac{1}{N_{r}}
$$

e

$$
\begin{aligned}
\sum_{i=1}^{n} b_{i} k_{i} v_{i} & =\left(1-\sum_{\substack{i=1 \\
i \neq r}}^{n} N_{i} v_{i}\right) \frac{b_{r} k_{r}}{N_{r}}+\sum_{\substack{i=1 \\
i \neq r}}^{n} b_{i} k_{i} v_{i} \\
& =\frac{b_{r} k_{r}}{N_{r}}+\sum_{\substack{i=1 \\
i \neq r}}^{n}\left[b_{i} k_{i}-\frac{N_{i} b_{r} k_{r}}{N_{r}}\right] v_{i}
\end{aligned}
$$

Portanto, para encontrar a solução ótima devemos escolher $r$ tal que

$$
\frac{b_{r} k_{r}}{N_{r}}=\max \left\{\frac{b_{i} k_{i}}{N_{i}}, i=1, \ldots, n\right\}
$$


e $v_{i}=0$ para $i \neq r$. A solução ótima é $\mathbf{v}^{*}=N_{r}^{-1} e_{r}$ onde $e_{r}$ é o vetor unitário com 1 ṇa $r$-ésima posição.

Assim, se $\sum_{i=1}^{n} b_{i} k_{i} v_{i}$ for maximizada por $\mathrm{v}^{*}=N_{i}^{-1} e_{1}$, a política ótima no instante $t_{1}=N_{1}$ é vacinar o grupo mais ativo, neste caso o grupo 1 . Indutivamente, vemos que a política ótima é vacinar unicamente no grupo $i\left(\mathrm{v}=N_{i}^{-1} e_{i}\right)$ entre os instantes $t_{i-1}$ e $t_{i}$ onde $t_{i}=\sum_{j=1}^{i} N_{j}$.

\subsubsection{Resultados Gerais para n Grupos}

Examinaremos somente dois aspectos: A política ótima inicial (que é ótima para valores iniciais de $t$ ) e a política ótima final (que é ótima para valores finais de $t$ ).

Teorema 4.4.1 Dentre todas as políticas iniciais, a política de vacinação constante maximiza $\sum_{i=1}^{n} x_{i} y_{i} u_{i}$ sobre $\mathbf{u}$, sujeito à $\mathbf{u} \geq \mathbf{0}, \mathbf{u} \cdot N=1$, onde $\mathbf{x}>\mathbf{0}$, $\mathrm{y}>\mathbf{0} e$

$$
R^{T} \mathbf{x}=\lambda \mathbf{x}, \quad \mathbf{x}^{T} \mathbf{x}=1, \quad R \mathbf{y}=\lambda \dot{y}, \quad \mathbf{x}^{T} \mathbf{y}=1, \quad \lambda=S(R)
$$

Prova: [1]. Consideremos qualquer política de vacinação constante $\mathbf{v}, \mathbf{v} \geq \mathbf{0}$, $v \cdot N=1$. Seja $\lambda(t)=S\left(R_{\mathrm{v}}(t)\right)$, onde $R_{\mathrm{v}}(t)=\left(r_{i j}\left(1-v_{i} t\right)\right)=(I-V t) R$, com $V=\operatorname{diag}\left(v_{i}\right)$. Pelo lema (4.4.1), temos $\lambda(t)=\lambda-\psi t+o(t)$, onde $\psi=\lambda y^{T} V x$. Devemos minimizar $\lambda(t)$ para $t$ pequeno sobre $\mathrm{v}$ sujeito à $\mathbf{v} \geq 0, \mathbf{v} \cdot N=1$. Portanto é necessário que $\mathrm{v}$ maximize $\psi=\sum_{i=1}^{n} x_{i} y_{i} v_{i}$.

Corolário 4.4.1 Se existe algum $\delta>0$ e $\mathrm{v} \in \mathcal{V}$ tal que $\mathrm{v}(t) \overleftrightarrow{e}$ ótima para $t<\delta$, então $\mathbf{v}$ deve maximizar $\psi$ sobre $\mathbf{u}$ sujeito à $\mathbf{u} \geq 0, \mathbf{u} \cdot N=1$, onde $\mathbf{v}(t) \rightarrow \mathbf{v}$ quando $t \rightarrow 0$ e $\psi=\lambda \sum_{i=1}^{n} x_{i} y_{i} v_{i}$.

Prova: [1]. Como $v(t) \in \mathcal{V}$ é continuamente diferenciável à direita em $t=0 \mathrm{e}$ pode ser expandida na forma $\mathbf{v}(t)=\mathbf{v}+\mathrm{z} t+o(t)$, onde $\mathbf{v}=\lim _{t \rightarrow 0} \mathbf{v}(t)$ e $\mathbf{z} \cdot N=0$. Agora

$$
R_{\mathrm{v}}(t)=\left(r_{i j}\left(1-\int_{0}^{t} v_{i}(s) d s\right) .\right)
$$

onde

$$
\int_{0}^{t} v_{i}(s) d s=v_{i} t+\frac{1}{2} z_{i} t^{2}+o\left(t^{2}\right)
$$

Assim $R_{\mathrm{V}}(t)=(I-V t) R+o(t)$, onde $V=\operatorname{diag}\left(v_{i}\right)$ e o resto da prova segue do teorema (4.4.1) 
Teorema 4.4.2 Uma política final ótima é a constante $\mathbf{v}(t)=\mathbf{v}^{*}$ para $t \in\left[t_{1}, t_{0}\right]$, onde $\mathbf{v}^{*}$ minimiza $S(B(\mathbf{u}))$ sobre $\mathbf{u}$, sujeito à $\mathbf{u} \geq 0, \mathbf{u} \cdot N^{*}=1, B(\mathbf{u})=\left(r_{i j} u_{i}\right)$, $e t_{1}=t_{0}-\inf \left\{\frac{1}{v_{i}^{*}}: i=1, \ldots, n\right\}$.

prova: [1]. Suponha

$$
S\left(B\left(\mathbf{v}^{*}\right)\right)=\inf \{S(B(\mathbf{u})): \mathbf{u} \geq \mathbf{0}, \mathbf{u} \cdot N=1\}
$$

Primeiro, construimos uma política factível que inclua $\mathbf{v}^{*}$ : Seja

$$
\overline{\mathbf{v}}(t)=\left\{\begin{array}{lll}
\frac{1}{t_{1}}\left[1-\left(t_{0}-t_{1}\right) \mathbf{v}^{*}\right] & \text { se } & t_{1}<t<t_{0} \\
\mathbf{v}^{*} & \text { se } 0<t<t_{1}
\end{array}\right.
$$

então claramente $\overline{\mathrm{v}} \in \mathcal{V}$. Para $t>t_{1}$, a fração no grupo $i$ não vacinada é $1-\int_{0}^{t} \bar{v}_{i}(s) d s=\left(t_{0}-t_{1}\right) v_{i}^{*}, \operatorname{logo}$

$$
R_{v}(t)=\left(r_{i j}\left[1-\int_{0}^{t} \bar{v}_{i}(s) d s\right]\right)=\left(r_{i j} v_{i}^{*}\left(t_{0}-t\right)\right)=\left(t_{0}-t\right) B\left(\mathrm{v}^{*}\right)
$$

Assim

$$
S\left(R_{\mathrm{v}^{*}}(t)\right)=S\left(B\left(\mathrm{v}^{*}\right)\right)\left(t_{0}-t\right) \quad \text { para } \quad t_{1}<t<t_{0}
$$

Para qualquer $\mathbf{v} \in \mathcal{V}$, seja $\left(t_{0}-t\right) w_{i}$ a fração não vacinada do grupo $i$ no instante $t$. Então

$$
\bar{S}(\mathbf{v} ; t)=S(B(\mathbf{w}))\left(t_{0}-t\right) \geq S\left(B\left(\mathbf{v}^{*}\right)\right)\left(t_{0}-t\right)=\bar{S}\left(\mathbf{v}^{*} ; t\right)
$$

Assim $v^{*}$ é ótima para todo $t \in\left[t_{1}, t_{0}\right]$. drew J. [1].

Outros resultados interessantes podem ser encontrados no artigo de An-

\subsection{Comentários}

Provavelmente o conceito mais importante no estudo de modelos epidêmicos é o teorema do limiar epidêmico; a sua importância reside no fato de que, imunizando uma determinada fração de susceptíveis em uma grande comunidade, se reduz o número inicial de susceptíveis e pode-se prever se uma determinada infeç̧ão.pode ou não vir a tornar-se epidêmica. E ainda possível, usando-se teoremas do limiar epidêmico, determinar a fração de susceptíveis que devem ser imunizados para prevenir grandes surtos epidêmicos, com um mínimo de custos. 
Na metodologia proposta por Andrew J., observamos que resultados a respeito do comportamento de um processo epidêmico podem ser determinados olhando unicamente para a matriz de transmissão. Esta aproximação tem a vantagem de que o problema da vacinação é apresentado de forma mais simples que na metodologia tradicional, onde são examinados os estados de equilíbrio do sistema. 


\section{Conclusão}

Durante o desenvolvimento do trabalho foram feitos os comentários pertinentes e, portanto, para encerrá-lo nos limitaremos às seguintes observações:

- Embora os modelos apresentados neste trabalho sejam bastante simplificados, eles são importantes porque estabelecem princípios simples e fundamentais, tais como: A tendência a oscilar de sistemas Presa-Predador, o Princípio de Exclusão Competitiva e a dependência dos limiares epidêmicos sobre o tamanho da população, entre outros.

- Muita pesquisa tem sido feita na área, como mostra a grande quantidade de artigos publicados. Nos últimos anos a maioria dos trabalhos tem se centrado no estudo de propriedades recém descobertas em modelos já conhecidos ou modificações destes e na apresentação de novos modelos. Isto com certeza tem enriquecido o conhecimento teórico, porém, talvez pelo fato de que a pesquisa seja feita quase totalmente em instituções acadêmicas, a aplicação do conhecimento à vida real tem sido pouco explorada.

A teoria só pode ser levada a sério por ecologistas e epidemiologistas, se for demonstrado que os modelos descrevem adequadamente situaçôes reais e podem ser aplicados com segurança. Torna-se evidente a necessidade de um ambiente verdadeiramente inter-disciplinar que possibilite a aplicação do conhecimento científico obtido, em projetos específicos, tanto na área da sáude pública, como na preservação do meio ambiente. 


\section{Bibliografia}

[1] ANDREW J.G.C. Epidemics in Heterogeneous Populations : Aspects of Optimal Vaccination Policies: IMA J. Math. Med. Biol. v. 6, p. 137$59,1989$.

[2] ANDREWS, J.G.; McLONE, R.R. Mathematical Modelling. London, Butterworths, 1976

[3] ANDRONOV, A.A.; VITT, A.A.; KHAIKIN, S.E. Theory of Oscillators. Moscou, MIR, 1966 (Series in advanced physics, 4)

[4] BASSANEZI, R.C.; FERREIRA Jr, W.C. Equações Diferenciais com Aplicações. São Paulo, Harbra, 1988

[5] BRAUER, F.; NOHEL, J.A.: The Qualitative Theory of Ordinary Differential Equations. New York, Benjamin, 1969

[6] -BUTLER, G.J.; WOLKOWICZ, G.S.K. Predator Mediated Competition in the Chemostat $J$. Math. Biology. v. 24, p. 167-191, 1986.

[7] EDELSTEIN-KESHET, L. Mathematical Models in Biology. New York, Random House, 1988

[8] ELSGOLTZ, L. Ecuaciones Diferenciales y Cálculo Variacional. Moscou, MIR, 1969

[9] FRAUENTAL, J. C. Mathematical Modeling in Epidemiology. New York, Springer, 1980

[10] HETHCOTE, H. W. Qualitative analyses of communicable disease modeis. Math. Biosci. v. 28, p. $335-56,1976$

[11] HETHCOTE, H. W. An immunization model for a heterogeneous populations. Theoretical Population Biology, v. 14, p. 338-49, 1978 
[12] HETHCOTE, H. W.; THIEME, H.R. Stability of the endemic equilibrium in epidemic models with subpopulations. Math. Biosci. v. 75, p. 205$227,1985$.

[13] HETHCOTE, H. W.; VAN ARK, J. W. Epidemiological models for heterogeneous populations: Proportionate mixing, parameter estimation, and immúnization programs. Math. Biosci. v. 84, p. 85-118, 1987.

[14] HIRSCH, M.W.; SMALE, S. Differential Equations, Dynamical Systems and Linear Algebra. New York, Academic Press, 1974

[15] HOFBAUER, J.; SIGMUND, K. On the Stabilizing Effect of Predators and Competitors on Ecological communities J. Math. Biology. v. 27, p. 537-548, 1989.

[16] HUREWICZ, W. Lectures on Ordinary Differential Equations. Massachusetts, MIT Press, 1958

[17] JORDAN, D.W.; SMITH, P. Nonlinear Ordinary Differential Equations. Oxford, Clarendom Press, 1979

[18] KRASNOSELSKII, A.A. Positive Solutions of Operator Equations. Noordhoff, Groningen, 1964

[19] KOCGAK, H. Differential and Difference Equations Through Computer Experiments. New York, Springer_Verlag, 1986

[20] LAJMANOVICH, A.; YORKE, J.A. A deterministic model for Gonorrhea in a nonhomogeneous population. Math. Biosci. v. 28, p. 221-236, 1976

[21] LANCASTER, P. Theory of Matrizes. London, Academic Press, 1969

[22] LASALLE, J.P.; LEFSCHETZ, S. Stability by Lyapunov's Direct Method with Applications. New York, Academic Press, 1961

[23] MAY, R.M. Stability in Multi Species Community Models. Math. Biosci. v. 12 , p. $59-79,1971$

[24] METZ, J.A.J.; DIEKMAM, O. The Dynamics of Physiologically Structured Populations. New York, Springer, 1986 (Lecture Notes in Biomathematics 68)

[25] MUÑOZ, J.M. Programa Traçador de Diagramas de Fase. Rio de Janeiro, Instituto de matemática UFRJ, s.d. 
[26] MURRAY, J.D. Mathematical Biology. New York, Springer-Verlag, 1989 (Biomathematical tex, 19)

[27] NOLD, A. Heterogeneity in disease-transmission modeling. Math. Biosci. v. 52 , p. $227-240,1980$

[28] ROXIN, E.O. Ordinary Differential Equations. Rhode Island, Wodsworth, 1972

[29] SCUDO, F.M.; ZIEGLER, J.M. The Golden Age of Theoretical Ecology: 1923-1940. New York, Springer, 1978 (Lecture Notes in Biomathematics 22)

[30] SMITH, J.M. Models in Ecology. Cambridge, Cambridge University Press, 1974

[31] VARGA, R.S. Matrix Iterative Analysis. New Jersey, Prentice-Hall, 1962 